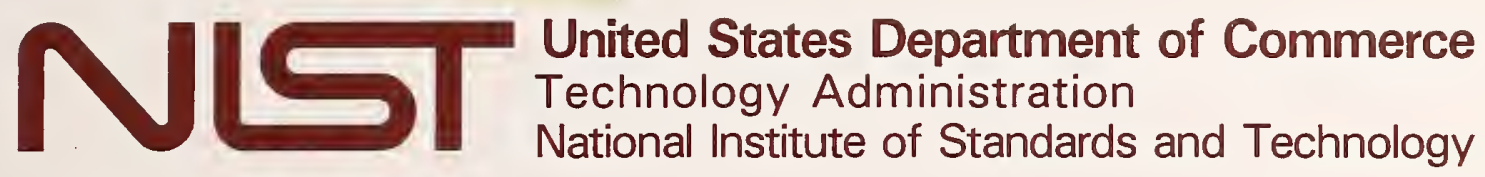

NIST Technical Note 1500-6 Materials Reliability Series

\title{
Constitutive Behavior Modeling of Steels Under Hot-Rolling Conditions
}

\author{
Y.W. Cheng \\ R.L. Tobler \\ B.J. Filla \\ K.J. Coakley
}



NIST Technical Note 1500-6

Materials Reliability Series

\title{
Constitutive Behavior Modeling of Steels Under Hot-Rolling Conditions
}

\author{
Y.W. Cheng \\ R.L. Tobler \\ B.J. Filla \\ K.J. Coakley
}

Materials Reliability Division

Materials Science and Engineering Laboratory

National Institute of Standards and Technology

325 Broadway

Boulder, Colorado 80303-3328

April 1999

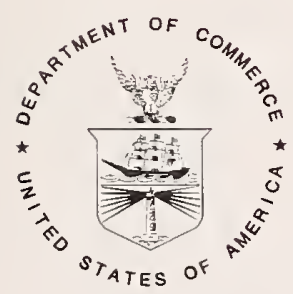

U.S. DEPARTMENT OF COMMERCE, William M. Daley, Secretary TECHNOLOGY ADMINISTRATION, Gary R. Bachula, Acting Under Secretary for Technology NATIONAL INSTITUTE OF STANDARDS AND TECHNOLOGY, Raymond G. Kammer, Director 
National Institute of Standards and Technology Technical Note Natl. Inst. Stand. Technol., Tech. Note 1500-6, 112 pages (April 1999) CODEN:NTNOEF

\section{U.S. GOVERNMENT PRINTING OFFICE \\ WASHINGTON: 1999}

For sale by the Superintendent of Documents, U.S. Government Printing Office, Washington, DC 20402-9325 


\section{Contents}

Foreword $\ldots \ldots \ldots \ldots \ldots \ldots \ldots \ldots \ldots \ldots \ldots \ldots \ldots \ldots \ldots \ldots \ldots$

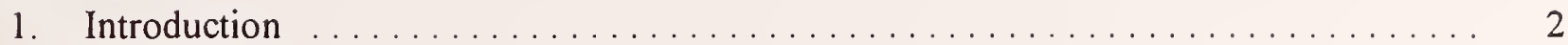

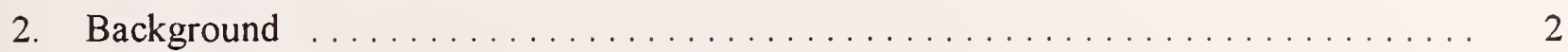

3. Constitutive Equations and Factors Affecting Flow Stress . . . . . . . . . . . 5

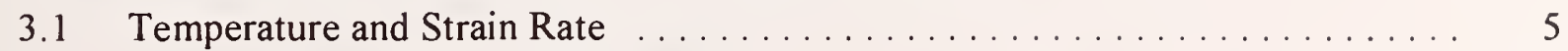

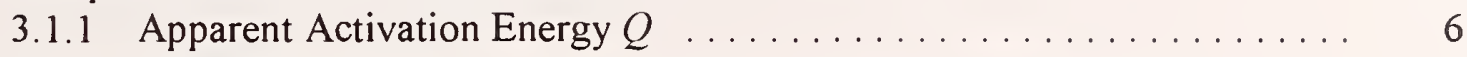

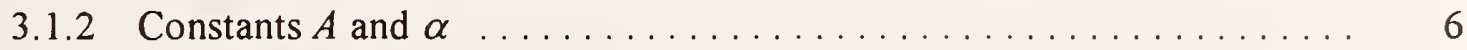

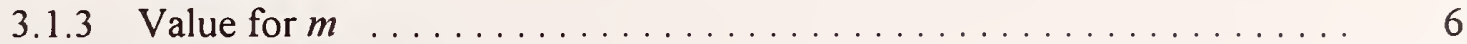

3.2 Dynamic Recrystallization $\ldots \ldots \ldots \ldots \ldots \ldots \ldots \ldots \ldots \ldots \ldots \ldots$

3.3 Chemical Composition $\ldots \ldots \ldots \ldots \ldots \ldots \ldots \ldots \ldots \ldots \ldots \ldots$

3.4 Austenite Grain Size $\ldots \ldots \ldots \ldots \ldots \ldots \ldots \ldots \ldots \ldots \ldots \ldots \ldots$

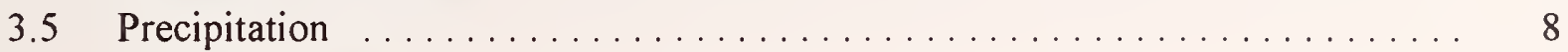

3.6 Adiabatic Heating $\ldots \ldots \ldots \ldots \ldots \ldots \ldots \ldots \ldots \ldots \ldots \ldots \ldots$

4. Experimental Approach $\ldots \ldots \ldots \ldots \ldots \ldots \ldots \ldots \ldots \ldots \ldots \ldots \ldots \ldots$

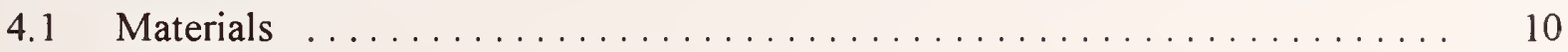

4.2 Test Specimen $\ldots \ldots \ldots \ldots \ldots \ldots \ldots \ldots \ldots \ldots \ldots \ldots \ldots \ldots \ldots$

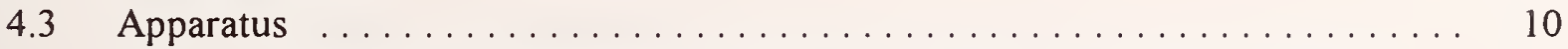

4.3.1 Computer and Peripherals for Machine Control and Data Acquisition . . 11

4.3 .2 Load Frames ............................. 11

4.3.3 Heating, Cooling, and Vacuum .................... 12

4.3.4 Machine Performance and Reproducibility ............... 13

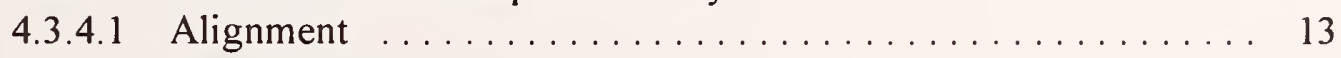

4.3.4.2 Reproducibility $\ldots \ldots \ldots \ldots \ldots \ldots \ldots \ldots \ldots \ldots \ldots \ldots \ldots$

4.3.4.3 Strain Rates .......................... 13

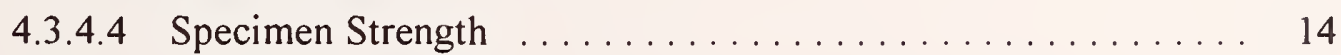

4.3.4.5 Adiabatic Heating $\ldots \ldots \ldots \ldots \ldots \ldots \ldots \ldots \ldots$

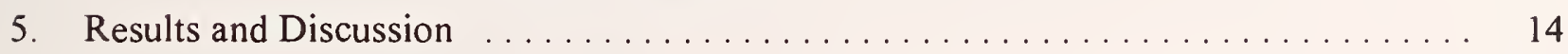

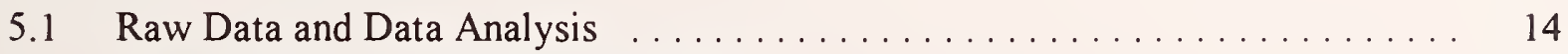

5.2 Round-Robin Test Program with UBC $\ldots \ldots \ldots \ldots \ldots \ldots \ldots \ldots$

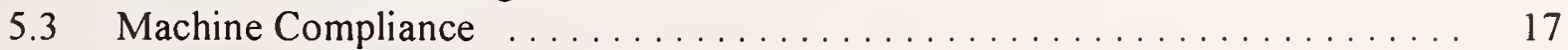

5.4 Mathematical Description of Stress-Strain Curves $\ldots \ldots \ldots \ldots \ldots \ldots \ldots$

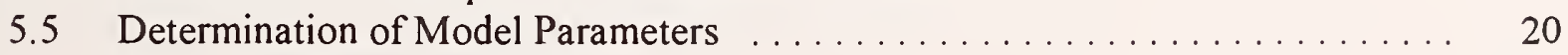

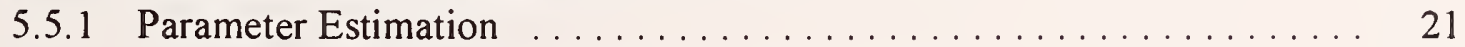

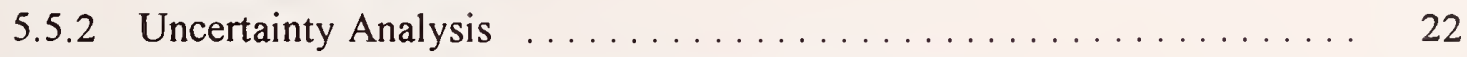

5.6 Experimental Stress-Strain Curves and Model Predictions . . . . . . . . . 23

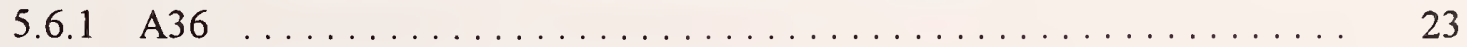

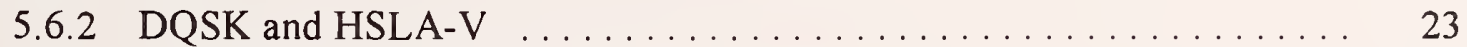

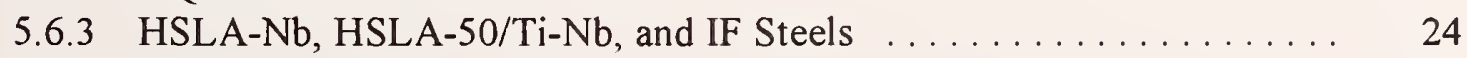

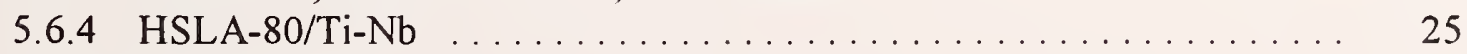

5.7 Strain at Peak Stress $\ldots \ldots \ldots \ldots \ldots \ldots \ldots \ldots \ldots \ldots \ldots \ldots \ldots \ldots$ 


\section{Contents (continued)}

5.8 Boundary Separating Dynamic Recrystallization and

No-Dynamic Recrystallization $\ldots \ldots \ldots \ldots \ldots \ldots \quad 26$

5.9 Effects of Prior Heat Treatments: HSLA-Nb . . . . . . . . . . . . . 26

5.10 Effects of Reheating Temperature and Model Adjustments: HSLA-80/Ti-Nb . 27

5.11 Effects of Retained Strain: HSLA-Nb . . . . . . . . . . . . . . . . . . . . . 28

5.12 Comparison with Data from CANMET $\ldots \ldots \ldots \ldots \ldots \ldots \ldots \ldots . \ldots \ldots$

5.13 Calculation of Roll-Separating Forces $\ldots \ldots \ldots \ldots \ldots \ldots \ldots \ldots . \ldots \ldots$

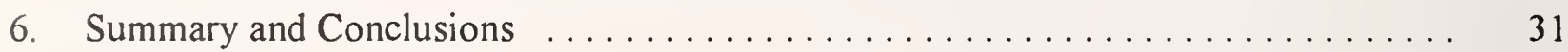

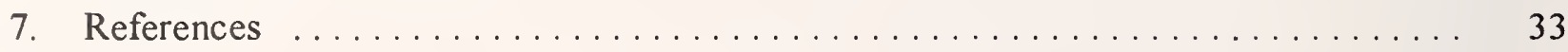

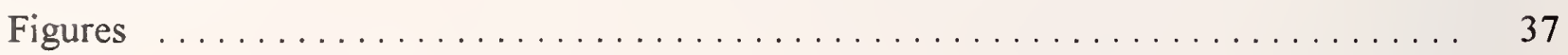




\section{Foreword}

The Materials Reliability Series of NIST Technical Notes are reports covering significant research accomplishments of the Materials Reliability Division. The Division develops measurement technologies that enable the producers and users of materials to improve the quality and reliability of their products. Measurement technologies are developed for process control to improve the quality and consistency of materials, for nondestructive evaluation to assure quality of finished materials and products, and for materials evaluation to assure reliable performance. Within these broad areas of measurement technology, the Division has focused its resources on three research themes:

- Intelligent Processing of Materials-To develop on-line sensors for measuring the materials' characteristics and/or processing conditions needed for real-time process control.

- Ultrasonic Characterization of Materials-To develop ultrasonic measurements for characterizing internal geometries of materials, such as defects, microstructures, and lattice distortions.

- Micrometer-Scale Measurements for Materials Evaluation-To develop measurement techniques for evaluating the mechanical, thermal, and magnetic behavior of thin films and coatings at the appropriate size scale.

This report is the sixth in the series. It covers research on constitutive behavior of steels under hot-rolling conditions, one of the projects on Intelligent Processing of Materials. Previous reports in this series are:

Technical Note 1500-1 Tensile Testing of Thin Films: Techniques and Results, by D.T. Read, 1997

Technical Note 1500-2 Procedures for the Electron-Beam Moiré Technique, by E.S. Drexler, 1998

Technical Note 1500-3 High-Energy, Transmission X-ray Diffraction for Monitoring Turbine-Blade Solidification, by D.W. Fitting, W.P. Dubé, and T.A. Siewert, 1998

Technical Note 1500-4 Nondestructive Characterization of Reactor Pressure Vessel Steels: A Feasibility Study, by H.I. McHenry and G.A. Alers, 1998

Technical Note 1500-5 Electron-Beam Moiré Technique: Advances, Verification, Application, by E.L. Drexler, 1998 



\title{
CONSTITUTIVE BEHAVIOR MODELING OF STEELS UNDER HOT-ROLLING CONDITIONS
}

\author{
Y. W. Cheng, R. L. Tobler, and B. J. Filla \\ Materials Reliability Division \\ National Institute of Standards and Technology \\ Boulder, CO 80303 \\ K. J. Coakley \\ Statistical Engineering Division \\ National Institute of Standards and Technology \\ Boulder, CO 80303
}

The purpose of this work is to develop constitutive equations that predict the stress-strain curves of steels as functions of hot-rolling process variables, such as temperature, strain rate, and microstructural features. Eight steels, A36, DQSK, HSLA-V, HSLA-Nb, HSLA-50/Ti-Nb, HSLA-80/Ti-Nb and two interstitial-free (IF) grades, were selectively tested at temperatures in the range from 900 to 1200 ${ }^{\circ} \mathrm{C}$, strain rates from 1 to $50 \mathrm{~s}^{-1}$, and austenite grain sizes from 0.012 to $0.29 \mathrm{~mm}$. The data were analyzed to support the development of constitutive models.

To cover a wider range of strain rates, a new computer-controlled servohydraulic laboratory apparatus was designed and built for high strain-rate experiments. The machine has a load capacity of $100 \mathrm{kN}$ and controllable constant strain rate of $50 \mathrm{~s}^{-1}$. It has been used to generate all the data with the strain rate of $50 \mathrm{~s}^{-1}$ in this project. Data for lower strain rates were generated with existing equipment.

Models for predicting stress-strain behaviors for the eight steel grades listed above have been developed. Model predictions correlate well with the experimental data, indicating that the models adequately describe the stress-strain behaviors of various steel grades under hot-rolling conditions. Model predictions for A36 and DQSK are further validated with high strain-rate (up to $150 \mathrm{~s}^{-1}$ ) data obtained at CANMET.

The models have been used in the Sims equations to calculate the rollseparating forces which agree well with mill measurements. The models are currently used in the Hot-Strip Mill Model developed at UBC, Canada.

Key words: Constitutive behavior; dynamic recrystallization; elevatedtemperature mechanical properties of steels; hot-strip rolling; IF steels; microalloyed steels; plain-carbon steels; thermomechanical process simulation. 


\section{Introduction}

In 1993, the American Iron and Steel Institute (AISI) sponsored a research project on microstructural engineering in hot-strip mills. The objective was to develop a predictive tool that quantitatively links the properties of hot-rolled products to mill processing parameters. The predictive tool will be a user-friendly computer model that incorporates knowledge of heat flow, microstructural phenomena (recrystallization, grain growth, precipitation, and austenite decomposition), and structure-composition-property relationships. It will compute the thermal and microstructural evolution of steel during hot rolling, as well as the final product properties, as a function of hot-strip mill design and operating practices.

The AISI project is a cooperative effort involving the National Institute of Standards and Technology (NIST), the University of British Columbia (UBC-Canada), and U.S. Steel. Major portions of the research have been performed at NIST and UBC. The University of British Columbia conducts heat-transfer studies, quantitative characterization of kinetics of microstructural evolution, and model verification with plant and pilot-plant measurements. NIST focuses on constitutive behavior and structure-composition-property relationships. The goal of the constitutive-behavior studies is to model the flow behavior of steels as functions of chemistry, temperature, strain rate, and other processing variables. This report presents the results of the constitutive-behavior studies, including experiments to provide stress-strain data and to understand the effects of different parameters and models to predict stress-strain curves under hot-rolling conditions.

\section{Background}

Characterizing the plastic flow of steels is essential to improve industrial hot-forming operations. During forging or hot rolling, the plastic-flow properties determine the power requirements of industrial equipment, as well as the mechanical properties and dimensional accuracy of finished products.

Forming at high temperatures and high strain rates involves a sizable number of variables. Material response is affected by changes in temperature and strain rate, as well as steel chemistry and microstructural factors including grain size, grain growth, recrystallization, and precipitation during processing. The demand for accurate flow-property predictions under hot-forming conditions has increased in recent years due to research pursuits in the field of deformation simulation and to commercial needs to manufacture products with ever increasing efficiency.

Figure 1 presents the block diagrams (rectangular blocks) of a typical hot-strip rolling operation and the various computer models for different stages (oval-shape blocks) of the operation. Steel experiences the following conditions during its conversion from slab to hot strip:

- Temperature may reach $1250^{\circ} \mathrm{C}$ at the first stand of the roughing mill, and $900{ }^{\circ} \mathrm{C}$ or lower at the last stand of the finishing mill. 
- Strain rate may reach $1 \mathrm{~s}^{-1}$ at the first stand of the roughing mill, and 100-200 $\mathrm{s}^{-1}$ or higher at the last stand of the finishing mill.

- Grain size may exceed $0.25 \mathrm{~mm}$ at the first stand of the roughing mill, but may be as small as $0.015 \mathrm{~mm}$ at the last stand of the finishing mill.

Obviously, the material's flow stress varies considerably during different stages of processing. The research objective is to develop and validate constitutive equations for use in strip-rolling simulations using numerical techniques, such as the finite element method. Constitutive equations describe the nonlinear relationships that exist among the process variables and the internal structures of materials, and they permit us to predict or estimate the steel's flow properties for specific strip-rolling conditions.

Figure 2 shows some experimentally determined flow-stress curves for DQSK steel. The relationship between true stress and true strain is called the flow-stress curve because it plots the stress required for plastic flow at a given strain. The shape of the flow-stress curve relates to different structural changes going on in the steel as it undergoes hot deformation in the austenite phase. The three shapes of these curves indicate three possible responses to hot deformation at high temperatures and high strain rates. The Type I flow-stress curve $\left(\right.$ at $\left.900{ }^{\circ} \mathrm{C}\right)$ rises continuously, owing to strain hardening in the austenite. The Type II curve (at $1000{ }^{\circ} \mathrm{C}$ ) rises at first, and then reaches a plateau. This plateau is caused by the occurrence of dynamic recovery in amounts sufficient to counterbalance the effect of strain hardening in austenite. Finally, the Type III curve (at $1100^{\circ} \mathrm{C}$ ) rises to a peak and then subsequently decreases. The decline of the flow stress in a Type III curve is caused by dynamic recrystallization, which begins when the critical strain $\varepsilon_{c}$ is reached.

An important factor that determines which type of the flow-stress curve will manifest is the Zener-Hollomon parameter [1]:

$$
Z=\dot{\varepsilon} \exp \left[\frac{Q}{R T}\right]
$$

Here, $\dot{\varepsilon}$ is strain rate, $T$ is temperature, $R$ is the universal gas constant, and $Q$ is the apparent activation energy of the rate-controlling dynamic softening process. High $Z$ promotes strain hardening, whereas low $Z$ favors dynamic recrystallization, which fosters the decline of flow stresses following a peak stress. Deformation at intermediate $Z$ corresponds to a balance between strain hardening and dynamic recovery, which is characterized by a constant flow stress after initial hardening. If strain rate is held constant in eq (1), then $Z$ increases with decreasing temperature and the flow stress at low temperature increases. Conversely, the flow stress will decrease at low strain rates.

The flow-stress curve is fundamental to materials engineering. From it, the important properties of a steel are interpolated, and the mechanisms of deformation can be determined. Many attempts have been made to fit mathematical expressions to empirical flow curves at selected temperatures and strain rates. Exponential equations or power laws and their derivatives 
Table 1. Stress-strain relationships cited in the literature.

\begin{tabular}{|c|c|c|}
\hline Equations & & References \\
\hline$\sigma=K \varepsilon^{n}$ & (2) & 2 \\
\hline$\sigma=\sigma_{0}+K \varepsilon^{n}$ & (3) & 3 \\
\hline$\sigma=b+c \varepsilon^{0.4}+d \varepsilon^{0.8}+e \varepsilon^{1.2}$ & (4) & 4 \\
\hline$\sigma=K\left(\varepsilon_{0}+\varepsilon\right)^{n}$ & (5) & 5 \\
\hline$\sigma=K \varepsilon^{n_{1}}+\exp \left(K^{\prime}+n_{2} \varepsilon\right)$ & (6) & 6 \\
\hline$\sigma=\sigma_{0}+(B+\varepsilon)^{n}$ & (7) & 7 \\
\hline$\sigma=\sigma_{0}+B \cdot \log (\varepsilon)$ & $(8)$ & 7 \\
\hline$\sigma=\sigma_{s}[1-\exp (-B \varepsilon)]^{n}$ & (9) & 8 \\
\hline$\sigma=\sigma_{0}+B[1-\exp (-C \varepsilon)]^{n}$ & (10) & 7,9 \\
\hline$\sigma=\sigma_{0}-(A-B) \cdot \exp (-C \varepsilon)$ & (11) & 10 \\
\hline$\sigma=B\left[1-\exp \left(-C \varepsilon^{n^{\prime} n}\right)\right]^{\left(\frac{1}{n}\right)}$ & (12) & 7 \\
\hline $\begin{array}{l}\sigma=1.64 \cdot \sigma_{p} \varepsilon^{n} \\
\quad \sigma_{p}=\text { peak stress; } n=0.22+0.001 \cdot \sigma_{p}\end{array}$ & (13) & 11 \\
\hline
\end{tabular}

are commonly used. The parametric constants that relate true stress $\sigma$, and true strain $\varepsilon$, in these equations must be determined experimentally.

Table 1 lists the various equations that are cited in the literature [2-11] and have been proposed for use in modeling. These equations were applied to describe Type I or Type II behaviors. Most equations in table 1 were developed to fit stress-strain relationships at relatively low temperatures; they may fit the experimental data well, but only for certain materials, and for limited experimental ranges. For steels at elevated temperatures, eq (4), which is a modified form of Ludwik's power-law equation of eq (3), has been shown to fit some experimental data rather well [4]. At NIST, we successfully used eq (9) to describe the stress-strain behavior of bar steels [8]. The parameters $B$ and $n$ are nearly constant for medium-C microalloyed steels when $\sigma_{\mathrm{s}}$ is taken as the flow stress in the steady state. Regarding Type III flow curves, no single governing equation has been found. Different approaches $[9,12-14]$ have been used to account for the amount and kinetics of softening due to dynamic recrystallization. 


\section{Constitutive Equations and Factors Affecting Flow Stress}

Constitutive equations describe nonlinear relationships that exist among the process variables such as effective stress, effective strain rate, and temperature at different strains. Such equations are unique for each material and processing condition. Usually, for practical applications they are developed using data obtained under simplified experimental conditions.

The constitutive equations are usually described using a rate expression

$$
\dot{\varepsilon}=f(\sigma, T, S),
$$

where $\dot{\varepsilon}$ is strain rate, $\sigma$ is stress, $T$ is temperature, and $S$ is the structural state of the material. In general, $S$ is affected by deformation (strain and strain rate), and temperature.

One of the goals in constitutive-behavior modeling is to predict the flow stress of a given steel under various processing conditions. For this purpose, rate expressions, such as eq (14), are rearranged to express the flow stress explicitly as a function of strain, temperature, and strain rate.

\subsection{Temperature and Strain Rate}

The rate at which strain is applied can have an important influence on the flow stress. In general, increasing strain rate increases flow stress. Also, the shape of the stress-strain curve depends strongly on temperature. Decreasing temperature, in general, increases flow stress. Typically, the temperature and strain-rate dependence of the rate expression is described by the hyperbolic sine equation [15]

$$
\dot{\varepsilon}=A[\sinh (\alpha \sigma)]^{m} \exp \left[\frac{-Q}{R T}\right],
$$

where $A, \alpha$, and $m$ are experimentally determined constants. At low stresses $(\alpha \sigma<0.8)$, the equation is reduced to a power relation such as the equation used to describe creep behavior,

$$
\dot{\varepsilon}=A_{1} \sigma^{m_{1}} \exp \left[\frac{-Q}{R T}\right],
$$

and at high stresses $(\alpha \sigma>1.2)$, it reduces to an exponential relation,

$$
\dot{\varepsilon}=A_{2} \exp \left(\beta m_{2} \sigma\right) \exp \left[\frac{-Q}{R T}\right] .
$$

Equation (15) was derived based on results of steady-state creep experiments. It has been observed that the parameters in eq (15) decrease with strain, especially at small strains, where steady state has not been reached. After the steady-state stress is reached, these parameters 
approach a constant with little variation. It has been shown that eq (15) describes the hotdeformation behavior of steels better than eqs (16) and (17) [16]. Rearranging and expressing the steady-state stress as a function of $Z$, we find from eq (15) that

$$
\sigma=\frac{\sinh ^{-1}\left(\frac{Z}{A}\right)^{\frac{1}{m}}}{\alpha} .
$$

Low $Z$ promotes dynamic recrystallization (Type III behavior in figure 2). As $Z$ increases, the peak in the curve broadens and the strain that corresponds to the peak stress also increases. With further increase of $Z$, Type III behavior approaches Type II behavior and the peak disappears.

Many hot-deformation studies are devoted to determining the constants $A, \alpha, m$, and $Q$ in eq (15). Once these constants are determined for a given steel, eq (15) can be used to interpolate or extrapolate to conditions for which data are unavailable.

\subsubsection{Apparent Activation Energy $Q$}

For C-Mn steels the values of $Q$ fall in the range 262 to $366 \mathrm{~kJ} \cdot \mathrm{mol}^{-1}[1,4,17-20]$. The values of $Q$ tend to increase with additions of certain alloying elements including $\mathrm{Nb}$. Values reported for some $\mathrm{Nb}$ microalloyed steels fall in the range 325 to $461 \mathrm{~kJ} \cdot \mathrm{mol}^{-1}[12,20,21]$. The apparent activation energy is frequently related to the activation energy for self-diffusion of iron in austenite, and the reported values are similar. However, some materials show distinct differences between activation energies determined under hot-working conditions and those measured during creep [22]. Such materials include steels [22]. In such cases, one should beware not to extrapolate to conditions beyond the range of actual experimental observations since $Q$ might vary with strain rate. Abnormal behavior of $Q$ has been reported for Nb steels [4].

\subsubsection{Constants $A$ and $\alpha$}

The unit for the constant $A$ is $\mathrm{s}^{-1}$, and values are usually expressed in $\ln A$. Some reported values for $\ln A$ are in the range 25 to 32 [4,12]. The values of $\alpha$ are usually fixed at 0.012 [12] or $0.013 \mathrm{MPa}^{-1}[4]$.

\subsubsection{Value for $m$}

The values of $m$ reported in the literature range from 3.2 to $5.0[4,12,20,22]$. This dimensionless parameter relates to the strain-rate sensitivity of the material, and this parameter is a measure of the dependence of flow stress on strain rate. The higher the strain rate, the higher the flow stress. It is widely reported that the strain-rate sensitivity increases with increasing temperature $[23,24]$. However, for hot-worked steels, the value of $m$ remains constant after the steady-state condition is reached [16]. Note that $m$, as expressed in eq (15), decreases with an increase of the strain-rate sensitivity. 


\subsection{Dynamic Recrystallization}

The occurrence of dynamic recrystallization may profoundly affect the flow stress, as shown in figure 2 . Although dynamic recrystallization and its effects have been widely studied, it has been argued that prospects for the occurrence of dynamic recrystallization during rolling in a single pass are remote since the critical strain $\varepsilon_{c}$ for dynamic recrystallization is seldom achieved $[20,25]$. However, the attainment of this critical strain is more probable during multipass rolling in the finishing stands. The interpass time in that case is short, and the rolling temperature is low; therefore grains deformed in a previous pass do not have sufficient time to statically recrystallize after deformation, and the strain is retained to the next pass. Thus, strain increments accumulated in the process of several passes can reach $\varepsilon_{\mathrm{c}}$ and induce dynamic recrystallization. Although the occurrence of dynamic recrystallization in an industrial rolling process seems likely, there has been no report in the literature to substantiate the hypothesis.

A model that considers the occurrence of dynamic recrystallization on stress-strain behavior has been reported $[13,14,24]$. This model derives from the fundamental theories of hardening and softening (recovery and recrystallization), and it applies to a wide range of materials and test conditions. As a consequence of its broad applicability, this model contains a large number of constants that must be determined experimentally. This necessitates some creep test experiments.

A simpler model that involves four constants has also been proposed for hot-worked steels [12]. Two of these four constants are material properties: the steady-state flow stress after dynamic recrystallization and $\varepsilon_{c}$, which is a function of the initial grain size and $Z$. The steadystate flow stress after dynamic recrystallization $\sigma_{r e x d}$ for a Nb-B steel is expressed as

$$
\sigma_{\text {rexd }}=84.34 \sinh ^{-1}\left[\left(\frac{Z}{5.2 \times 10^{11}}\right)^{0.2}\right] .
$$

\subsection{Chemical Composition}

In general, the effects of chemical composition on flow properties are embedded in the constants of the stress-strain equations. For example, additions of Nb increase $Q$ in eq (15), as noted previously. Few attempts have been made to express the flow stress in terms of composition [26]. But systematic research quantifying the effects of individual alloying elements is scarce.

\subsection{Austenite Grain Size}

Grain size is an important parameter governing the low-temperature mechanical properties of steels, such as strength and toughness. However, the existing literature for steels contains little information describing the effects of grain size on flow stress under hot-working conditions, aside from its effects on the occurrence of dynamic recrystallization. 
It is stated that equilibrium subgrain structures are established early during deformation at high temperatures $[22,27]$. These subgrain structures determine the flow stress under hotworking conditions, except at the very early stage of deformation before the subgrain structures are established. Thus, the initial austenite grain size plays little role in determining the flow stress of steels. Nevertheless, the austenite grain size does change from one pass to another during rolling. And the initial grain size influences the value of $\varepsilon_{c}$, which increases with an increase of grain size [1]. Therefore, more research is needed to arrive at conclusive results about the effects of grain size on the flow behavior of steels.

\subsection{Precipitation}

Precipitation is another factor that has potent effects on low-temperature mechanical properties but is not widely discussed in the field of high-temperature flow properties. During hot rolling, precipitation in C-Mn steels is insignificant, but it does occur in microalloyed steels. Dynamic precipitation is not likely to take place in single-pass rolling because insufficient time is available $[12,25]$. However, the conditions for strain-induced precipitation seem to be sufficient in the finishing stands of a multipass rolling operation, especially in the case of $\mathrm{Nb}$ alloyed steels. Temperature is relatively low during rolling in the finishing stands, and strain is accumulated over several passes. However, even if precipitates do form during rolling, their potency remains at issue.

\subsection{Adiabatic Heating}

Adiabatic heating is a factor in tests at high strain rates. Typically, at strain rates exceeding $1 \mathrm{~s}^{-1}$, the temperature of a test specimen will increase continuously while the test is progressing. The heat generated in a specimen during deformation at such rates cannot be dissipated quickly enough to maintain an isothermal condition. If we assume that all the mechanical energy is converted into heating the specimen, then the temperature increase $\Delta T$ due to deformation can be estimated [4]:

$$
\Delta T=\frac{\sigma_{m} \delta \varepsilon}{\rho C_{p}} .
$$

$\left(\sigma_{m} \delta \varepsilon\right)$ is the area under the stress-strain curve without temperature correction, $\rho$ is the steel's density, and $C_{p}$ is its heat capacity. The incremental stress decrease due to the adiabatic heating is

$$
\Delta \sigma=\left(\frac{Q}{m \alpha R}\right)\left(\frac{1}{T}-\frac{1}{T+\Delta T}\right)
$$

Depending on test conditions, the specimen's temperature rise can be as high as $30^{\circ} \mathrm{C}$ at a strain of 0.7 [4]. An increase in temperature of $10^{\circ} \mathrm{C}$ will generally decrease the flow stress by 2 to $5 \mathrm{MPa}$. According to one report, the measured and calculated temperature increases due to adiabatic deformation agree well [4]. 


\section{Experimental Approach}

The goal of constitutive modeling is to predict material flow properties. Knowledge of the stress-strain curve is needed for efficient processing, along with the yield- and flow-strength data. Experiments provide an accurate mechanical-property database for each steel composition. Models must then be developed, based on equations that relate the deformation parameters.

In this study, we used uniaxial compression tests and right-circular cylindrical specimens to characterize the mechanical behavior of selected steels. There are no standard test procedures for determining flow-stress curves at the relatively high temperature and strain-rate conditions encountered in industrial processing and metalworking. Compression testing offers advantages over other test methodologies, especially in simplicity and economy of experimental apparatus.

Tension and torsion tests are viable alternatives. Tension test specimens are not desirable for hot-deformation studies because they typically neck at strains in the range 10 to $30 \%$. Much larger strains without plastic instability can be achieved using torsion or compression tests.

However, the strain and strain rate in torsion tests will vary from a maximum at the surface of the cylindrical specimen to 0 at the center. The measured flow stress is then an average stress over a certain volume of material at the outer layer of the specimen. The strain and strain rate in torsion tests are likewise averages. It is assumed that the outer layer of the torsion specimen provides the major contribution to the flow stress because of the stress distribution and work hardening [28]. Torsion test specimens are usually rigidly fixed in the drive system. Therefore, the strain-rate transient depends on the time needed to attain the operating speed. The strain rate in this transient period is usually limited to less than $10 \mathrm{~s}^{-1}$ [29].

The right-circular cylinder is often used in tests of metals to simulate thermomechanical processing effects. Cylindrical specimens are small and readily machinable compared to specimens used in other test methodologies. The cylindrical specimen is also recognized in the ASTM Standard Practice for Compression Tests of Metallic Materials at Elevated Temperatures with Conventional or Rapid Heating Rates and Strain Rates (ASTM E 209 - 65).

A disadvantage of the cylindrical specimen is that it barrels during compression testing. Barreling in axisymmetrical compression testing is caused by (1) the friction at the platenspecimen interface, and (2) the temperature gradient between the platen-specimen interface and the middle of the specimen.

Barreling in compression tests causes nonuniform strain and strain rates. Nevertheless, reports show that barreling does not affect the measured flow stress if the specimen aspect ratio (the specimen diameter divided by its height) is kept between 0.5 and 0.8 [30,31]. Higher loads are needed to deform a specimen when friction is present. However, barreling is usually accompanied by shear instability, which reduces the load. In certain specimen geometries the load increase due to friction is possibly compensated by the load reduction due to shear instability. For this reason, we used no lubricants for the experiments described in this study. Lubricants at the platen-specimen interface may reduce barreling, but they introduce other complications. 
Nonuniform deformation from barreling does cause problems in the interpretation of microstructures that are developed during deformation $[32,33]$. Strain imposed on the specimen during deformation is a major factor influencing the recrystallized austenite grain size after deformation. The nominal strain that is measured during deformation differs significantly from the actual strain of the specimen [33]. Therefore, barreling may be ignored if the testing is solely for the measurement of flow stress, but it must be taken into account if microstructural evaluation is involved.

\subsection{Materials}

Two plain C steels, two interstitial-free (IF) steels, and four microalloyed steels were tested in this study. Table 2 identifies the eight steels and their chemical compositions. Mechanical properties of the steels at room temperature are reported in a different report [34].

\subsection{Test Specimen}

The cylindrical test specimen was $10 \mathrm{~mm}$ in diameter and $15 \mathrm{~mm}$ high. The cylindrical specimens were machined from crop samples such that the cylindrical axis coincided with the through-thickness direction. The steel types were identified in table 2.

\subsection{Apparatus}

Two servohydraulic test machines are available in our laboratory: one has a load capacity of $250 \mathrm{kN}$ and the other $100 \mathrm{kN}$. In addition to this difference in load capacity, the two machines differ in attainable strain rates, and in heating and cooling techniques. The $250 \mathrm{kN}$ machine is an existing machine, and the $100 \mathrm{kN}$ machine was developed and commissioned during the

Table 2. Chemical compositions (mass \%).

\begin{tabular}{ccccccccc}
\hline Elem. & $\begin{array}{c}\text { HSLA- } \\
\mathrm{V}\end{array}$ & $\begin{array}{c}\text { HSLA- } \\
\mathrm{Nb}\end{array}$ & $\begin{array}{c}\text { HSLA-50 } \\
\mathrm{Ti}-\mathrm{Nb}\end{array}$ & $\begin{array}{c}\text { HSLA-80 } \\
\text { Ti-Nb }\end{array}$ & A36 & DQSK & $\begin{array}{c}\text { IF } \\
\text { Nb rich }\end{array}$ & $\begin{array}{c}\text { IF } \\
\text { Nb lean }\end{array}$ \\
\hline $\mathrm{C}$ & 0.045 & 0.082 & 0.071 & 0.07 & 0.17 & 0.038 & 0.0028 & 0.002 \\
$\mathrm{Mn}$ & 0.45 & 0.48 & 0.758 & 1.35 & 0.74 & 0.30 & 0.17 & 0.106 \\
$\mathrm{~S}$ & 0.005 & 0.005 & 0.013 & 0.003 & 0.008 & 0.008 & 0.006 & 0.008 \\
$\mathrm{Si}$ & & & & 0.13 & & & & \\
$\mathrm{~V}$ & 0.080 & & & & & & & \\
$\mathrm{Ti}$ & & & 0.013 & 0.042 & & & 0.035 & 0.059 \\
$\mathrm{Nb}$ & & 0.036 & 0.023 & 0.085 & & & 0.035 & 0.009 \\
$\mathrm{Al}$ & 0.078 & 0.024 & 0.053 & 0.039 & 0.040 & 0.040 & 0.027 & 0.033 \\
$\mathrm{~N}$ & 0.0072 & 0.0054 & 0.0067 & 0.0075 & 0.0047 & 0.0052 & 0.0029 & 0.0041 \\
\hline
\end{tabular}


investigation of this project. Using these machines, we compressed specimens between quartz or ceramic platens located inside an evacuated test chamber at elevated temperatures.

Fused quartz or ceramic rods are used for platens. The ceramic platens are transformation-toughened zirconia (TTZ) in the form of solid white rods. The TTZ rods are more expensive than quartz rods, but are preferable in our experience since quartz rods are more susceptible to crack after repeated use.

The apparatus are described elsewhere [35,36], and only brief descriptions of the apparatus are given here. The subcomponents of the apparatus include a computer-controlled servohydraulic load frame, a test chamber providing vacuum environment, a furnace equipped with a programmable temperature controller, a microcomputer, and a storage oscilloscope. The axisymmetric compression test methodology offers benefits since the required specimen size is relatively small. This facilitates system design by minimizing the volume and mass of test fixtures.

\subsubsection{Computer and Peripherals for Machine Control and Data Acquisition}

Figure 3 is a flowchart of the plan for machine control and data acquisition. The computer is a $25 \mathrm{MHz} 80486$ personal computer (PC), equipped with a board-level analog-digital (A/D) plug-in board having a $45 \mathrm{kHz}$ throughput and an IEEE GPIB board. The A/D board contains eight differential A/D channels (input) and two digital-analog (D/A) channels (output). Peripherals include a line printer, a $340 \mathrm{MB}$ hard disk, a 1.2 MB floppy disk drive, and a $360 \mathrm{~KB}$ floppy disk drive.

The apparatus is equipped with a programmable digital storage oscilloscope for highspeed data acquisition. The oscilloscope includes four $15 \mathrm{bit}, 100 \mathrm{kHz}$ digitizers. Each channel stores up to 4000 data points when all four channels are operating simultaneously. The same computer and the storage oscilloscope are used interchangeably with the two test machines.

The computer components and accessories described here are existing pieces of equipment that serve multiple uses in our laboratory. They do not represent up-to-date technology. Different types of components may perform the same functions. For example, the storage oscilloscope is used for data acquisition simply because it is readily available and has been used for such purposes at NIST for the past 15 years [37,38]. More affordable board-level A/D plug-in boards are available and may be substituted for the oscilloscope described here. Also, the capabilities of today's personal computer and its peripherals, such as disk drives, are much superior to those described in this investigation.

\subsubsection{Load Frames}

Each machine is equipped with a closed-loop servohydraulic load frame. One machine has a load capacity of $250 \mathrm{kN}$ and the other $100 \mathrm{kN}$. These machines are not conventional in terms of actuator travel speed. The machines have been modified by using high flow-rate servovalves and large accumulators. The modification gives attainable actuator speeds up to 500 
$\mathrm{mm} \cdot \mathrm{s}^{-1}$. With the currently used specimen geometry, this travel speed produces controllable strain rates up to $25 \mathrm{~s}^{-1}$ for the $250 \mathrm{kN}$ machine, and $50 \mathrm{~s}^{-1}$ for the $100 \mathrm{kN}$ machine.

The most desirable deformation mode for rolling simulation is a constant true-strain-rate compression, which greatly eases data analysis and interpretation. Constant true-stain-rate compression is accomplished through displacement control of the load train by a PC using the equation

$$
h(t)=h_{i} \exp (-t \dot{\varepsilon}) .
$$

Here, $h(t)$ is the specimen's instantaneous height at time $t, h_{i}$ is the initial height, and $\dot{\varepsilon}$ is the desired constant true strain rate.

In a high strain-rate experiment, the actuator's travel starts from a rest position and then accelerates to the desired speed that results in slow rates at the very beginning of the experiment. To overcome the problem, we retract the actuator at the beginning of a test so that the specimen is compressed using only that portion of the actuator travel that produces constant rate. Then, the value of $\dot{\varepsilon}$ is calculated using the actual signals recorded by the data acquisition system [39].

\subsubsection{Heating, Cooling, and Vacuum}

For the $100 \mathrm{kN}$ machine, a vertically mounted electrical tube furnace (power rating is 6.0 $\mathrm{kW}$ at $240 \mathrm{~V}$ and $21.6 \mathrm{~A}$ ) is used for heating. The heating elements are four tubular tungstenfilament quartz lamps, each backed by an elliptical reflecting wall. The vacuum chamber is a quartz tube that encapsulates the ceramic rods and the specimen. The tube is $50.8 \mathrm{~mm}$ in diameter and $264 \mathrm{~mm}$ long. The elliptical reflectors, which surround the quartz tube, focus radiant energy from the tungsten lamps to the outer surfaces of the specimen in the quartz tube at the center of the heating chamber. The physical sizes of this furnace and its power supply are small, which contributes substantially to the compact design and efficiency of the entire test facility.

Heating of a specimen is achieved through radiation and the heating rate is limited to about $2{ }^{\circ} \mathrm{C} \cdot \mathrm{s}^{-1}$. There is no forced cooling device for fast cooling of a heated specimen. The cooling is achieved through radiation to the surrounding and through conduction to the loading rods. Thus, cooling of a heated specimen after a test is slow, and it takes 2 to $3 \mathrm{~h}$ to furnace-cool the specimen. The vacuum system consists simply of a pressure gage and a mechanical pump by which the chamber is evacuated during a test to minimize oxidation of the specimen at high temperatures.

The $250 \mathrm{kN}$ apparatus uses an induction furnace and a controlled gas-flow cooling process. A $10 \mathrm{~kW}, 450 \mathrm{kHz}$ radio-frequency ( $\mathrm{rf}$ ) induction generator generates the heat demanded by the temperature controller. The heating coil is a $\mathrm{Cu}$ tube $4.76 \mathrm{~mm}$ in diameter. A stainless-steel vacuum chamber encloses the specimen, and the heating and cooling coils. A vacuum is obtained with a $100 \mathrm{~mm}$ diffusion pump which can achieve a vacuum of $1.33 \times 10^{-3}$ $\mathrm{Pa}\left(1 \times 10^{-5} \mathrm{Torr}\right)$ within $20 \mathrm{~min}$. At a pressure of about $1.33 \times 10^{-1} \mathrm{~Pa}\left(10^{-3} \mathrm{Torr}\right)$, gasses are 
ionized between the specimen and the heating coils. At this pressure, it is impossible to heat the specimen because the rf field arcs and shuts off the rf generator.

Cooling of a specimen for the $250 \mathrm{kN}$ machine is controlled with a $\mathrm{PC}$ that regulates gas flow onto the specimen through a $\mathrm{Cu}$ coil $6.35 \mathrm{~mm}$ in diameter and concentric with the heating coil. The side of the cooling coil facing the specimen is perforated to provide a gas flow that cools the specimen uniformly. Either He or $\mathrm{N}$ gas is used for cooling. Because of its higher specific heat $\left(5230\right.$ versus $1030 \mathrm{~J} \cdot \mathrm{kg}^{-1} \cdot \mathrm{K}^{-1}$ at $25^{\circ} \mathrm{C}$ ) and greater mobility, He is more efficient than $\mathrm{N}$ in rapid cooling. For a cylindrical steel specimen $10 \mathrm{~mm}$ in diameter by $18 \mathrm{~mm}$ in height, the cooling rate is controllable to a maximum rate of $25^{\circ} \mathrm{C} \cdot \mathrm{s}^{-1}$.

Both furnaces are operated automatically by means of a programmable temperature controller that has ramp-and-soak and multiple set-point capabilities. Before testing, the desired thermal profile is selected and preprogrammed into the controller. The temperature at any phase of the experiment is then monitored by means of an S-type thermocouple ( $\mathrm{Pt}$ and $\mathrm{Pt}-10 \% \mathrm{Rh})$ that is spot-welded to the surface of the cylindrical specimen at the midpoint of height.

\subsubsection{Machine Performance and Reproducibility}

\subsubsection{Alignment}

Both test machines are rigidly constructed. The specimen dimensions were measured before and after compression using a micrometer to confirm the final value of strain, and to confirm that good axial symmetry is retained after testing. The fact that the top and bottom surfaces of specimens remain parallel after compression testing is a qualitative indication of good mechanical alignment.

\subsubsection{Reproducibility}

Figure 4 shows the results of triplicate tests of DQSK specimens using the $250 \mathrm{kN}$ machine. The results demonstrate excellent reproducibility of the machine. Figure 5 shows a pair of stress-strain curves for DQSK specimens that were tested using the 100 and $250 \mathrm{kN}$ machines at nominally identical test conditions. In this example, the grain size of the steel is $0.114 \mathrm{~mm}$, the test temperature is $1000^{\circ} \mathrm{C}$, and the strain rate is $25 \mathrm{~s}^{-1}$ (the maximum possible strain rate of the $250 \mathrm{kN}$ apparatus). The near equivalence of the stress-strain curves presented in this figure demonstrates acceptable reproducibility.

\subsubsection{Strain Rates}

At low strain rates, the actuator of the machine follows the command signals quite well. As a result, the nominal constant strain rate can be achieved and maintained. Figure 6 shows the results of tests at nominal constant strain rates of 1 and $10 \mathrm{~s}^{-1}$. Here, the strain rates were calculated using the actuator's displacement-versus-time signals.

If the command signals call for instant high speeds, the actuator is not capable of following the demands instantaneously due to inherent characteristics of servohydraulic test 
machines. The actuator's speed will be slower than the command signals at the beginning and at the end of a command cycle. After receiving the commands at the onset of a test, the actuator needs time to accelerate from a rest position to the desired speed. Similarly, it needs time to decelerate from a high-speed travel to rest as called for by the command signals at the end of the test. This behavior is clearly demonstrated in figure 7 .

As mentioned in section 4.3.2, the problem of slower speed at the beginning of a test has been remedied by actuator retraction. However, the problem at the end of a test has not been corrected in our laboratory. The problem limits the valid strain range during a high strain-rate test. Thus, the actual strain rate during a high-speed test varies instantaneously, so specified values are necessarily quoted in nominal terms.

\subsubsection{Specimen Strength}

The machine's performance is slightly affected by secondary factors such as the specimen's size and flow strength. The data in figure 8 show implicitly that the machine's performance is influenced by the properties of the test material. Here, machine performance is gaged in terms of the ratio $H_{f c} / H_{f m}$. The measured and commanded final heights are $H_{f m}$ and $H_{f c}$, respectively. A ratio of 1 means the commanded strain value is precisely achieved. Specimens in this series were tested at the same nominal strain rate, using identical machine settings (span of ram travel fixed at a constant value). Larger grain size and higher temperature implies softer steel; so the trend of results in figure 8 reflects the $100 \mathrm{kN}$ machine's ability to meet a commanded value of compressive strain at high strain rate, and how that is affected by the specimen response.

\subsubsection{Adiabatic Heating}

Figure 9 is an example of specimen self-heating during a typical compression test at a strain rate of $50 \mathrm{~s}^{-1}$. Experiments indicate that the temperature rise $\Delta T$ at a strain of 0.7 ranges from 5 to $10{ }^{\circ} \mathrm{C}$, with modest variation depending on test conditions. Normally, $\Delta T$ values less than $10^{\circ} \mathrm{C}$ may be considered negligible for engineering purposes. On the other hand, the observed values here are certainly smaller than expected. Based on predictions from mechanical-equivalence equations assuming all deformation energy is converted into heat as described in section 3.6 , the calculated $\Delta T$ is about $20^{\circ} \mathrm{C}$. The disparity may be due to nonuniform heating throughout the specimen. Therefore, additional analysis is needed to clarify the role of adiabatic heating in hot-deformation studies. Because of this uncertainty, the stressstrain results presented in this report are not adjusted for the adiabatic heating correction.

\section{Results and Discussion}

\subsection{Raw Data and Data Analysis}

During each test, the load, actuator's displacement, temperature, and time were measured, recorded by the storage oscilloscope, and saved onto floppy disks for processing. Outputs of interest are the curves of true stress as a function of true strain, the true strain rate as a function 
Table 3. Summary of test results from UBC and NIST.

\begin{tabular}{|c|c|c|c|c|}
\hline \multirow{2}{*}{ Steel } & \multirow{2}{*}{$\dot{\varepsilon}, \mathrm{s}^{-1}$} & \multirow{2}{*}{$\mathrm{T},{ }^{\circ} \mathrm{C}$} & \multicolumn{2}{|c|}{$\sigma$ at $\varepsilon=0.5, \mathrm{MPa}$} \\
\hline & & & UBC & NIST \\
\hline \multirow{8}{*}{ DQSK } & \multirow{4}{*}{1} & 900 & 135 & 154 \\
\hline & & 1000 & 98 & 108 \\
\hline & & 1100 & 71 & 66 \\
\hline & & 1200 & 43 & 44 \\
\hline & \multirow{4}{*}{10} & 900 & 171 & 174 \\
\hline & & 1000 & 129 & 138 \\
\hline & & 1100 & 103 & 102 \\
\hline & & 1200 & 75 & 74 \\
\hline \multirow{8}{*}{ A36 } & \multirow{4}{*}{1} & 900 & 133 & 133 \\
\hline & & 1000 & 95 & 89 \\
\hline & & 1100 & 66 & 57 \\
\hline & & 1200 & 46 & 44 \\
\hline & \multirow{4}{*}{10} & 900 & 171 & 165 \\
\hline & & 1000 & 120 & 131 \\
\hline & & 1100 & 104 & 104 \\
\hline & & 1200 & 80 & 76 \\
\hline
\end{tabular}

of true strain, and the temperature change during deformation. Information on the software programs for the data reduction and analysis is given elsewhere [39].

\subsection{Round-Robin Test Program with UBC}

A round-robin test program with UBC was initiated to compare the test results using the respective laboratory facilities and analyses. Two steels, the A36 and DQSK grades, from the same slabs after rough rolling were used for the program. The round-robin test program is important because there are no published test standards for the high-temperature and high-strainrate compression tests, and test procedures vary widely from laboratory to laboratory. Consistent and agreeable stress-strain data generated from different laboratories are essential for any modeling effort. The cylindrical specimens used were $15 \mathrm{~mm}$ in height and $10 \mathrm{~mm}$ in diameter. The testing parameters included 3 strain rates, $0.1,1$, and $10 \mathrm{~s}^{-1}$, and 4 temperatures, 900, 1000, 1100 , and $1200^{\circ} \mathrm{C}$.

The test results are presented in figures 10 through 13. The flow stresses at a strain of 0.5 are tabulated in table 3. In general, the agreement between the results generated in the two laboratories is good. At a strain of 0.5 , the difference in flow stress is within $10 \mathrm{MPa}$, except that 
Table 4. Constants in hyperbolic sine equation for DQSK and A36 steels.

\begin{tabular}{cccccc}
\hline Steel & Laboratory & $\alpha, \mathrm{MPa}^{-1}$ & $Q, \mathrm{~kJ}^{-1} \mathrm{~mol}^{-1}$ & $m$ & $\ln A$ \\
\hline \multirow{2}{*}{ DQSK } & UBC & 0.013 & 293 & 4.07 & 25.6 \\
& NIST & 0.013 & 326 & 4.41 & 28.4 \\
\hline \multirow{2}{*}{ A36 } & UBC & 0.013 & 314 & 4.34 & 27.6 \\
& NIST & 0.013 & 321 & 4.39 & 28.4 \\
\hline C-Mn & Literature & 0.013 & 262 to 366 & 3.2 to 5.0 & 25 to 32 \\
\hline
\end{tabular}

in two cases, where one difference is 19 and the other is $11 \mathrm{MPa}$. This is within the variability observed for the same steel tested with the same machine.

The flow stresses at a strain of 0.5 were used to fit eq (15). The results are presented in table 4. Here again the agreement between the results from the two laboratories is good. The results also agree well with those published in the literature.

However, there is a consistent difference observed in the results from the two laboratories; that is the hardening behavior at strains below about 0.1 . This is due to the difference in the way strain has been calculated. At UBC, the uniaxial strain was inferred from the direct measurement of diametrical changes during testing. The measurement was performed directly on the specimen at its mid-section. At NIST, the axial strain was calculated from the displacement signals of load train with the assumption of incompressibility of steel during plastic deformation (constant-volume assumption). Implicit in this strain calculation is the assumption of uniform deformation.

As mentioned previously, at NIST the displacement signals were not measured directly on the specimen. The displacement signals also contained the displacement of the load train in addition to the displacement due to specimen. With rigid machines such as those at NIST, the displacement due to the load train was negligible. However, even this usually negligible displacement due to the machine becomes noticeable at small strains. This results in a slight overestimation of strain in the results produced at NIST. The correction for displacement due to machine compliance will be discussed in section 5.3, "Machine Compliance."

In addition to the difference in strain calculations, there is another significant difference between the machines at UBC and at NIST. That is the heating method. At UBC, resistance heating was used, and the jaws were water-cooled. This produced a temperature gradient along the specimen axis from the mid-section of the specimen to the interface between the specimen and the anvils. The temperature difference was between 50 and $70^{\circ} \mathrm{C}$. At NIST, induction heating was used, and the specimen was placed on a quartz platen. The upper platen was retracted; thus it was not in contact with the specimen before testing. This specimen-platen arrangement produced a slight temperature gradient with higher temperature at the top of the specimen and lower temperature at the bottom. However, because of the low thermal conductivity of quartz platen plus poor contact between the specimen and the platen before testing, the temperature gradient should be small. 
Induction heating is inherently slower than resistance heating, such as used at UBC. For tests at NIST, with a strain rate less than $0.5 \mathrm{~s}^{-1}$, heat loss from the specimen to the platen through conduction was significant during deformation. The heater control cannot respond to this heat loss until about halfway through the test at a strain of about 0.5 . Therefore, heat loss in tests of a strain rate of $0.1 \mathrm{~s}^{-1}$ is significant. The temperature of the test specimen decreased slowly from the start of the test and then slowly increased again after a strain of about 0.5 when the heater control started to respond to the temperature decrease. The isothermal test condition had not been maintained. Flow stress from these tests (strain rate of $0.1 \mathrm{~s}^{-1}$ ) showed higher values due to temperature drop during test. Due to this effect, the results of testing at the strain rate of $0.1 \mathrm{~s}^{-1}$ are not presented in this report. Under hot-rolling conditions, the strain rate is expected to be much higher than $0.1 \mathrm{~s}^{-1}$, so the results at this strain rate are much less important than those at high strain rates.

Another point worth mentioning is the friction between the specimen and the anvil. At UBC, because heating is resistive, the contact between specimen and anvil has to be good in order for the electrical current to go through. This specimen-anvil arrangement increases the friction between the specimen and the anvils. Large friction between specimen and anvil (platen) causes barreling and increases the deformation loads. This is evidenced in most of the UBC's results at large strains; the flow stress increases at strains greater than about 0.7 . This increase in flow stress at strains greater than 0.7 is not real, but due to large friction between specimen and anvil. However, barreling is usually accompanied by shear instability that reduces the load. Specimens tested at both laboratories did show barreling after deformation. Reports in the literature $[4,31]$ have shown that with the specimen dimension used in this round-robin program, barreling will not affect the measured flow stresses, at least at strains less than 0.7 , in both laboratories. This is probably because the increase in load due to friction is cancelled out by reduction in load due to shear instability.

Despite all these differences between the test machines at UBC and at NIST, the agreement between the test results is reasonably good. Although detailed comparison between the results obtained from this program with those published in the literature is impossible because of the differences in steel grades and testing details, computed results using Shida's equation [26] with comparable $C$ contents and testing conditions agree well with present results. This confirmation seems to exclude the possibility that both laboratories produce erroneous data.

\subsection{Machine Compliance}

The accurate way to measure strain is to measure the displacement, from which strain is calculated, directly on specimen with strain gages, extensometers, or optical devices. In our experiments, however, the strain has been calculated using displacement signals that are not taken directly on the specimen (due to experimental difficulties), but away from the specimen. The experimental difficulties arise because of space constraints resulting from heating furnace, high temperature, and large strain. The displacement signals recorded away from the specimen consist of the displacement due to the specimen plus the displacement of the load train.

Our experimental setup measures the displacement at a location about one meter away from the specimen with a linear variable displacement transducer (LVDT). The displacement of 
the load train typically consists of two parts. First, it comes from the loose contact between the anvils and the specimen at the beginning of test. This portion of the displacement will vary from specimen to specimen and is relatively large. The other is the elastic deformation of the load train. This portion of the displacement is proportional to the applied load and is reproducible from test to test.

Using aluminum specimens at room temperature (investigation at high temperature is difficult to conduct, if not impossible), we determined the displacement of the load train as a function of load experimentally. In this experiment, a clip-on gage was attached to measure the gap between the two anvil surfaces that compress the specimen. This device measured the actual specimen displacement. At the same time the displacement was recorded away from the specimen just like those experiments conducted at high temperatures. The difference between these two quantities is the displacement due to machine. Except for those results in section 5.2, the stress-strain results presented in this report have been corrected for the machine displacement.

\subsection{Mathematical Description of Stress-Strain Curves}

The goal of this study is to provide models that estimate the stress-strain curves of steels under hot-rolling conditions. These models are then used to calculate the roll-separating forces during rolling and to provide data as input to the numerical tools, such as finite-element method, for detailed calculations of stress, strain, and related properties. The focus has been on modeling the stress-strain behavior as functions of temperature, strain rate, and austenite grain size. Little has been performed to detail the effects of individual parameters.

Besides chemical composition, three other major parameters have significant influence on the flow behavior of steels: temperature, strain rate, and austenite grain size. For models to be useful, they have to consider these parameters explicitly. In this study, there are not enough systematic variations of chemical compositions to provide enough data for modeling. Thus, there is no general modeling effort in this area and each grade of steel will have its own model that considers the effects of temperature, strain rate, and austenite grain size.

The effects of temperature, strain rate, and austenite grain size on flow behavior are given in figures 14 through 16. As expected, decreasing temperature increases flow stress (figure 14). Also, increasing strain rate increases flow stress (figure 15).

The influence of austenite grain size is more complicated. As indicated in figure 16, reduction of grain size promotes dynamic recrystallization. Grain-size reduction also increases the flow stress and the rate of hardening in the early stage of deformation. As for the effects of grain size on the steady-state flow stresses, either with or without dynamic recrystallization, the results are not very conclusive. However, observations support the theory that grain size has little effect on the steady-state flow stresses [22,27]. Equilibrium subgrain structures are established in the early stage of deformation. The development of subgrain structure controls the early stage of deformation and the equilibrium subgrain structure controls the steady-state stresses. So, the initial grain size has little influence on the steady-state flow stresses. 
To describe the stress-strain curve mathematically, our initial choice was eq (9), which fitted the elevated-temperature experimental data well for the stress-strain portion that was prior to dynamic recrystallization. Later, UBC suggested that we use the rigid-plastic model to describe the flow behavior and incorporate yield stress at the start of the stress-strain curve. Thus, eq (9) was modified and the following equation was used,

$$
\sigma_{1}=\sigma_{0}+\left(\sigma_{s s 1}-\sigma_{0}\right)[1-\exp (-\beta \varepsilon)]^{n} .
$$

Here, $\sigma_{0}$ is the $0.2 \%$ offset yield stress in $\mathrm{MPa}, \sigma_{\mathrm{ss}}$ is the steady-state stress without dynamic recrystallization in $\mathrm{MPa}, \beta$ is a dimensionless constant related to the hardening behavior, and $n$ is a constant related to the relationship between applied stress and dislocation density.

The hyperbolic sine equation (eq (15)) is used to describe the combined effects of temperature and strain rate on the steady-state stresses. Grain size is considered to have no influence on the steady-state stresses. The effects of temperature, strain rate, and grain size on $\sigma_{0}$ and $\beta$ are treated separately. The constant $n$ is considered to be independent of temperature, strain rate, and grain size.

Different equations have been proposed to treat the effects of temperature, strain rate, and grain size on $\sigma_{0}$ and $\beta$. The task has proven to be difficult because the equations must describe the effects that follow some physical principles and still cover a wide range of conditions. The equations are required to meet the following conditions:

- $\sigma_{0}$ increases with decreasing temperature, increasing strain rate, and decreasing grain size.

- Within the range of interest, $\beta$ increases with increasing temperature, decreasing strain rate, and decreasing grain size.

- Within the experimental range, where the machines are capable of generating reliable data, the equations should be able to reproduce the stress-strain curves.

- Outside the experimental range, where no reliable experimental data exist, the equations should be able to estimate the stress-strain curves reasonably well. The operational ranges are temperature from 800 to $1300^{\circ} \mathrm{C}$, strain rate from 1 to $400 \mathrm{~s}^{-1}$, and grain size from 0.02 to $0.5 \mathrm{~mm}$.

After some trial and error, we found that the power law performs well and used the following equations,

$$
\begin{aligned}
& \sigma_{0}=a_{1}\left(\frac{T}{T_{0}}\right)^{a_{2}}\left(\frac{\dot{\varepsilon}}{\dot{\varepsilon}_{0}}\right)^{a_{3}}\left(\frac{d}{d_{0}}\right)^{a_{4}}, \\
& \beta=b_{1}\left(\frac{T}{T_{0}}\right)^{b_{2}}\left(\frac{\dot{\varepsilon}}{\dot{\varepsilon}_{0}}\right)^{b_{3}}\left(\frac{d}{d_{0}}\right)^{b_{4}},
\end{aligned}
$$


where $a_{\mathrm{i}}$ and $b_{\mathrm{i}}$ are constants to be determined experimentally, and $T_{0}=1273, \dot{\varepsilon}_{0}=10$, and $d_{0}$ $=0.08$ are scaling factors. $T, \dot{\varepsilon}$, and $d$ are temperature, strain rate, and grain size in $\mathrm{K}, \mathrm{s}^{-1}$, and $\mathrm{mm}$, respectively.

To account for the softening due to dynamic recrystallization, we introduced,

$$
\Delta \sigma=\max \left[0,\left(\sigma_{s s 1}-\sigma_{s s 2}\right)\left(1-\exp \left(-\left(\frac{\varepsilon}{\varepsilon^{*}}\right)\right)^{m_{4}}\right)\right] \text {, }
$$

where $\Delta \sigma$ is the amount of softening due to dynamic recrystallization after the peak stress in the stress-strain curve has been reached, $\varepsilon^{*}$ is a scaling factor depending on temperature, strain rate, and grain size, and $m_{4}$ is a constant to be determined experimentally. A simple power law

$$
\varepsilon^{*}=\eta_{1}\left(\frac{T}{T_{0}}\right)^{\eta_{2}}\left(\frac{\dot{\varepsilon}}{\dot{\varepsilon}_{0}}\right)^{\eta_{3}}\left(\frac{d}{d_{0}}\right)^{\eta_{4}}
$$

is used to describe the dependence of $\varepsilon^{*}$ on temperature, strain rate, and grain size. $\sigma_{\mathrm{ss} 2}$ is the steady-state stress after the occurrence of dynamic recrystallization. The dependence of $\sigma_{\mathrm{ss} 2}$ on temperature and strain rate is treated with the hyperbolic sine equation (eq (15)). Grain size is assumed to have no influence on $\sigma_{\mathrm{ss} 2}$.

Equation (27) is substracted from eq (23) after the peak stress in the stress-strain curve is reached, and the overall stress component becomes

$$
\sigma=\sigma_{1}-\Delta \sigma .
$$

The determinations of the strain at peak stress and the boundary separating dynamic recrystallization and no dynamic recrystallization are treated in sections 5.7 and 5.8 later in this report.

The combination of eq (18) and eqs (23) through (28) fully describes the stress-strain curve. The subsequent task is to determine the coefficients in these equations.

\subsection{Determination of Model Parameters}

At the beginning of the modeling effort in this project, experimental data were fitted to obtain the coefficients in eq (23) for each individual specimen. Then, coefficients in other equations were obtained individually and separately. This procedure has the advantage for detailed analyses of the effects of individual parameters on the overall stress-strain curve, and of the deformation mechanisms. But it is very tedious and time-consuming. For the purpose of this study, which is to provide models that estimate the stress-strain curve for hot-rolling simulations, some statistical techniques that estimate all the coefficients in all the equations with one computer run are available. 
This latter approach, which we adopted, is fast in obtaining the coefficients that describe the stress-strain behavior adequately. It also tends to smooth out the experimental abnormalities. However, it loses the details of the effects of individual parameters. Also, the original meanings of some parameters are lost. These include the steady-state stresses without or after dynamic recrystallization. And the significance of the value of $\varepsilon^{*}$, which was originally proposed to be the critical strain for dynamic recrystallization [9], no longer exists. Therefore the reader is cautioned that, as presented in this report, the parameters should not be interpreted as necessarily having their intended original meanings. They must be regarded only as fitting parameters.

\subsubsection{Parameter Estimation}

The empirical mathematical model just described has 20 adjustable parameters, with $\sigma_{\text {ss } 1}$ and $\sigma_{\mathrm{ss} 2}$ expressed as

$$
\sigma_{s s 1}=\frac{\sinh ^{-1}\left(k_{1} Z_{1}^{k_{2}}\right)}{\alpha}
$$

and

$$
\sigma_{s s 2}=\frac{\sinh ^{-1}\left(k_{3} Z_{2}^{k_{4}}\right)}{\alpha}
$$

Here, $Z_{\mathrm{i}}(\mathrm{i}=1$ and 2$)$ is the Zener-Hollomon parameter

$$
Z_{i}=\dot{\varepsilon} \exp \left[\frac{Q_{i}}{R T}\right]
$$

For each material, there are $\mathrm{K}$ experimental stress-strain curves. The empirical model was fitted to the data in two stages. Yield stress, as described in eq (24), was modeled and fitted separately. To estimate the constants $a_{1}, a_{2}, a_{3}$, and $a_{4}$, we minimized

$$
L=\sum_{k=1}^{K}\left(\hat{\sigma}_{0}(k)-\sigma_{0}(k)\right)^{2}
$$

In this expression, $\hat{\sigma}_{0}(k)$ and $\sigma_{0}(k)$ denote the predicated and observed true stress for the $k$-th curve (at true strain equal to 0 ). We minimized $L$ using quasi-Newton method, where the Hessian matrix and gradient are approximated numerically [40].

Once the fitted values of $a_{\mathrm{i}}, \mathrm{i}=1,2,3,4$, were obtained, we determined the value of the other 16 parameters by a "penalized" least-squares fit. Specifically, we minimized

$$
L=\sum_{k=1}^{K} \sum_{i=1}^{N_{k}}\left[(\hat{\sigma}(k, i)-\sigma(k, i))^{2}+\lambda_{\kappa}\left(\hat{\sigma}_{s s 2}(k, i)-\sigma_{s s 2}^{G}(k)\right)^{2}\right],
$$


where, $\sigma(k, i)$ and $\hat{\sigma}(k, i)$ denote the measured and predicted true strain for the $i$-th sample in the $k$-th experimental curve. For the $k$-th curve, there are $N_{\mathrm{k}}$ samples in the stress-strain curve. The first term on the right side is the sum of the squared prediction errors. The second term is a penalty function which increases $L$ when the predicted asymptotic stress $\hat{\sigma}_{\mathrm{ss} 2}$, varies from a reasonable guess $\sigma_{s s 2}^{G}$ of the asymptotic stress. The relative contribution of the penalty function was controlled by the value of the (positive) parameter $\lambda_{k}$. Estimates of $\hat{\sigma}_{\mathrm{ss} 2}$ are not available for all experimental curves. For curves where there was no prior information, we set $\lambda_{\mathrm{k}}=0$. When we have prior information, we set $\lambda_{k}=0.1$. For the cases studied, for $\lambda_{k} \leq 0.1$, the agreement between the observed and predicted data is about the same. However, when extrapolating the model to higher strains, our judgement is that a nonzero value of $\lambda_{k}$ improves the quality of the prediction.

In the fitting procedure, the parameters were constrained to fall between selected lower and upper bounds. For the $i$-th parameter, if the bounds are $L_{\mathrm{i}}$ and $U_{\mathrm{i}}$, we expressed the constrained parameter $\alpha_{\mathrm{i}}$ in terms of an unconstrained parameter $q_{\mathrm{i}}$ :

$$
\alpha_{i}=L_{i}+\frac{U_{i}-L_{i}}{1+\exp \left(q_{i}\right)} .
$$

We minimized $L$ as a function of the unconstrained parameters using a quasi-Newton method where the Hessian matrix and gradient are approximated numerically [40]. In a complicated optimization problem such as ours, results may depend on the initial guess for the model parameters and on the type of algorithm used to estimate the parameters. As a check, for each material, we refitted the model at least 20 additional times. In each additional run, the initial parameter values were randomly perturbed. In all cases, additional runs did not yield a lower value of $L$. However, sometimes a large value of $L$ was obtained.

This analysis generated values for all the coefficients: $a_{1}-a_{4}, b_{1}-b_{4}, k_{1}-k_{4}, \alpha, Q_{1}, Q_{2}, \eta_{1}$ $\eta_{4}, n$, and $m_{4}$. They were generated separately for grades HSLA/Ti-Nb, HSLA-Nb, DQSK, and A36. The stress-strain behaviors of grades HSLA-50/Ti-Nb, and the two IF steels were found to be similar to that of HSLA-Nb. As a result, we used the model for HSLA-Nb for these steels. For the same reason, the DQSK model was used for the HSLA-V grade. The units for the parameters in the model are $\sigma$ in $\mathrm{MPa}, \varepsilon$ in $\mathrm{s}^{-1}, T$ in $\mathrm{K}, d$ in $\mathrm{mm}$, and $Q$ in $\mathrm{J} \cdot \mathrm{mol}^{-1} . R=8.314$ $\mathrm{J} \cdot \mathrm{mol}^{-1} \cdot \mathrm{K}^{-1}$ is the universal gas constant. The range of experimental conditions that were used for the determination of model parameters is tabulated in table 5. It should be noted that in DQSK, the data of strain rate higher than $50 \mathrm{~s}^{-1}$ are from CANMET, and those lower than $0.1 \mathrm{~s}^{-1}$ in A36 are from UBC. All other data were generated at NIST.

\subsubsection{Uncertainty Analysis}

We estimated the random statistical error in the parameter estimates by a bootstrap resampling procedure $[41,42]$. For each material, we have data from $\mathrm{K}$ experiments. We indexed the experimental curves as $\bar{I}=(1,2, \ldots K)$ and simulated synthetic data by bootstrap resampling. First, we simulated a new index set $\bar{I}^{*}=\left(i_{1}, i_{2}, \ldots i_{\mathrm{K}}\right)$. In this resampled index set, $i_{\mathrm{j}}$ is a random integer which is uniformly distributed between 1 and $K$. All of the $i_{\mathrm{j}}$ were simulated 
Table 5. Range of experimental conditions used for statistical regression.

\begin{tabular}{cccc}
\hline Steel & $T,{ }^{\circ} \mathrm{C}$ & $\dot{\varepsilon}, \mathrm{s}^{-1}$ & $d, \mathrm{~mm}$ \\
\hline HSLA-80/Ti-Nb & 900 to 1200 & 1 to 25 & 0.012 to 0.2 \\
HSLA-Nb & 900 to 1200 & 1 to 50 & 0.015 to 0.249 \\
DQSK & 884 to 1200 & 1 to 163 & 0.04 to 0.29 \\
A36 & 900 to 1200 & 0.1 to 50 & 0.014 to 0.244 \\
\hline
\end{tabular}

independently. For instance, if $K=5$, a simulated index set might be $(3,1,2,1,4)$. For this case, data from experiment 1 are represented twice and data from experiments 2,3 , and 4 are represented once. Data from experiment 5 are not represented. To the $m$-th synthetic data, we fitted the model and got a bootstrap replication of the model parameters. The fitting procedure was the same as used for the observed data. That is, we got a new set of parameter estimates (20 in all) for each synthetic data set. From this set of parameter estimates, we estimated the standard deviation of each of the 20 model parameters. We divided the bootstrap estimate of the standard deviation of the model parameter by the model parameter to get a fractional standard deviation. When this fractional error is high, it means the model parameter is not well determined. In general, except in a few cases, the parameters were well determined.

\subsection{Experimental Stress-Strain Curves and Model Predictions}

This section presents the results of model predictions versus experimental data for each individual grade of steel. The experimental conditions are given on the graphs.

\subsubsection{A36}

The results for $\mathrm{A} 36$ are presented in figures 17 through 24. In general, the agreement between the experimental data and the model predictions is excellent.

\subsubsection{DQSK and HSLA-V}

The results for DQSK are presented in figures 25 through 36 . In general, the agreement between the experimental data and the model predictions is excellent.

For HSLA-V grade, the test matrix covers a range of temperature from 900 to $1200{ }^{\circ} \mathrm{C}$, strain rate from 1 to $50 \mathrm{~s}^{-1}$, and grain size from 0.03 to $0.3 \mathrm{~mm}$. After completing the experiments, we compared the data of HSLA-V specimens with predictions obtained using the DQSK model. Figure 37 presents some of the typical results showing that the DQSK model predictions agree well with the HSLA-V experimental data.

We believe that $\mathrm{V}$ has little effect on the flow response of the steel in the process variable ranges of interest and that the model developed for the DQSK grade steel is suitable for the HSLA-V steel because the two steels have similar chemical compositions. Figure 37 
Table 6. Dynamic recrystallization of DQSK and HSLA-V steels.

\begin{tabular}{cc|cl|cl}
\hline & & \multicolumn{2}{|c|}{ DQSK } & \multicolumn{2}{c}{ HSLA-V } \\
\hline $\begin{array}{c}\text { Temp, } \\
{ }^{\circ} \mathrm{C}\end{array}$ & $\begin{array}{c}\text { Strain rate, } \\
\mathrm{s}^{-1}\end{array}$ & $\begin{array}{c}\text { Grain size, } \\
\mathrm{mm}\end{array}$ & $\mathcal{E}_{\mathrm{p}}{ }^{*}$ & $\begin{array}{c}\text { Grain size, } \\
\mathrm{mm}\end{array}$ & $\mathcal{E}_{\mathrm{p}}{ }^{*}$ \\
\hline 1200 & 10 & 0.29 & 0.3 & 0.3 & 0.33 \\
1200 & 1 & 0.29 & 0.17 & 0.3 & 0.185 \\
1100 & 25 & 0.114 & 0.44 & 0.1 & 0.42 \\
1100 & 10 & 0.29 & 0.33 & 0.3 & 0.35 \\
1100 & 10 & 0.114 & 0.337 & 0.1 & 0.335 \\
1100 & 10 & 0.114 & 0.342 & 0.11 & 0.335 \\
1100 & 10 & 0.114 & 0.34 & 0.1 & 0.335 \\
1100 & 10 & 0.114 & 0.336 & 0.1 & 0.335 \\
1100 & 1 & 0.29 & 0.22 & 0.3 & 0.235 \\
1100 & 1 & 0.114 & 0.195 & 0.1 & 0.225 \\
1000 & 1 & 0.29 & 0.321 & 0.3 & 0.33 \\
1000 & 1 & 0.114 & 0.26 & 0.1 & 0.3 \\
900 & 1 & 0.04 & 0.331 & 0.03 & 0.335 \\
\hline
\end{tabular}

* Strain at which peak stress occurs in the stress-strain curves. This table lists only those specimens that indicate the presence of the occurrence of dynamic recrystallization.

presents data that support these expectations. As shown in table 6, detailed analysis of dynamic recrystallization in the two grades further demonstrates the similarities in flow behavior for these two grades. Therefore, we used exactly the same model for HSLA-V and DQSK.

\subsubsection{HSLA-Nb, HSLA-50/Ti-Nb, and IF steels}

The results for HSLA-Nb grade are presented in figures 38 through 46. In general, the agreement between the experimental data and model predictions is excellent.

Selected experiments with a scaled-down test matrix were completed for HSLA-50/Ti-Nb grade. The experimental conditions span temperatures from 900 to $1150{ }^{\circ} \mathrm{C}$, strain rates from 1 to $25 \mathrm{~s}^{-1}$, and grain sizes from 0.013 to $0.061 \mathrm{~mm}$. We expected the flow behavior of the HSLA50 grade to be similar to that of HSLA-Nb because the compositions of the two grades are similar. Therefore, the series of experiments performed using this grade was less extensive than those for other grades. 
Some flow stress measurements for HSLA-50 were compared with predictions using the model developed for HSLA-Nb, and the results are presented in figure 47. As expected, the flow curves agree well with predictions from the HSLA-Nb model. On this basis, we conclude that the model developed for the HSLA-Nb grade is in fact suitable for HSLA-50 also.

Two IF steel grades, $\mathrm{Nb}$-rich and $\mathrm{Nb}$-lean, were tested. Identical experimental conditions were used for both grades. Our results lead to the conclusion that the flow behaviors of both grades of IF steel are similar to that of the HSLA-Nb grade within the range of experimental variables studied.

For the $\mathrm{Nb}$-rich IF grade, figure 48 shows some of the results, wherein the experimental stress-strain curves for the IF grade are compared with predictions made using the model for the HSLA-Nb grade. The flow behavior of this IF grade is very similar to that of the HSLA-Nb grade. The same conclusion is obtained from torsion experiments conducted at UBC. The results of the torsion experiments are presented in figure 49 . We conclude that the model developed for the HSLA-Nb grade also predicts the flow behavior of the Nb-rich IF steel.

For the $\mathrm{Nb}$-lean grade, figure 50 shows some of the experimental data compared with predictions made using the HSLA-Nb model. We find that the flow behavior of this grade is also similar to that of the HSLA-Nb. However, results obtained in multiple-hit torsion tests at UBC show that the flow stresses of this grade are lower than those of the Nb-rich IF grade when temperatures are below $980^{\circ} \mathrm{C}$ and total true strains are larger than 1.2 .

Scrutiny of the torsion test results has indicated that little softening takes place in Nb-rich grade between the hits which produce higher flow stresses, whereas substantial softening occurs in the Nb-lean grade. This means that there is little static recrystallization between hits for the $\mathrm{Nb}$-rich grade, whereas the $\mathrm{Nb}$-lean grade almost fully recrystallized. This is probably due to $\mathrm{Nb}$ in retarding the static recrystallization for the $\mathrm{Nb}$-rich grade and explains why the $\mathrm{Nb}$-rich grade has higher flow stresses in later stages of deformation in multiple-hit experiments and at low temperatures.

\subsubsection{HSLA-80/Ti-Nb}

The results for HSLA-80/Ti-Nb grade are presented in figures 51 through 62. In general, the agreement between the experimental data and model predictions is excellent.

\subsection{Strain at Peak Stress}

Dynamic recrystallization is an important phenomenon in hot deformation. It not only softens material's resistance to deformation, but also refines the microstructure. It is useful to estimate the conditions under which it will occur.

Based on the experimental data generated in this study, we developed models correlating the strain at the peak stress in the stress-strain curve with temperature, strain rate, and grain size for the A36, DQSK, HSLA-Nb, and HSLA-80 grades. Two different forms of equations were used to make the correlation. One used the power law, and the other used the conventional 
approach involving the Zener-Hollomon parameter. For the power-law approach, we used the equation

$$
\varepsilon_{p}=A_{1}\left(\frac{T}{T_{0}}\right)^{A_{2}}\left(\frac{\dot{\varepsilon}}{\dot{\varepsilon}_{0}}\right)^{A_{3}}\left(\frac{d}{d_{0}}\right)^{A_{4}}
$$

where $\varepsilon_{\mathrm{p}}$ is the strain at which the peak stress appears in the stress-strain curve. $A_{1}, A_{2}, A_{3}$, and $A_{4}$ are constants. Other parameters were previously defined in section 5.4 . The results are plotted in figure 63. equation

For the conventional approach incorporating the Zener-Hollomon parameter, we used the

$$
\varepsilon_{p}=B_{1} Z^{B_{2}} d^{B_{3}}
$$

where $B_{1}, B_{2}$, and $B_{3}$ are constants. Other parameters were previously defined. The results are plotted in figure 64. It should be noted that the reported value of $B_{2}$ in the literature is 0.15 , while the values for $B_{3}$ range from 0.18 to 0.5 [29,43]. As shown in figures 63 and 64 , the two approaches have a similar statistical correlation.

\subsection{Boundary Separating Dynamic Recrystallization and No-Dynamic Recrystallization}

As described in section 5.7, if strains exceed $\varepsilon_{\mathrm{p}}$ as described by eq (35) or (36) the steel will undergo dynamic recrystallization. However, there is experimental evidence suggesting that under certain conditions, dynamic recrystallization will not occur with a single deformation even though strains exceed those described by eq (35) or (36). To determine whether dynamic recrystallization will occur during a single deformation regardless of the conditions set forth by eq (35) or (36), we used the Zener-Hollomon parameter as a criterion. If $Z$ is greater than a critical value $Z_{c}$, then dynamic recrystallization will not occur in a single deformation. The model, as described by the equation

$$
Z_{c}=A \exp (B d)+C
$$

also takes grain size into consideration, where $A, B$, and $C$ are experimentally determined constants. $Z$ and $d$ are defined previously.

\subsection{Effects of Prior Heat Treatments: HSLA-Nb}

We also conducted experiments to evaluate the effects of precipitates on the flow behavior of HSLA-Nb steel. In earlier experiments we obtained small austenite grain sizes using low reheating temperatures. Under these conditions, the $\mathrm{Nb}$ precipitates were not dissolved in the matrix when the experiments were conducted. This represents a departure from mill conditions, where the reheating temperature is high and the $\mathrm{Nb}$ precipitates are dissolved. 
Specimens used in this series of experiments were reheated to $1200^{\circ} \mathrm{C}$, held for $30 \mathrm{~min}$, and water-quenched to the ambient temperature. The majority of the precipitates would be dissolved after this treatment. The specimens were then reheated to $1000^{\circ} \mathrm{C}$ with a heating rate of $5{ }^{\circ} \mathrm{C} \cdot \mathrm{s}^{-1}$, held at that temperature for $150 \mathrm{~s}$, cooled to $900{ }^{\circ} \mathrm{C}$ at a rate of $1{ }^{\circ} \mathrm{C} \cdot \mathrm{s}^{-1}$, and held for $30 \mathrm{~s}$ before testing. In tests at $1000{ }^{\circ} \mathrm{C}$, the specimens were tested immediately after the $150 \mathrm{~s}$ hold at that temperature.

Figures 65 through 68 present the experimental results. For some test conditions, there is no discernible difference in the flow behavior with or without prior heat treatment. However, at the test condition of $900^{\circ} \mathrm{C}$ and $1 \mathrm{~s}^{-1}$ (figure 65), there is a significant difference in flow behavior after a strain of 0.4 . In this case, the specimen without prior heat treatment shows evidence of dynamic recrystallization, whereas the specimen with prior heat treatment shows continuous hardening, with no indication of dynamic recrystallization. It is likely that the dissolved $\mathrm{Nb}$ retards the process of dynamic recrystallization in the specimen with heat treatment.

Although mill conditions will not produce a strain rate of $1 \mathrm{~s}^{-1}$ at $900{ }^{\circ} \mathrm{C}$, the observed experimental effect deserves closer attention, particularly in cases where dynamic recrystallization could occur. The effect vanishes at higher strain rates or higher temperatures.

\subsection{Effects of Reheating Temperature and Model Adjustments: HSLA-80/Ti-Nb}

In comparison with those samples that were reheated to $1200^{\circ} \mathrm{C}, \mathrm{UBC}$ has observed that in torsion experiments, the flow stresses are lower when samples were reheated to $1250{ }^{\circ} \mathrm{C}$ and held for $30 \mathrm{~min}$. To confirm this observation, we conducted experiments with the following two different reheating conditions:

1. Reheated at $1250^{\circ} \mathrm{C}$ and held $10 \mathrm{~min}$ to obtain a grain size of $0.3 \mathrm{~mm}$

2. Reheated at $1250^{\circ} \mathrm{C}$ and held $10 \mathrm{~s}$ to obtain a grain size of $0.1 \mathrm{~mm}$

Typical results of the experiments are presented in figures 69 through 72. As shown in figures 69 and 70 , under condition 2 there is no significant difference between the experimental data and the model predictions, which were based on the experiments using lower reheating temperatures. However, as figures 71 and 72 indicate, a higher reheating temperature and a longer holding time (condition 1), appears to lower the flow stress.

The effects of reheating temperature on the flow behavior of HSLA-80 were examined further in experiments using different test temperatures. The flow stresses for specimens with reheating temperature of $1250{ }^{\circ} \mathrm{C}$ and holding time of $10 \mathrm{~min}$ appear to be approximately $9 \%$ lower than those for specimens reheated at a lower reheat temperature. This $9 \%$ drop is consistent throughout the whole stress-strain curve and has been observed for specimens tested at various temperatures. Thus, the model described in section 5.5 should be adjusted for this effect if the reheating temperature and holding time are high and long.

The effect of reheating temperature has not been studied with other grades. The effect might be due to larger grains resulting from a higher reheating temperature and longer holding 
Table 7. Test matrix for double-hit experiments: HSLA-Nb.

\begin{tabular}{cccccccc}
\hline $\begin{array}{c}\text { Case } \\
\#\end{array}$ & $\begin{array}{c}\text { Soaking } \\
\text { temp., }{ }^{\circ} \mathrm{C}\end{array}$ & $\begin{array}{c}\text { Soaking } \\
\text { time, } \mathrm{s}\end{array}$ & $\begin{array}{c}\text { Grain size, } \\
\mathrm{mm}\end{array}$ & $\begin{array}{c}\text { Testing } \\
\text { temp., }{ }^{\circ} \mathrm{C}\end{array}$ & $\begin{array}{c}\text { Strain for } \\
\text { the first hit }\end{array}$ & $\begin{array}{c}\text { Strain } \\
\text { rate, } \mathrm{s}^{-1}\end{array}$ & $\begin{array}{c}\text { Inter-hit } \\
\text { time, } \mathbf{s}\end{array}$ \\
\hline 1 & 1200 & 600 & 0.249 & 900 & 0.2 & 10 & 20 \\
2 & 1200 & 600 & 0.249 & 900 & 0.6 & 10 & 10 \\
3 & 1200 & 600 & 0.249 & 900 & 0.6 & 25 & 5 \\
4 & 1200 & 600 & 0.249 & 1000 & 0.2 & 10 & 5 \\
5 & 1000 & 150 & 0.015 & 900 & 0.2 & 10 & 5 \\
\hline
\end{tabular}

time. If this is the cause for lowering the flow stress, then the effect should also be observed for other grades of steels. The other potential cause for the effect is due to the dissolution of precipitates of microalloying elements, also resulting from a higher reheating temperature and longer holding time. If this is the factor, then the effect will be observed in the Ti-Nb- and Nbbearing grades because the precipitates of these grades will not dissolve unless the reheating temperature is high and the holding time is long. The effect on plain-C or V-bearing grades should be minimal because precipitates in these grades usually dissolve at lower temperatures during reheating.

\subsection{Effects of Retained Strain: HSLA-Nb}

Using a double-hit experiment, we evaluated the effects of retained strain on the flow behavior of HSLA-Nb steel. The strain retained from one pass to the next not only significantly increases the rolling forces but also affects microstructural development. The retained strain is usually small, and the effects are negligible in plain-C (A36 or DQSK grades) and V-treated steels because static recrystallization is rapid in these steels. Retained strain is important for the HSLA-Nb grade in the last few finishing passes because the interpass time is short and the process of static recrystallization is comparatively sluggish.

The test matrix of the double-hit experiments is given in table 7. Figure 73 presents results which suggest that, under the experimental conditions described in table 7 , little softening takes place between the two hits. As indicated in these figures, the established model predicts the flow behavior well once the retained strain is taken into consideration.

\subsection{Comparison with Data from CANMET}

We received from CANMET sets of high-strain-rate stress-strain data for three steels: A36, DQSK, and HSLA-Nb. These experimental data covered temperatures from 900 to 1100 ${ }^{\circ} \mathrm{C}$ and strain rates from 10 to $150 \mathrm{~s}^{-1}$. Austenite grain sizes ranged from 0.014 to $0.25 \mathrm{~mm}$ for A36, from 0.038 to $0.155 \mathrm{~mm}$ for DQSK, and from 0.015 to $0.249 \mathrm{~mm}$ for HSLA-Nb.

We compared CANMET's data with our own model predictions for A36 and DQSK. Figure 74 compares some CANMET's data with our model predictions for the DQSK grade. 
The agreement is generally good for stresses in regions of high strain (larger than 0.6). However, poor agreement is observed in the regions of small strain (less than 0.4 ).

A similar trend is found for the A36 grade, as shown in figure 75. In general, the agreement between CANMET's data and our model predictions for A36 is not as good as that for DQSK, and in a few cases the agreement is poor for the entire stress-strain curve, as shown for example in figure 76.

Two reasons are advanced to explain the disagreement between the observed trend at small strains. First, CANMET's strain values include displacements due to machine compliance, which are accounted for in NIST's analyses. As discussed earlier, including displacements due to machine compliance in strain calculations promotes large errors in the stress-strain curve at small strains. Second, we have assumed rigid-plastic behavior in our models, so the flow stress begins at the yield stress when strain is 0 .

In view of these differences in data treatment, we performed a second comparison. We compared our experimental data (without machine compliance correction) with CANMET's data at similar test conditions. The results in figures 77 through 79 show fair, but better, agreement. CANMET's data tend to exhibit lower strain hardening at the onset of deformation, and the hardening continues to large deformations (large strains). In contrast, NIST's data tend to show a rapid increase in stress due to a high strain hardening rate at the onset of deformation, and thereafter the stress levels off at large deformations. Thus, CANMET's data exhibit lower stresses at small strain regions and higher stresses at large strain regions. The cause of this difference in hardening behaviors between results obtained at CANMET and NIST remains unclear. It should be noted that the hardening behavior observed at NIST is more consistent with some findings reported at UBC.

Efforts have been made to correct for the effect of machine compliance in CANMET's data. When machine compliance is accounted for, the stresses in the early portion of the flow curve increase; thus the agreement between NIST's model predictions (or data) and CANMET's data improves. Figure 79 is a typical example showing good agreement between NIST's model prediction and CANMET's data for A36 after correction for compliance.

\subsection{Calculation of Roll-Separating Forces}

One of the important applications of constitutive equations in hot rolling is the roll-force calculation, which requires other parameters, such as roll diameter during rolling, thickness of slab at roll entry and roll exit, and the friction between the workpiece and the rolls. One of the commonly used models for roll-force calculations is the Sims method [44], which simplified the slab analysis [45] and assumed that only sticking friction exists in the roll contact zone. The rollseparating force per unit width is given by Sims as

$$
F=2 k R^{\prime}\left[\frac{\pi}{2} \sqrt{\frac{h_{2}}{R^{\prime}}} \tan ^{-1} \sqrt{\frac{\Delta h}{h_{2}}}-\frac{\pi \phi}{4}-\ln \frac{h\left(\phi_{n}\right)}{h_{2}}+\frac{1}{2} \ln \left(\frac{h_{1}}{h_{2}}\right)\right],
$$


where $k$ is defined as the yield strength of the workpiece in pure shear, $R^{\prime}$ is the radius of deformed roll, $h_{1}$ and $h_{2}$ are the entry and the exit slab thicknesses, and $\Delta h$ is the draft, which equals to $\left(h_{1}-h_{2}\right) . \phi$ is the contact angle, which is approximated as

$$
\phi=\sqrt{R^{\prime} \Delta h},
$$

and $h\left(\phi_{n}\right)$ is the slab thickness at the neutral point, which is the point along the surface of contact between the roll and the workpiece where the surface velocity of the roll is equal to the velocity of the workpiece.

According to the von Mises yielding criterion, $k$ is equal to $57.7 \%$ of the yield strength of the workpiece in uniaxial tension or compression; it is only $50 \%$ if the Tresca criterion is applied. In this investigation, the von Mises criterion is adopted and the yield strength under uniaxial compression is taken to be the stress calculated with models presented in section 5.5. The strain used to calculate the stress is the true strain computed from $h_{1}$ and $h_{2}$ or the cumulative strain if there are retained strains from previous passes.

The value of $R^{\prime}$ depends on the roll material, the original roll radius $R$, the roll-separating force, and the draft. The relationship among these parameters is [26]

$$
\frac{R^{\prime}}{R}=1+\frac{C F}{\Delta h}
$$

For steel rolls, the value of $\mathrm{C}$ is between $2.1 \times 10^{-4}$ and $2.5 \times 10^{-4} \mathrm{~mm}^{2} \cdot \mathrm{N}^{-1}$, and is taken to be $2.21 \times 10^{-4}$ in the present investigation [46].

The angle at the neutral point is calculated from

$$
\frac{\pi}{4} \ln \left(\frac{h_{1}}{h_{2}}\right)=2 \sqrt{\frac{R^{\prime}}{h_{2}}} \tan ^{-1}\left(\sqrt{\frac{R^{\prime}}{h_{2}}} \phi_{n}\right)-\sqrt{\frac{R^{\prime}}{h_{2}}} \tan ^{-1}\left(\sqrt{\frac{\Delta h}{h_{2}}}\right) .
$$

The thickness at the neutral point is

$$
h\left(\phi_{n}\right)=2 R^{\prime}\left(1-\cos \left(\phi_{n}\right)\right)+h_{2} .
$$

The results of roll-force calculations along with actual mill measurements for a 13-pass rolling on HSLA-80 steel are presented in table 8 and figure 80 . Based on precipitation calculation using the model developed by Dutta and Sellars [47], precipitation of $\mathrm{Nb}(\mathrm{CN})$ particles occurred after the first pass at $965^{\circ} \mathrm{C}$. No static recrystallization between passes in all 13 passes was assumed and strain was accumulated from one pass to the subsequent passes. The predicted results agree reasonably well with the actual measurements. Due to the assumption of sticking friction, however, the Sims equations are expected to slightly overestimate the rolling loads. 
Table 8. Comparison of calculated roll forces with actual mill measurements.

\begin{tabular}{c|ccc}
\hline & \multicolumn{3}{|c}{ Roll forces, ton } \\
\hline Pass \# & Measured & Calculated & \% difference \\
\hline 1 & 3324 & 3608 & 8.54 \\
2 & 3456 & 3326 & -3.76 \\
3 & 3690 & 3646 & -1.19 \\
4 & 3113 & 3226 & 3.63 \\
5 & 2678 & 2957 & 10.42 \\
6 & 2137 & 2370 & 10.90 \\
7 & 1827 & 2035 & 11.38 \\
8 & 2990 & 3046 & 1.87 \\
9 & 3080 & 3182 & 3.31 \\
10 & 2720 & 3153 & 15.92 \\
11 & 2610 & 2587 & -0.88 \\
12 & 2428 & 2754 & 13.43 \\
13 & 2250 & 2393 & 6.36 \\
\hline
\end{tabular}

\section{Summary and Conclusions}

The purpose of this work is to develop constitutive equations that predict the stress-strain curves of steels as functions of hot-rolling process variables, such as temperature, strain rate, and microstructural features. Eight steels: DQSK, A36, HSLA-V, HSLA-Nb, HSLA-50/Ti-Nb, HSLA-80/Ti-Nb, and two interstitial-free (IF) grades, were selectively tested at temperatures in the range from 900 to $1200^{\circ} \mathrm{C}$, strain rates from 1 to $50 \mathrm{~s}^{-1}$, and austenite grain sizes from 0.012 to $0.29 \mathrm{~mm}$. The data were analyzed to support the development of constitutive models.

To cover a wider range of strain rates, a new computer-controlled servo-hydraulic laboratory apparatus was designed and built for experiments at high strain rate. A constant strain rate of $65 \mathrm{~s}^{-1}$ was obtained with the machine. The usable range of strain at this rate is about 0.4 . The strain rate drops off substantially at strains larger than 0.4 . At a constant strain rate of $50 \mathrm{~s}^{-1}$, the usable range is about 0.6 . The strain rate of $50 \mathrm{~s}^{-1}$ was used for the majority of tests in this project. The machine has a load capacity of $100 \mathrm{kN}$ and its radiant furnace can heat a specimen (a cylinder with $10 \mathrm{~mm}$ diameter and $15 \mathrm{~mm}$ long) to $1200^{\circ} \mathrm{C}$. The maximum heating rate is about $2{ }^{\circ} \mathrm{C} \cdot \mathrm{s}^{-1}$. The machine has multiple-strike capabilities and is equipped with a roughvacuum pump to prevent oxidation during test at high temperatures. The machine and the dataacquisition system are computer controlled.

Models for predicting stress-strain behaviors for A36, DQSK, HSLA-Nb, and HSLA$80 / \mathrm{Ti}-\mathrm{Nb}$ were developed. The model developed for DQSK is also adequate for HSLA-V, since 
we find that $\mathrm{V}$ has little influence on the flow behavior of low-C steels, and the chemical compositions of the two grades are similar (except for the V addition in the HSLA-V grade). The model developed for HSLA-Nb was also found to be suitable for predicting the stress-strain behaviors of HSLA-50/Ti-Nb, and two Nb-treated IF steels, which all contain Nb. Model predictions correlate well with the experimental data, indicating that the models adequately describe the stress-strain behaviors of various steel grades under hot-rolling conditions.

Models were also developed for correlating the strain at peak stress in the stress-strain curve with temperature, strain rate, and austenite grain size for the following four steels: A36, DQSK, HSLA-Nb, and HSLA-80/Ti-Nb. In addition, we proposed models for predicting the conditions under which there will be no dynamic recrystallization for the same steels. This will precede the former conditions.

We also conducted experiments to evaluate the effects of precipitates on the flow behavior of HSLA-Nb grade. It was found that under one condition with low strain rate $\left(1 \mathrm{~s}^{-1}\right)$ and low temperature $\left(900^{\circ} \mathrm{C}\right)$, the specimen with undissolved precipitates displayed occurrence of dynamic recrystallization, while the specimen with prior high-temperature soaking heat treatment (precipitates dissolved at the time of experiment) did not show the same behavior. It is likely that the dissolved $\mathrm{Nb}$ retards the process of dynamic recrystallization under this condition. At high temperatures and higher strain rates, there is no difference in flow behavior between the specimens (with or without the high-temperature soaking heat treatment). It should be noted that mill conditions rarely encounter a strain rate as low as $1 \mathrm{~s}^{-1}$ at $900^{\circ} \mathrm{C}$.

For the HSLA-80/Ti-Nb grade, it was found that specimens with treatment of reheating at $1250{ }^{\circ} \mathrm{C}$ and holding for $10 \mathrm{~min}(0.3 \mathrm{~mm}$ in grain size) reduced the flow stress about $9 \%$ when compared with those specimens that were reheated at lower temperatures. This behavior has been observed for various experiments with testing at different temperatures and strain rates. It is, therefore, suggested that the $9 \%$ reduction in flow stress be corrected if the actual conditions are close to our experimental conditions (reheated at $1250{ }^{\circ} \mathrm{C}$ and held for $10 \mathrm{~min}$ ).

In HSLA-80/Ti-Nb, we found the static recrystallization to be sluggish. Our double-hit experiments show that at testing temperatures of 900 and $1000^{\circ} \mathrm{C}$ and inter-hit times of 5 to $20 \mathrm{~s}$, little softening occurred between hits. If retained strain is properly considered, the model based on single-hit deformation is adequate to describe the stress-strain behaviors under multiple-hit conditions.

Our model predictions for A36 and DQSK were compared with Camplastometer's high strain-rate data obtained at CANMET. CANMET's data cover the strain-rate range from 10 to $150 \mathrm{~s}^{-1}$, which are beyond NIST's experimental capability. The agreement between CANMET's data and NIST's model predictions is good at large strains $(>0.6)$ but poor at small strains $(<$ 0.4). The discrepancy mainly comes from the different treatment of data in the two laboratories. NIST corrected the data for displacements due to machine compliance and used rigid-plastic model to describe the stress-strain behavior, whereas CANMET did not correct for machine compliance and reported the data as generated (no stress-strain model had been used). After correction for machine compliance in CANMET's data, the agreement was improved, and the results indicated that NIST's models can be extrapolated beyond the experimental range that 
were used to obtain the coefficients in the constitutive equations. However, caution should be exercised in extrapolation because the results might not be reliable.

Finally, we used the Sims equation with NIST's constitutive model to calculate the rollseparating forces for rolling an HSLA-80 slab. The calculated results were compared with the actual mill measurements. The results are encouraging. For 8 of the 13 passes, the calculated loads are within $10 \%$ of the measured loads. The worst discrepancy is an overestimation by $15.9 \%$. For the other 4 passes, the discrepancy is slightly over $10 \%$. For 10 of the 13 passes, the calculated loads are higher than the measured. This is to be expected since the Sims equation assumes the presence of sticking friction (maximum friction) between the rolls and the workpiece.

This work represents one subtask of the Microstructural Engineering in Hot-Strip Mill Project, a cooperative research project sponsored by the AIS1 Advanced Process Control Program. Other tasks of this project have been performed at the University of British Columbia and at the U.S. Steel Technical Center. We gratefully acknowledge the support and sponsorship of the American Iron and Steel Institute, particularly the two directors of the Project: L. W. Kavanagh and J. R. Vehec.

The actual values for the coefficients for the constitutive equations are not published in this report, as these are considered proprietary data of AISI.

This work was performed under the supervision of G. Alers and H. I. McHenry. We also acknowledge J. R. Orth (Rocket Seals Corporation, Denver, CO), and C. McFadeen (Coors Ceramics Division, Golden, $\mathrm{CO}$ ) for providing advice and information about the hightemperature polymer seals and ceramic materials used in the construction of the hot-deformation test apparatus.

\section{References}

[1] Sellars, C. M. The physical metallurgy of hot working. Sellars, C. M.; Davies, G. J., eds. Proc., int. conf. on hot working and forming processes; 1979 July 17-20; University of Sheffield, U.K.; The Metals Society, London; 1979. 3-15.

[2] Hollomon, J. H. Tensile deformation. Trans. AIME. 162: 268-290; 1945.

[3] Ludwik, P. Elemente der Technologischen Mechanik, Verlag Von Julius Springer, Leipzig; 1909. 32.

[4] Baragar, D. L. The high temperature and high strain-rate behavior of a plain carbon and an HSLA steel. J. Mech. Working Technol. 14: 295-307; 1987.

[5] Swift, H. W. Plastic instability under plane stress. J. Mech. Phys. Solids. 1: 1-18; 1952 Oct.

[6] Ludwigson, D. C. Modified stress-strain relation for FCC metals and alloys. Metall. Trans. 2: 2825-2828; 1971.

[7] ASM Metals Handbook, 9th edition, Vol. 14, Forming and Forging; ASM Int., Metals Park, OH; 1988. 
[8] Cheng, Y. W. Unpublished results, NIST, Boulder, CO.

[9] Benyon, J. H.; Sellars, C. M. Modeling microstructure and its effects during multipass hot rolling. ISIJ Int. 32(3): 359-367; 1992.

[10] Voce, E. The relationship between stress and strain for homogeneous deformation. J. Inst. Mets. 74: 537-562; 1948.

[11] Hatta, N.; Kokado, J.; Kikuchi, S.; Takuda, H. Modeling on flow stress of plain carbon steel at elevated temperatures. Steel Res. 56: 575-582; 1985.

[12] Laasraoui, A.; Jonas, J. J. Prediction of steel flow stress at high temperatures and strain rates. Metall. Trans. 22A: 1545-1558; 1991 July.

[13] Adebanjo, R. O.; Miller, A. K. Modeling the effects of recrystallization on the flow behavior during hot deformation by modifying an existing constitutive model. 1 . conceptual development of the MATMOD-REX equations. Mat. Sci. Engr. A1 19: 87-94; 1989.

[14] Adebanjo, R. O.; Miller, A. K. Modeling the effects of recrystallization on the flow behavior during hot deformation by modifying an existing constitutive model. 2 . predictive and fitting capabilities. Mat. Sci. Engr. A1 19: 95-101; 1989.

[15] Sellars, C. M.; McG Tegart, W. J. Mem. Sci. Rev. Metall. 63: 731-746; 1966.

[16] Rao, K. P.; Hawbolt, E. B. Assessment of simple flow-stress relationships using literature data for a range of steels. J. Mater. Proc. Technol. 29(1-3): 15-40; 1992.

[17] Hodgson, P. D.; Gibbs, R. K. A mathematical model to predict the mechanical properties of hot rolled C-Mn and microalloyed steels. ISIJ Int. 32: 1329-1338; 1992.

[18] Nakamura, T.; Ueki, M. The high temperature torsional deformation of a $0.06 \% \mathrm{C}$ mild steel. Trans. ISIJ. 15: 185-193; 1975.

[19] Sakai, S.; Sakai, T.; Takeishi, K. Hot deformation of austenite in a plain carbon steel. Trans. ISIJ. 17: 718-725; 1977.

[20] Devadas, C.; Baragar, D. L.; Ruddle, G.; Samarasekera, I. V.; Hawbolt, E. B. The thermal and metallurgical state of steel strip during hot-rolling. 2. factors influencing rolling loads. Metall. Trans. 22A(2): 321-333; 1991.

[21] Sankar, J.; Hawkins, D.; McQueen, H. J. Behavior of low-carbon and HSLA steels during torsion-simulated continuous and interrupted hot-rolling practice. Met. Technol. 6(9): 325-331; 1979.

[22] Roberts, W. Dynamic changes that occur during hot working and their significance regarding microstructural development and hot workability. Krauss, G. ed. Proc., seminar on deformation, processing, and structure; 1982 October 23-24; St. Louis MO. ASM, Metals Park, OH; 1984. 109-184.

[23] Dieter, G. E. Mechanical metallurgy, second edition. New York: McGraw-Hill Book Company, 1976. $774 \mathrm{p}$.

[24] Miller, A. K. An inelastic constitutive model for monotonic, cyclic, and creep deformation: part 1 -equations development and analytical procedures. J. Engr. Mat. Technol. 98H: 97-105; 1976 April.

[25] DeArdo, A. J. Modeling of deformation processing: wonderful tool or wishful thinking. Yue, S. ed. Proc., Mathematical modeling of hot rolling of steel; 1990 August 26-29; Hamilton, Ontario, Canada. AIME, Warrendale, PA; 1990. 220-238.

[26] Pietrzyk, M.; Lenard, J. G. Thermal-mechanical modeling of the flat rolling process. Heidelberg, Germany: Springer-Verlag; 1991. 187 p. 
[27] Jonas, J. J.; Sellars, C. M.; McG Tegart, W. J. Strength and structure under hot-working conditions. Metall. Rev. 14: 1-24; 1969 Jan.

[28] McQueen, H. J. Deformation mechanisms in hot working. J. Metals: 31-38; 1968 April.

[29] Sellars, C. M. Physical simulation to determine hot forming behavior. Proc., Physical simulation of welding, hot forming, and continuous casting; 1988 May 2-4; Ottawa, Ontario, Canada; 1988. III-1-14.

[30] Baragar, D. L.; Crawley, A. F. Frictional effects on flow stress determination at high temperatures and strain rates. J. Mech. Working Technol. 9: 291-299; 1984.

[31] Gelin, J. C.; Oudin, J.; Ravaland, Y. Determination of flow stress-strain curves for metals from axisymmetric upsetting. J. Mech. Working Technol. 5: 297-308; 1981.

[32] Cheng, Y. W.; McHenry, H. A hot-deformation apparatus for thermomechanical processing simulation. Proc., Physical simulation of welding, hot forming, and continuous casting; 1988 May 2-4; Ottawa, Ontario, Canada; 1988. III-15-22.

[33] Kuziak, R. M.; Cheng, Y. W. Microstructural evolution in microalloyed medium-carbon forging steels during thermomechanical processing. DeArdo, A. J. ed. Proc., Int. conf. on processing, microstructure, and properties of microalloyed and other modern high strength low alloy steels. ISS, Warrendale, PA.; 1992. 51-64.

[34] Purtscher, P. T.; Cheng, Y. W. Structure-properties relations in steels. To be published as NIST Technical Note; NIST, Boulder, CO.

[35] Cheng, Y. W.; Rosenthal, Y.; McHenry, H. I. Development of a computer-controlled hot-deformation apparatus at NIST. Natl. Inst. Stand. Technol. NISTIR 89-3925; 1989 October. $92 \mathrm{p}$.

[36] Cheng, Y. W.; Filla, B. J.; Tobler, R. L. Design and performance of an automated test facility for hot-compression testing. J. Testing Eval., JTEVA. 26(1): 38-44; 1998 Jan.

[37] Cheng, Y. W.; Read, D. T. An automated fatigue crack growth rate test system. Cullen, W. H.; Landgraf, R. W.; Kaisand, L. R.; Underwood, J. H. eds. Proc., symp. on automated test methods for fracture and fatigue crack growth. ASTM 877, Amer. Society Testing Mater.; Philadelphia, PA.; 1985. 213-223.

[38] Tobler, R. L.; Cheng, Y. W. Automatic near-threshold fatigue crack growth rate measurements at liquid helium temperature. Int. J. Fatigue. 7(4): 191-197; 1985.

[39] Cheng, Y. W.; Sargent, C. L. Data reduction and analysis procedures used in NIST's thermomechanical research. Natl. Inst. Stand. Technol. NISTIR 90-3950; 1990 August. $61 \mathrm{p}$.

[40] Dennis, J. E.; Schabel, R. B. Numerical methods for unconstrained optimization and nonlinear equations. Englewood Cliffs, NJ: Prentice-Hall; 1983.

[41] Efron, B. The Jacknife, the bootstrap, and other resampling plans. Proc., CBMS-NSF regional conf. series in applied mathematics, SIAM; Philadelphia, PA; 1982

[42] Efron, B.; Tibshirani, R. An introduction to the bootstrap. New York: Chapman and Hall; 1993.

[43] Kuziak, R. M.; Cheng, Y. W.; Glowacki, M.; Pietrzyk, M. Modeling of the microstructure and mechanical properties of steels during thermomechanical processing. Natl. Inst. Stand. Technol. NIST Tech. Note 1393; 1997 Nov. 72 p.

[44] Sims, R. B. The calculation of roll force and torque in hot rolling. Proc., Inst. Mech. Engr. 168: 191-200; 1954.

[45] Orowan, E. The calculation of roll pressure in hot and cold flat rolling. Proc., Inst. Mech. Engr. 150: 140-167; 1943. 
[46] D. Q. Jin, University of British Columbia, Vancouver, Canada, private communication.

[47] Dutta, B.; Sellars, C. M. Effect of composition and process variables on $\mathrm{Nb}(\mathrm{CN})$ precipitation in niobium microalloyed austenite. Mater. Science and Technol. 3: 197$206 ; 1987$. 


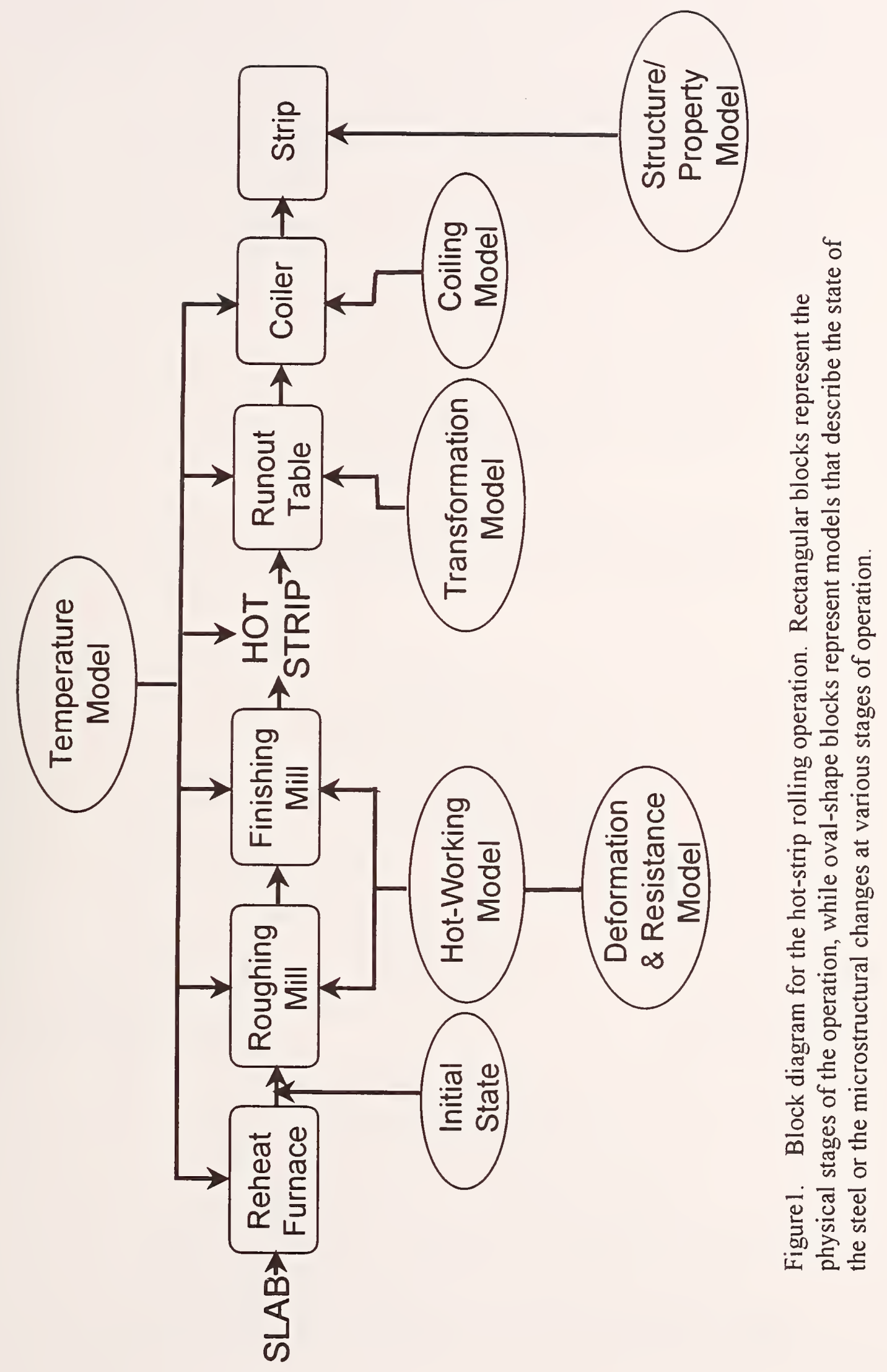




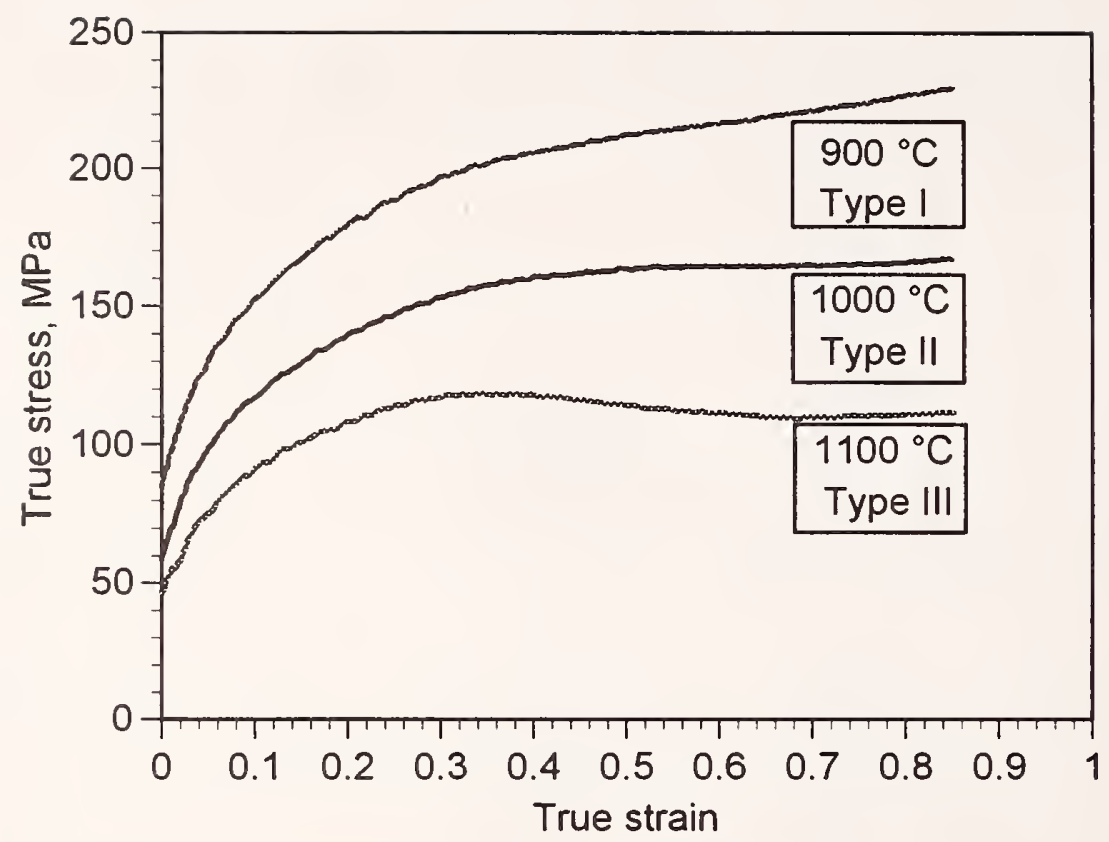

Figure. 2. Stress-strain curves of DQSK steel. Test temperatures are indicated and strain rate is $10 \mathrm{~s}^{-1}$

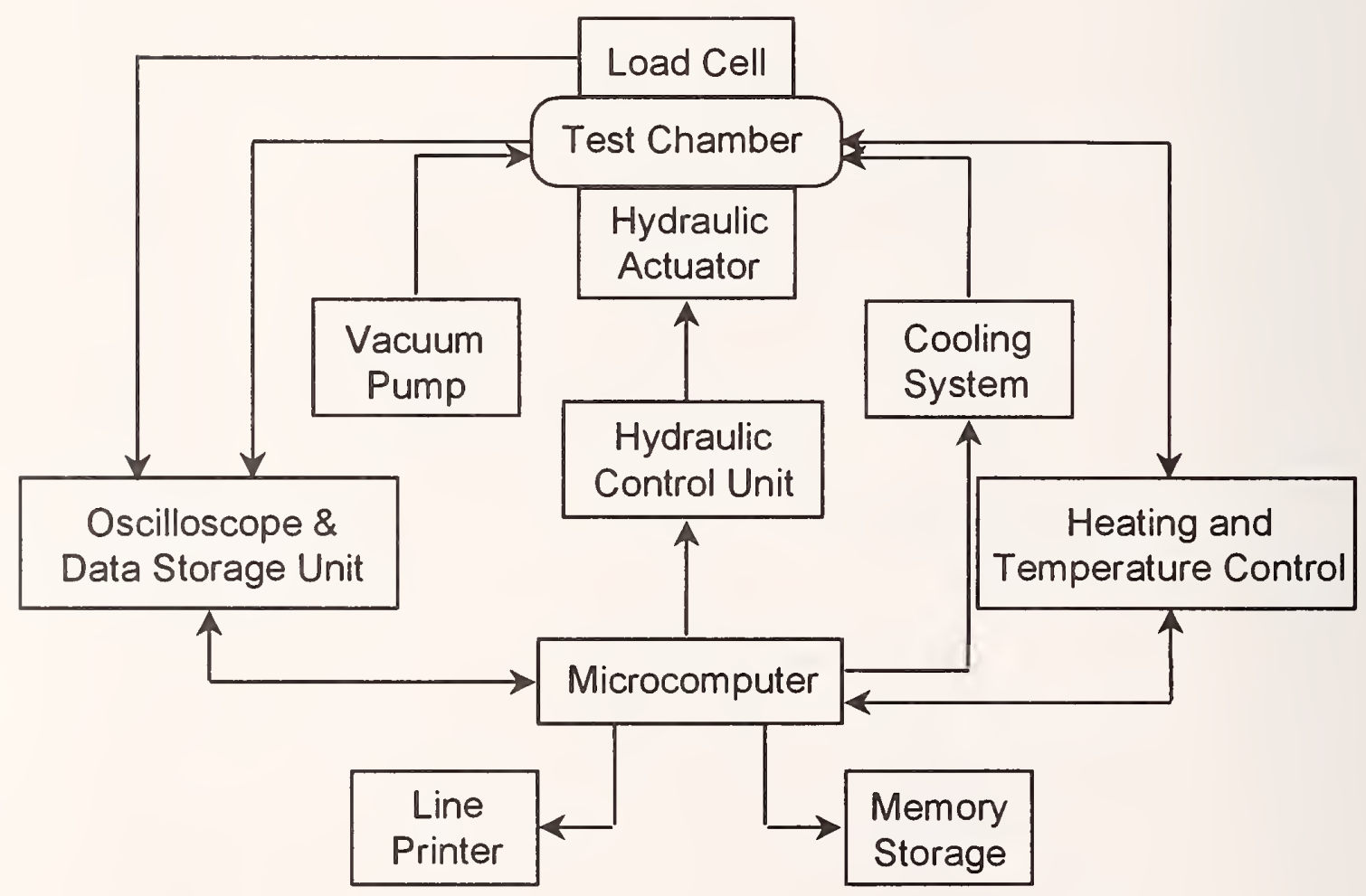

Figure 3. Basic components and flowchart of the test apparatus. 


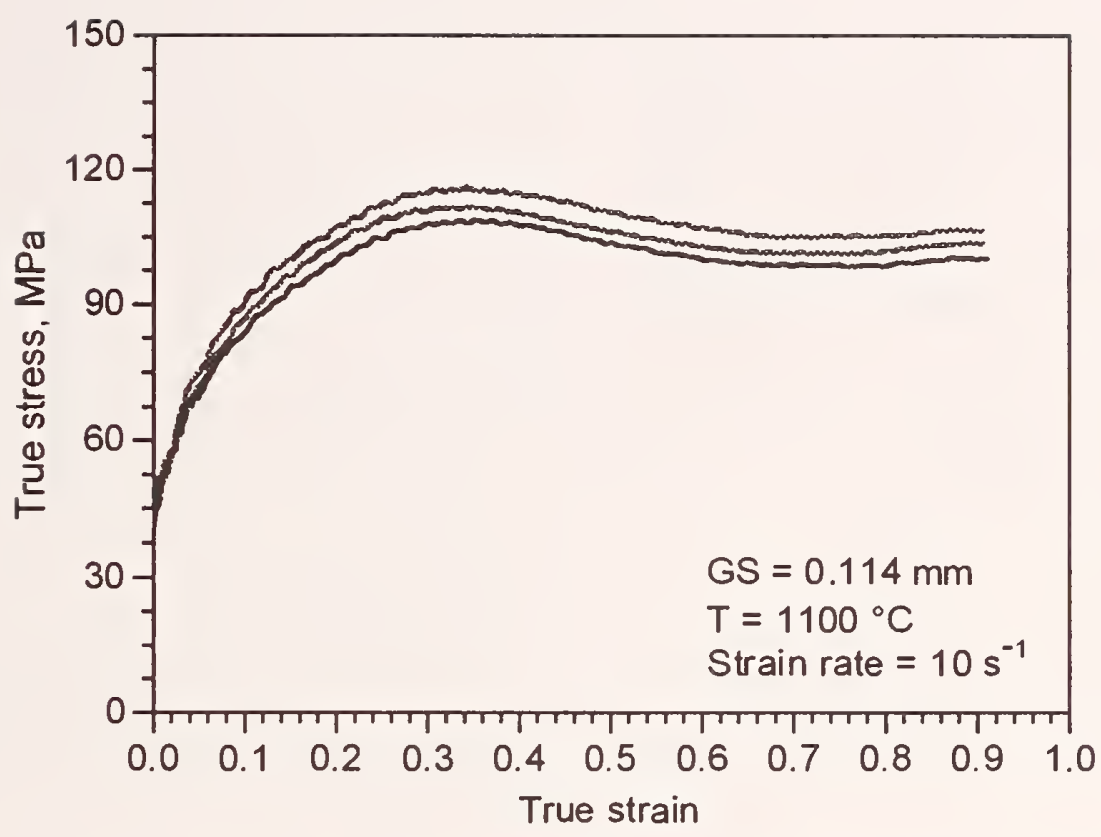

Figure 4. Triplicate tests of DQSK steel. The results show good reproducibility of the machine.

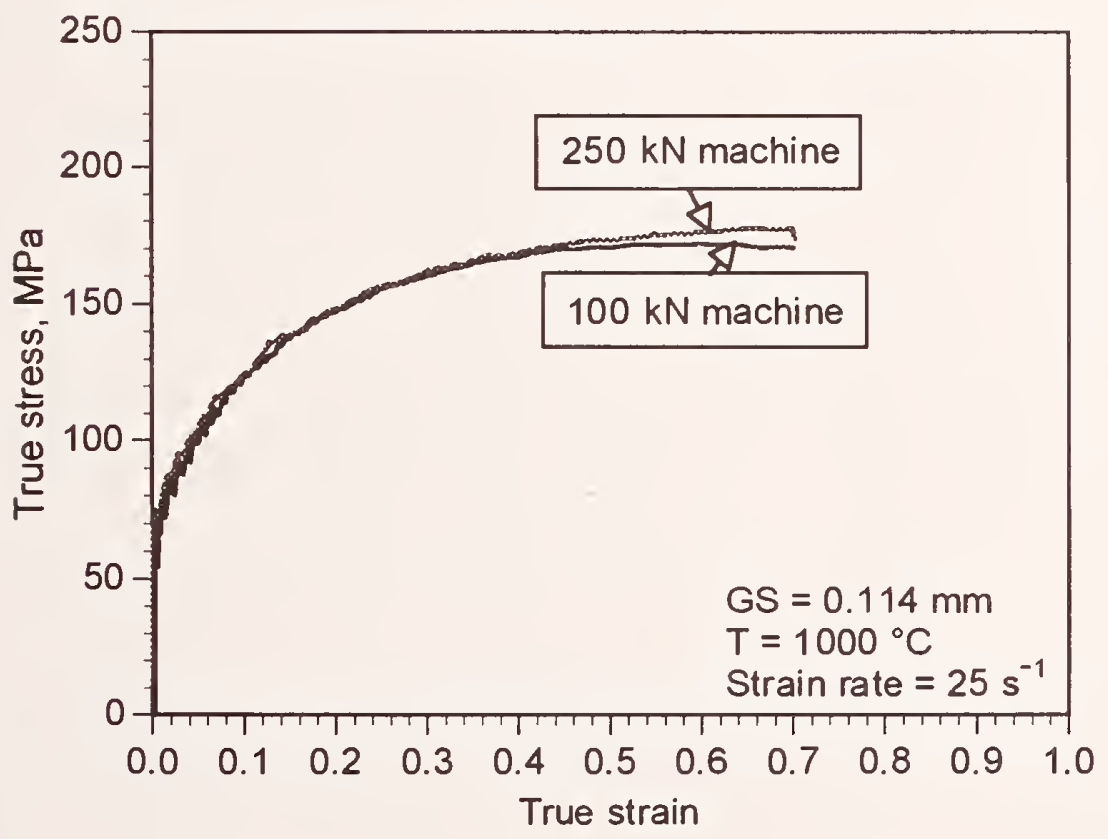

Figure 5. Stress-strain curves for two specimens of DQSK using different test machines. The results show the consistency between the two machines. 


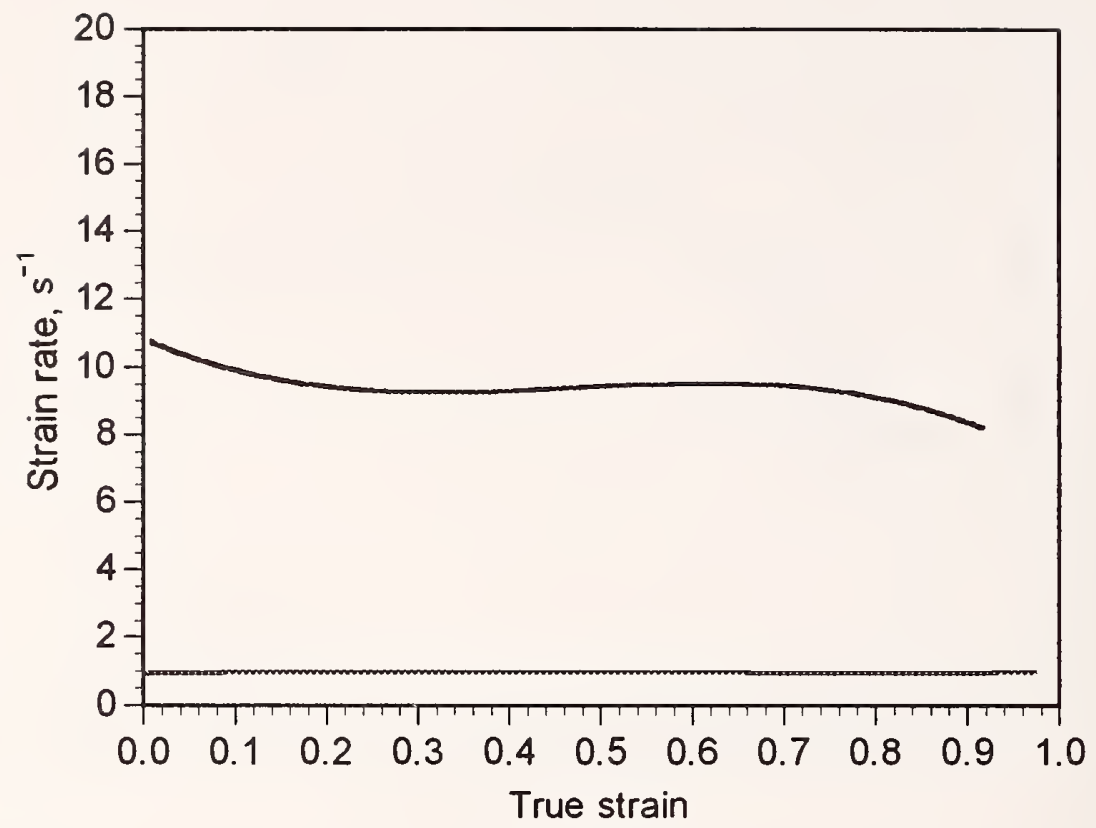

Figure 6. Typical plot of strain rate versus true strain for nominal strain rates of 1 and $10 \mathrm{~s}^{-1}$.

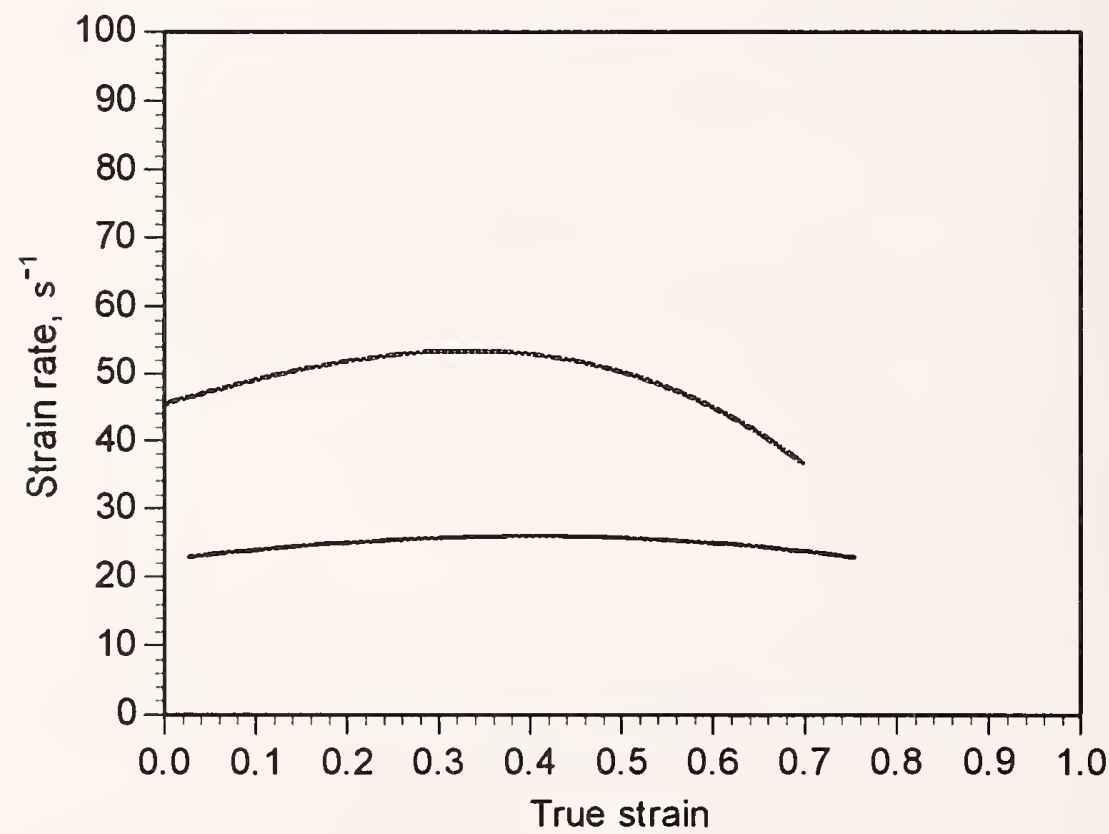

Figure 7. Typical plot of strain rate versus true strain for nominal strain rates of 25 and $50 \mathrm{~s}^{-1}$. 


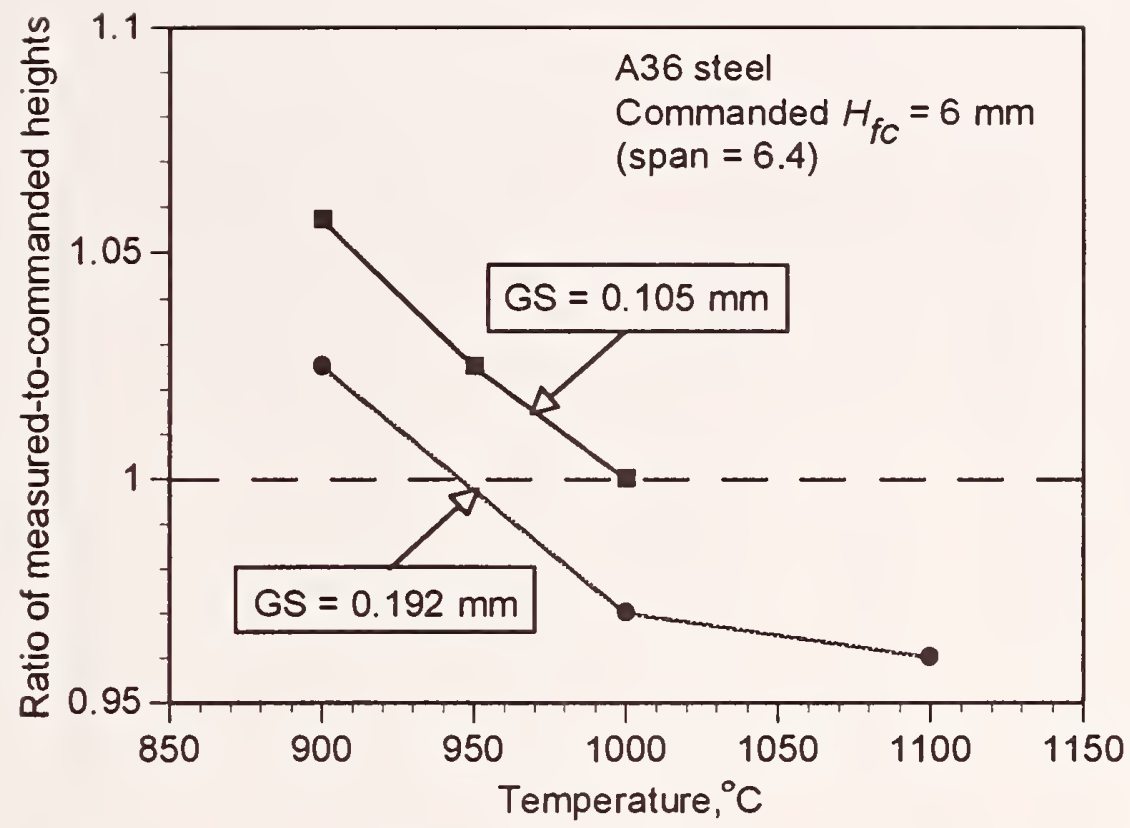

Figure 8. Ratio of measured-to-commanded final heights for A36 steel sample tested at various temperatures and grain sizes.

Time, ms

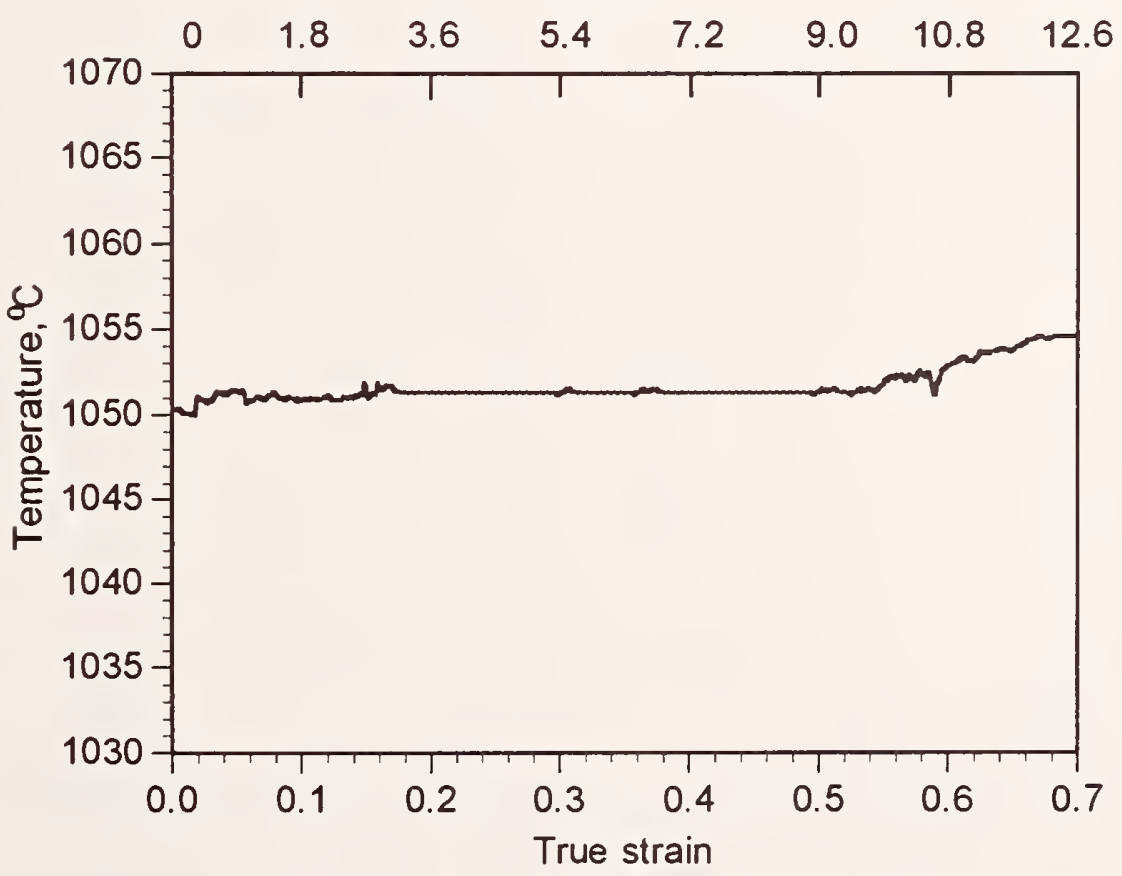

Figure 9. Temperature versus true strain of an A36 steel specimen showing self-heating during a high strain-rate test. 

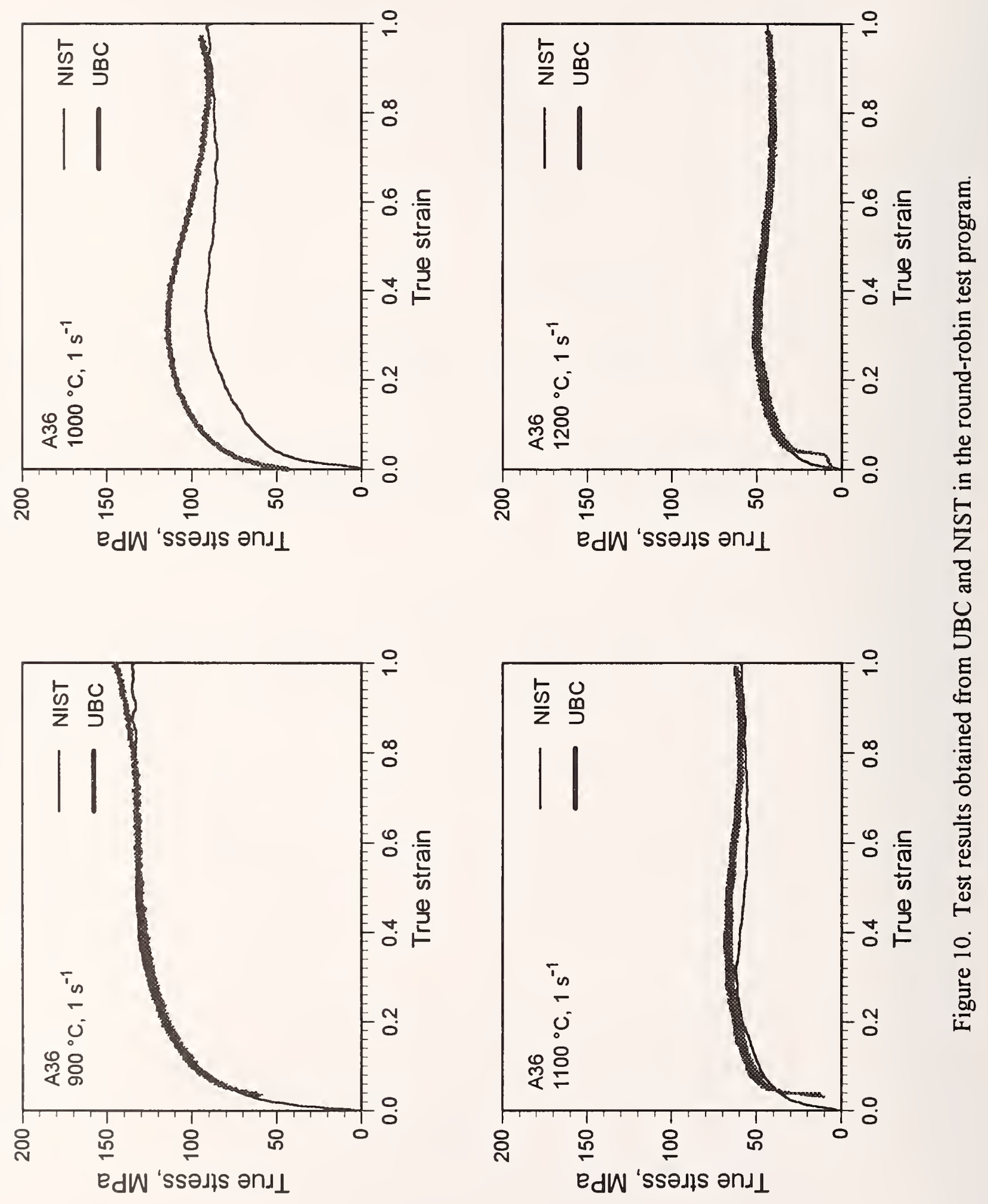

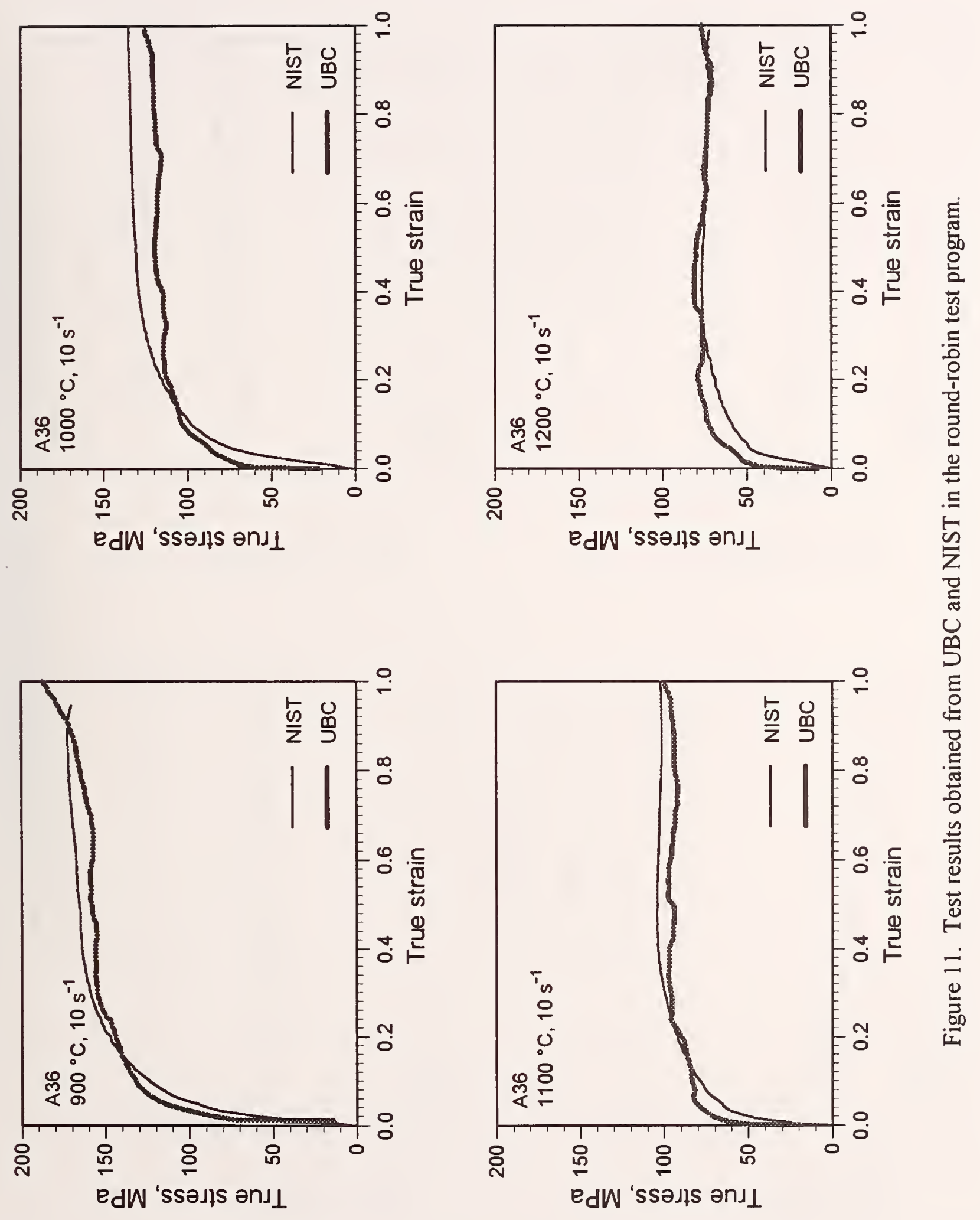

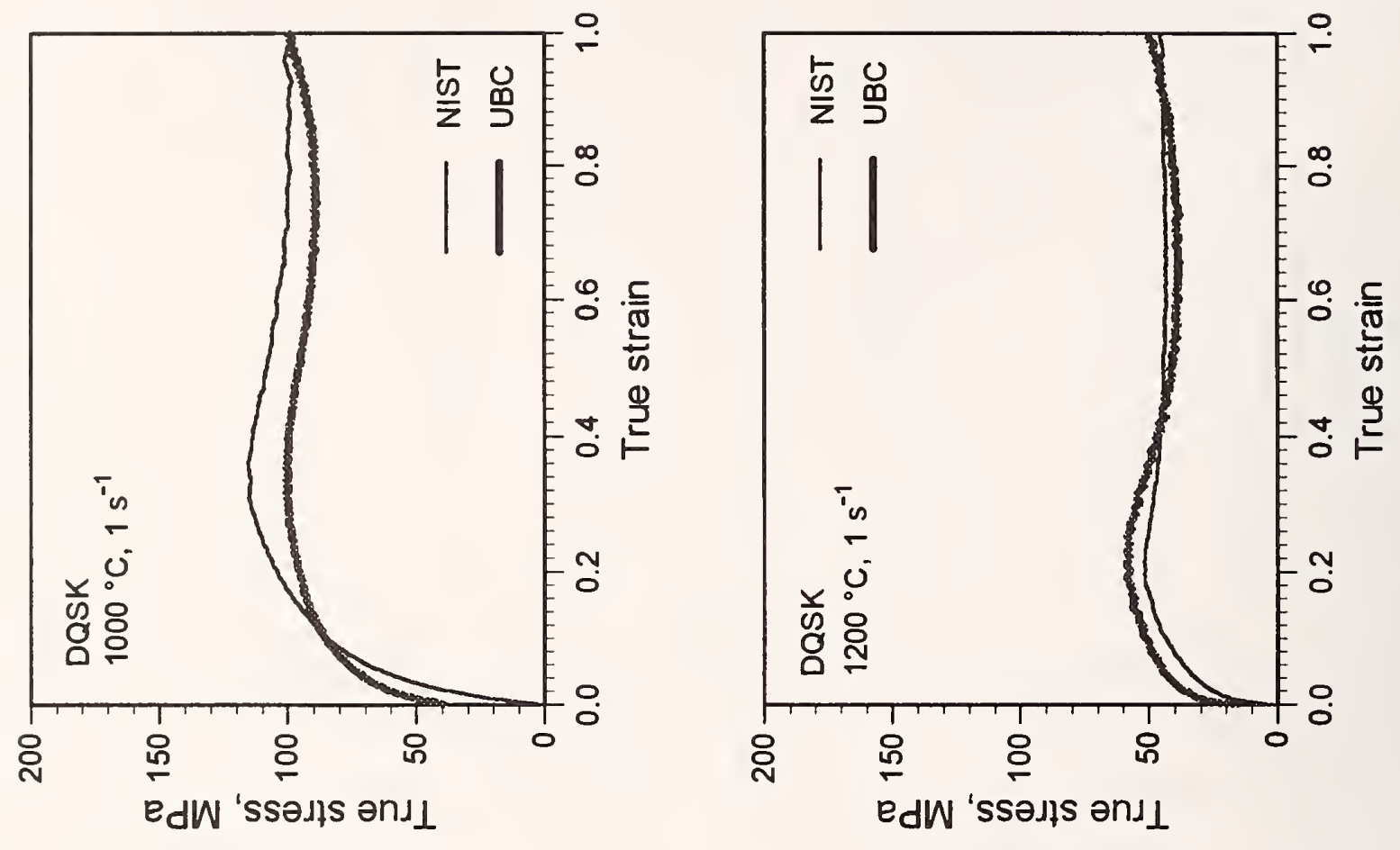

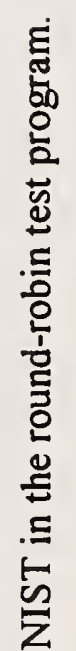
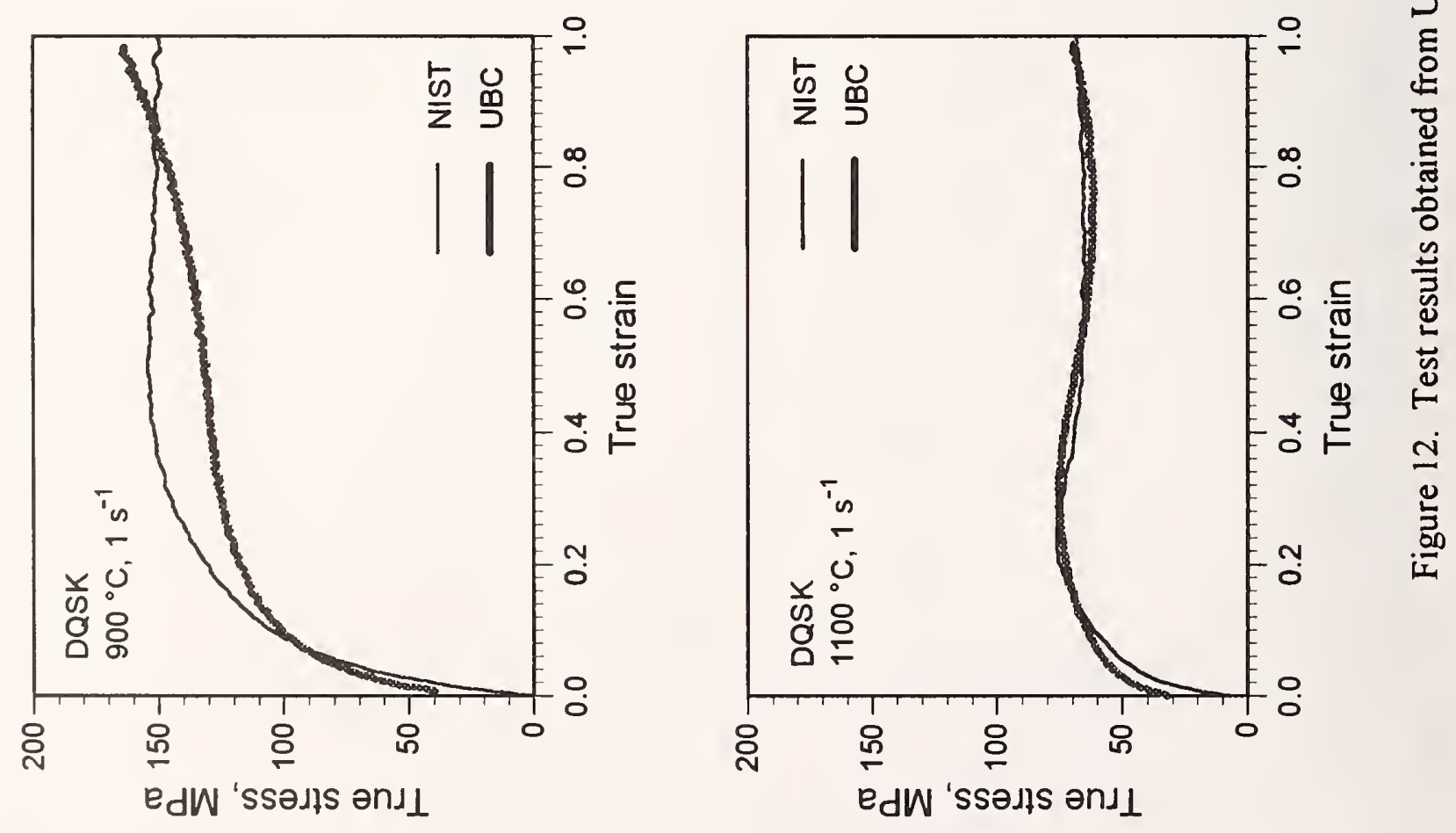

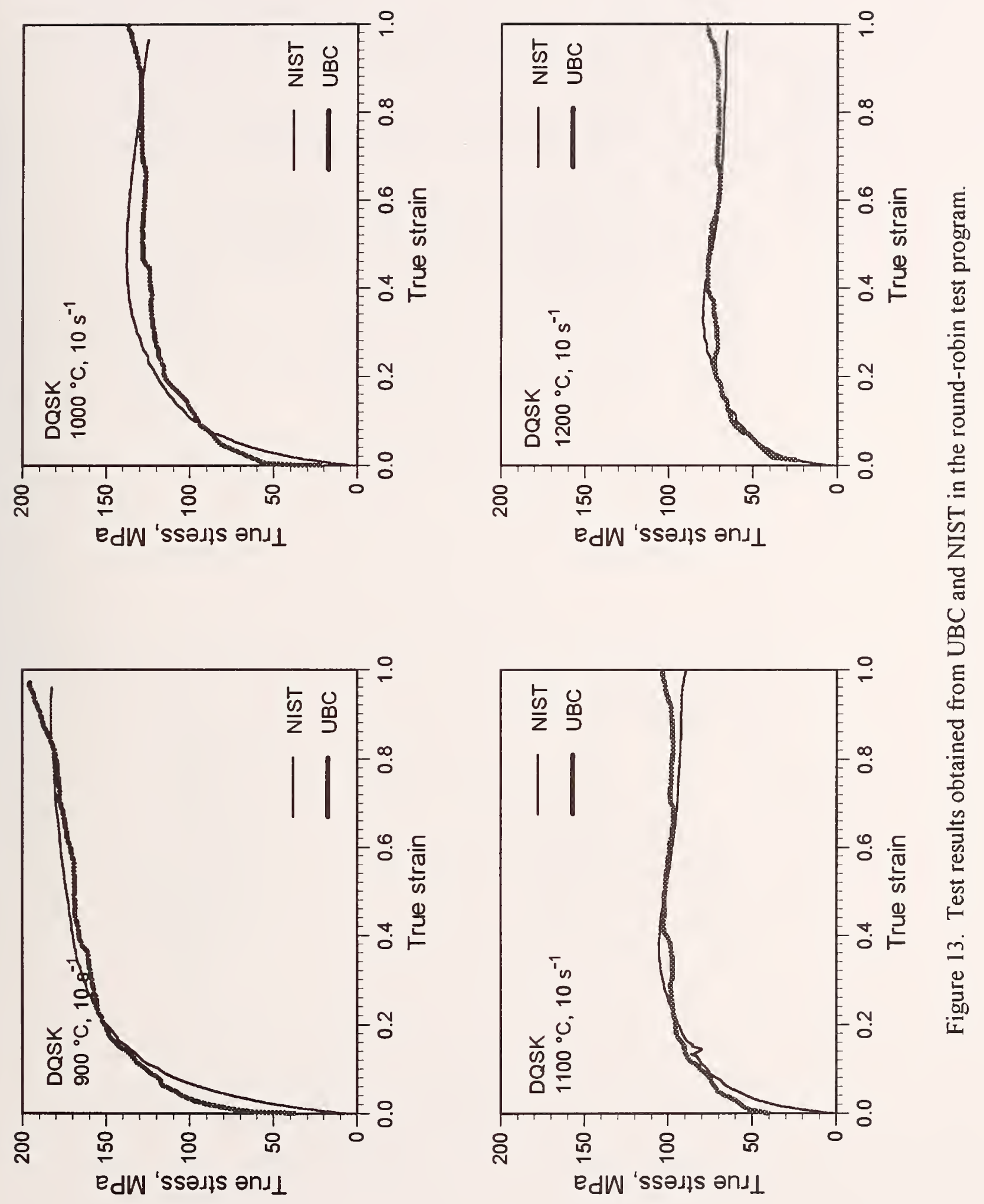


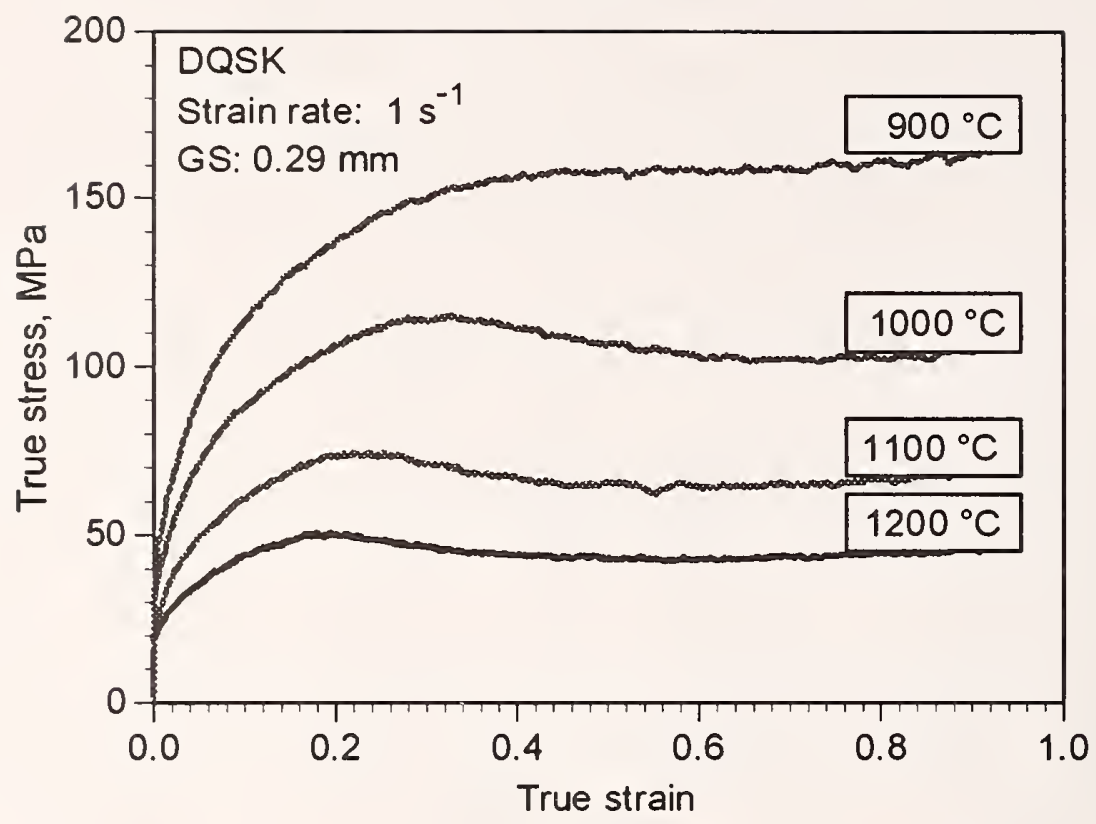

Figure 14. Dependence of flow stress on temperature.

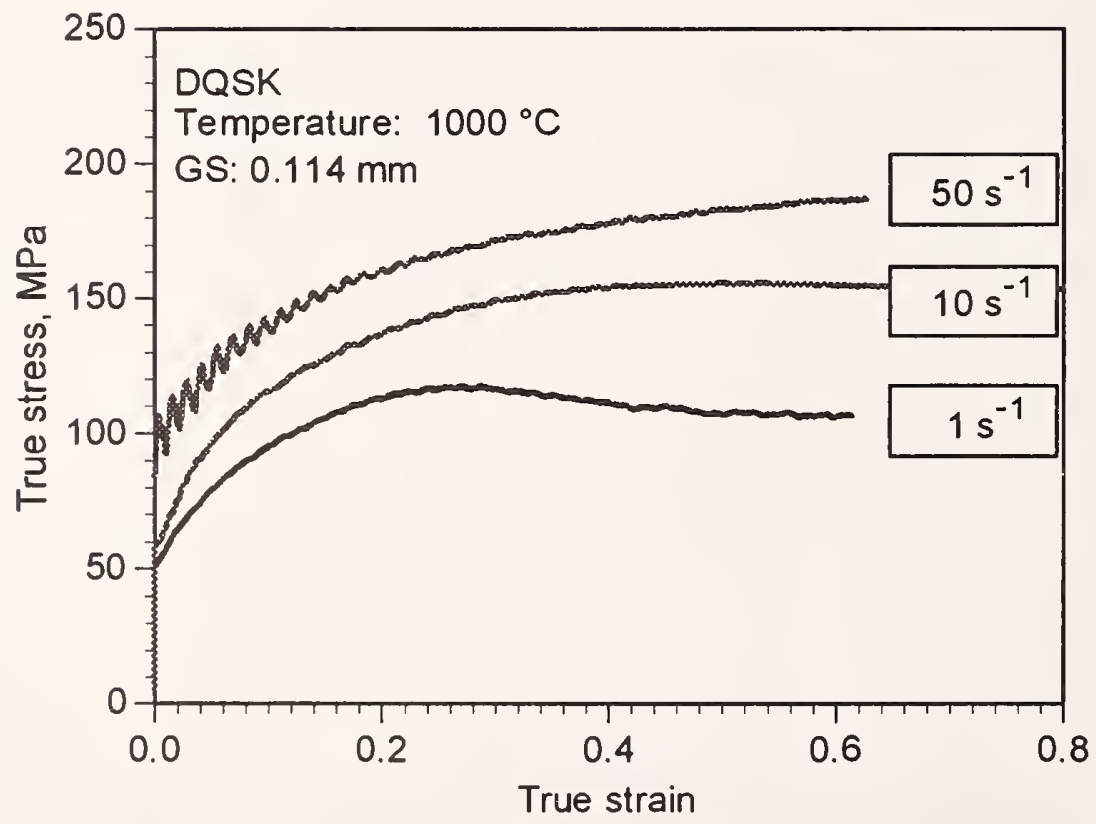

Figure 15. Dependence of flow stress on strain rate. 

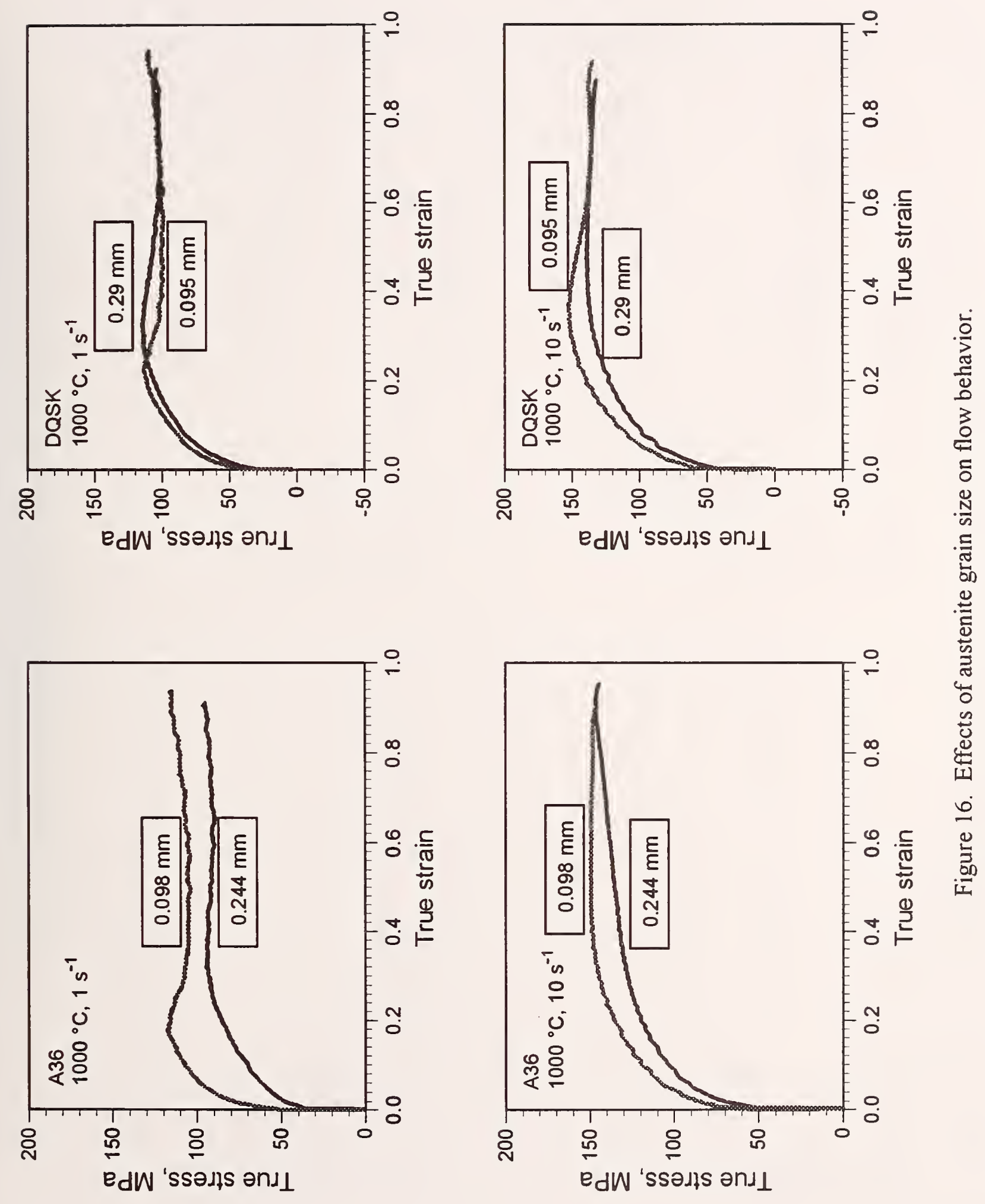

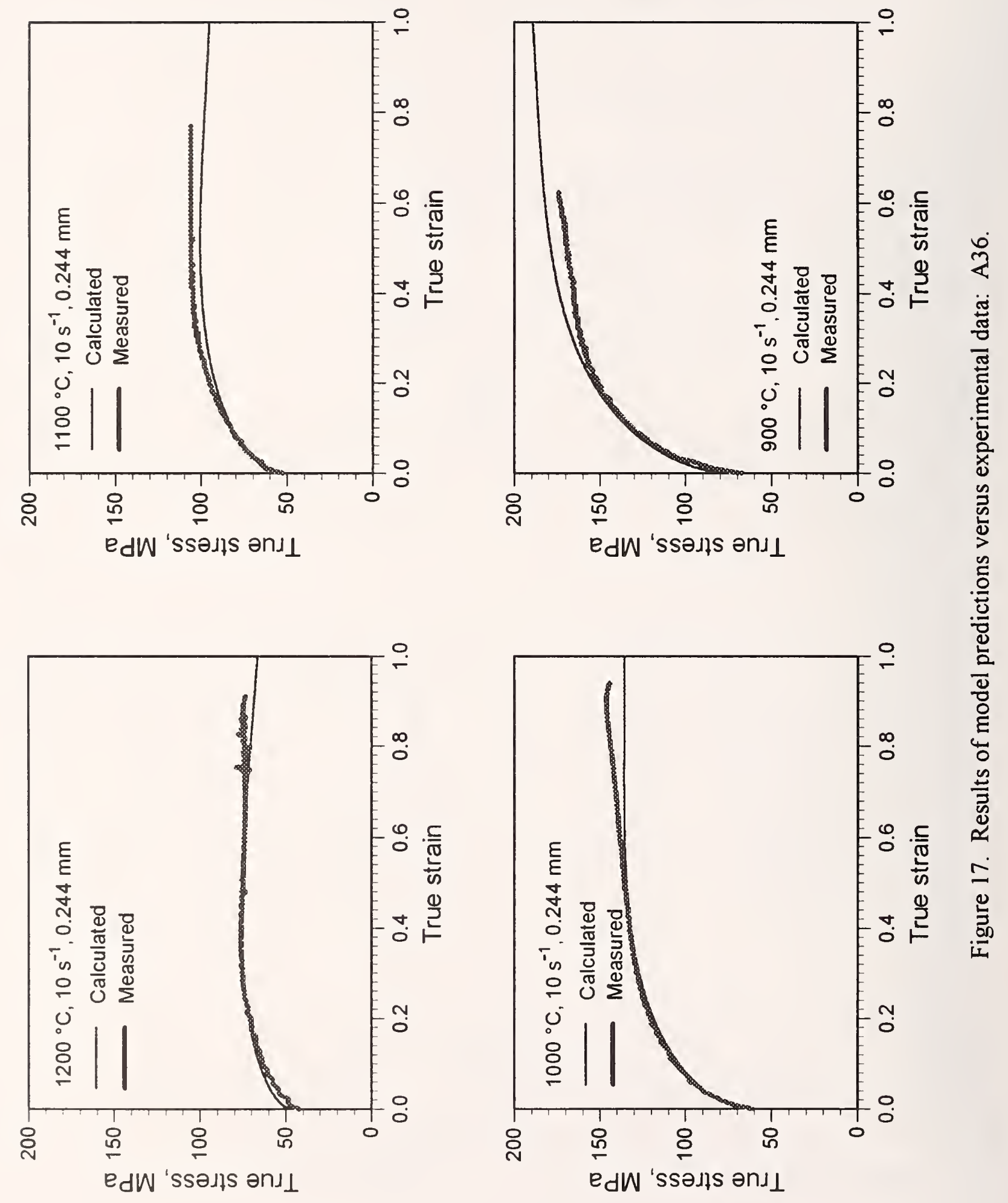

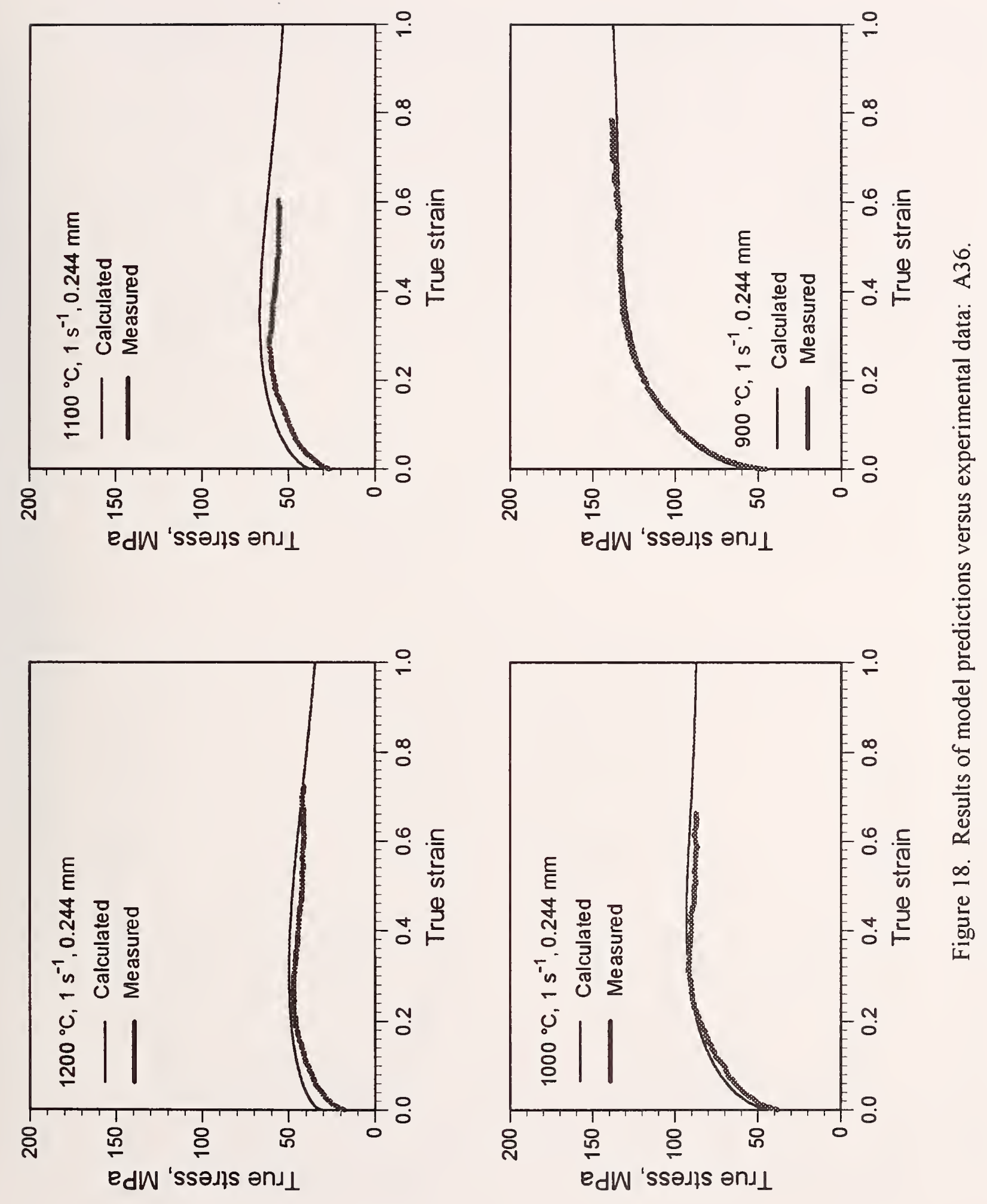

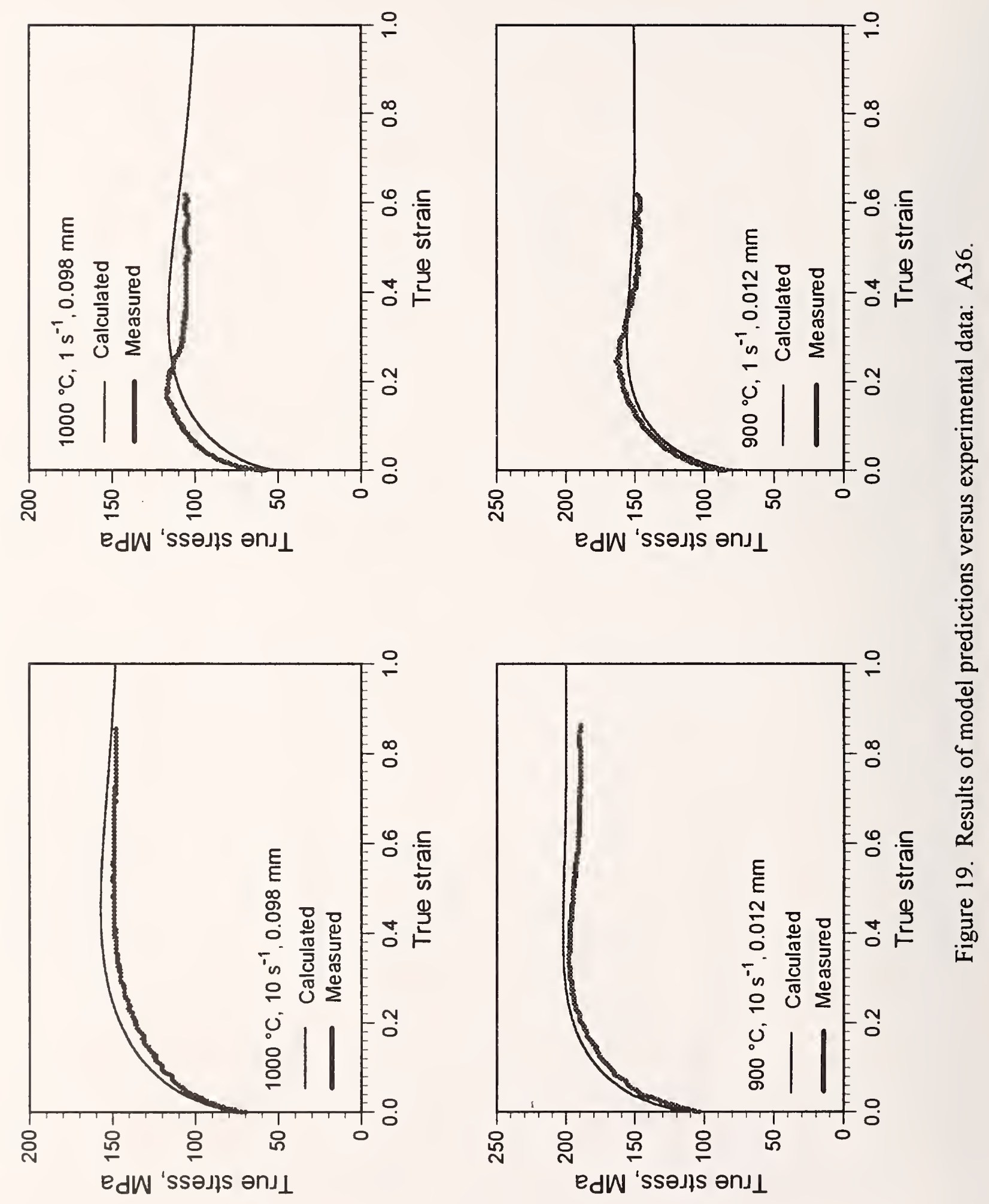

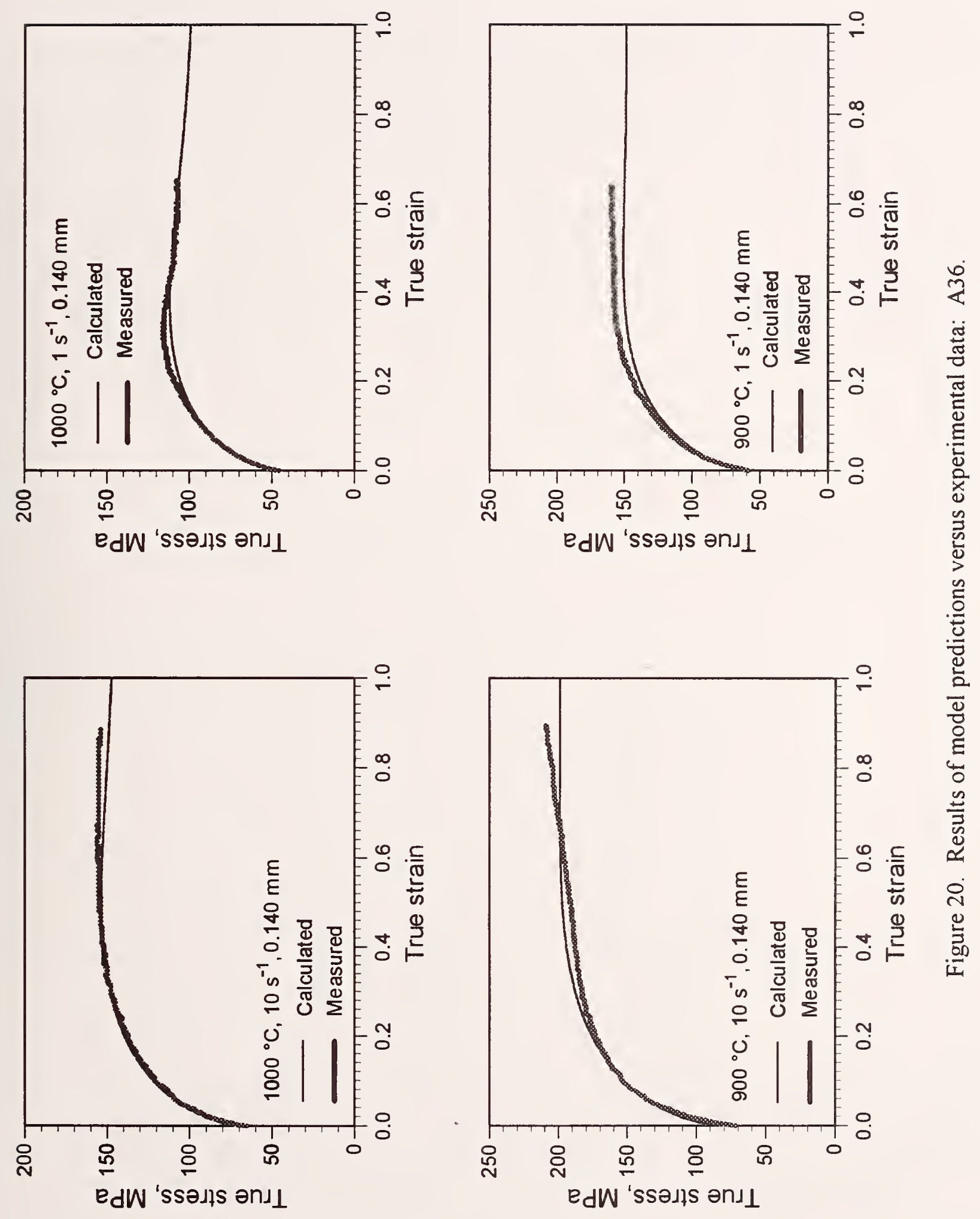

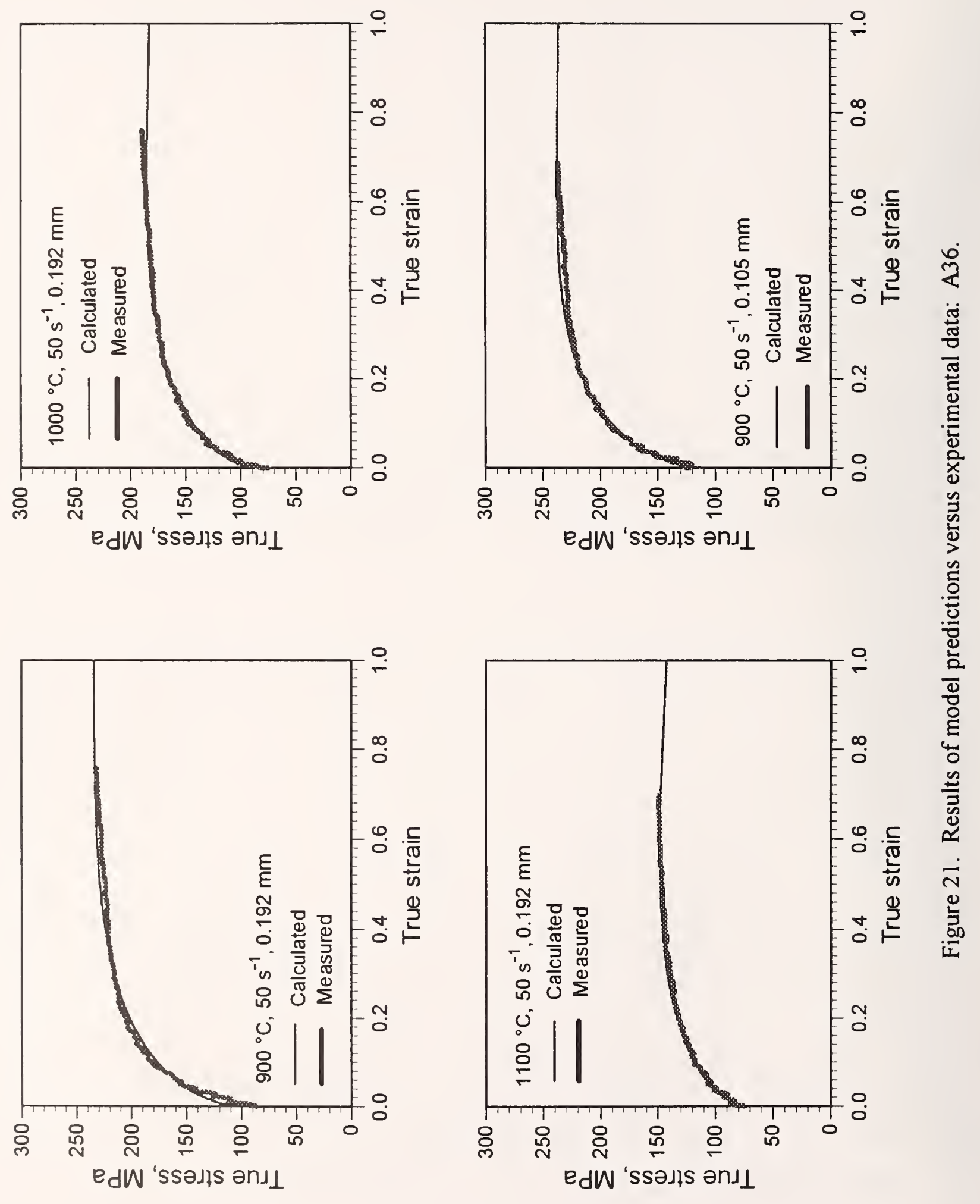

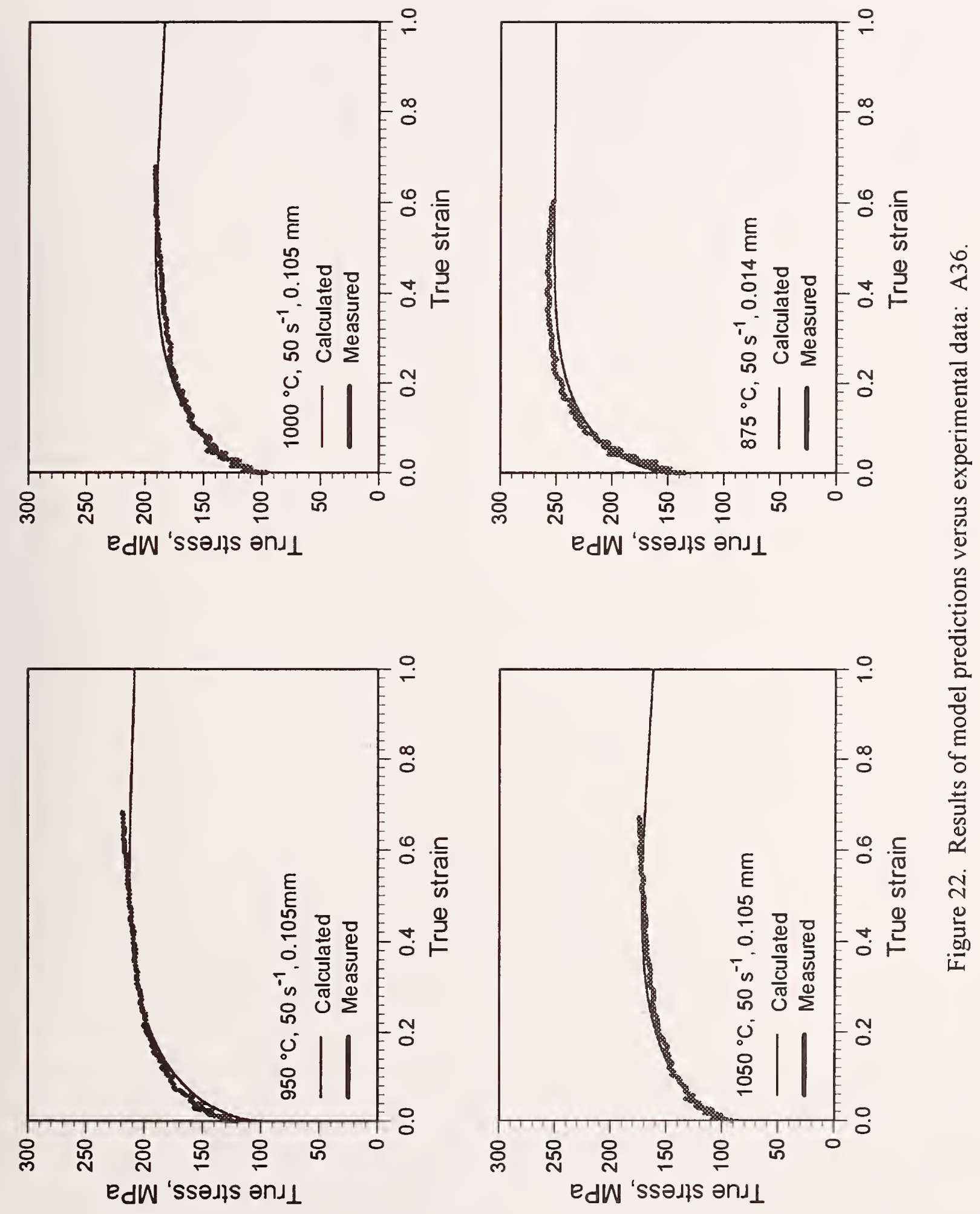

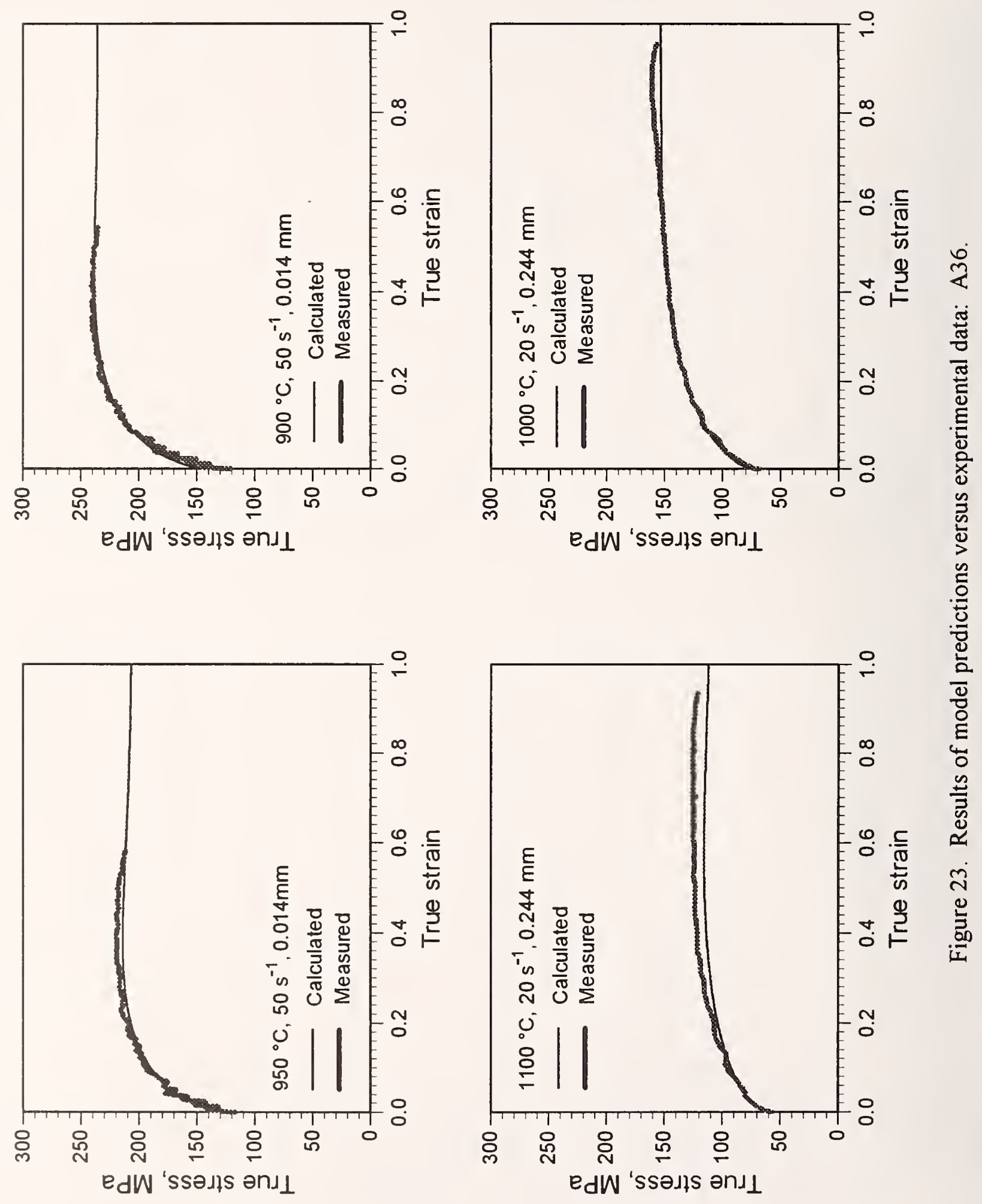


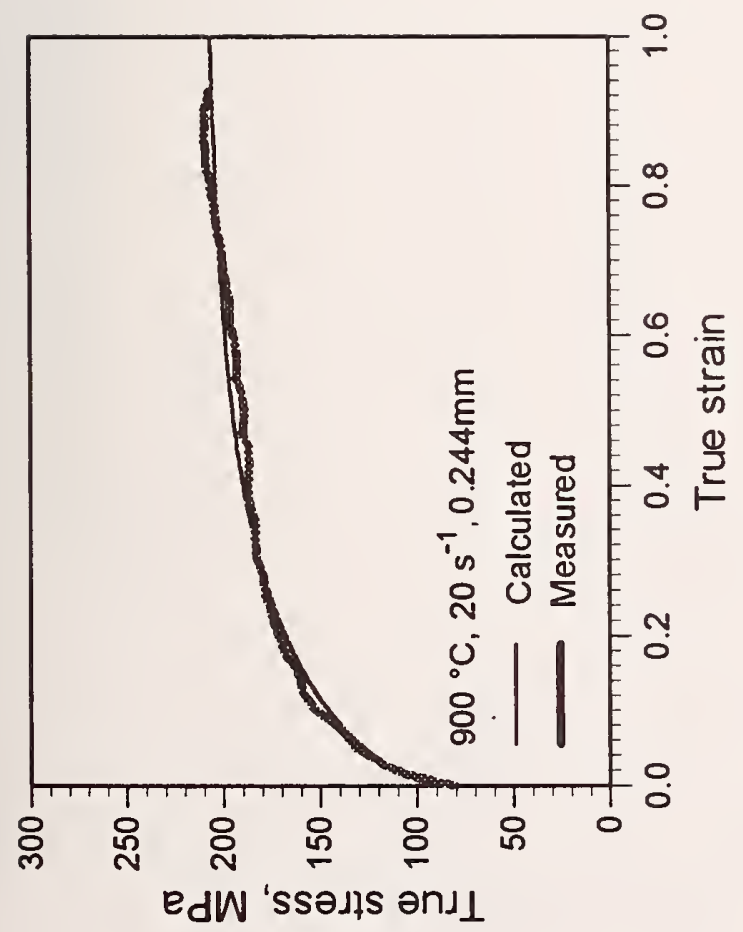

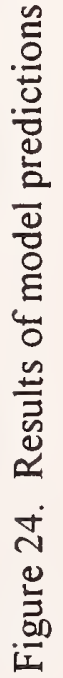



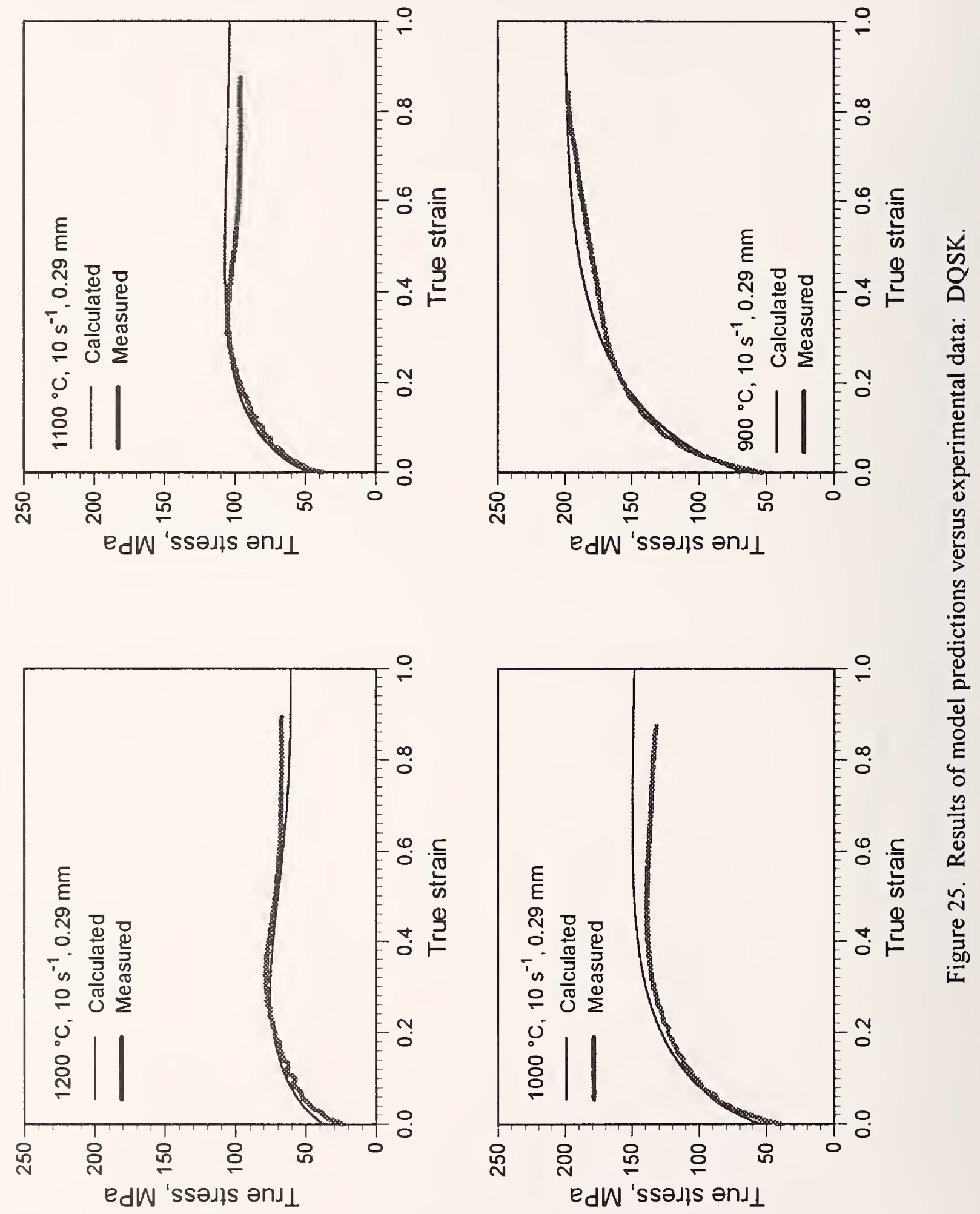

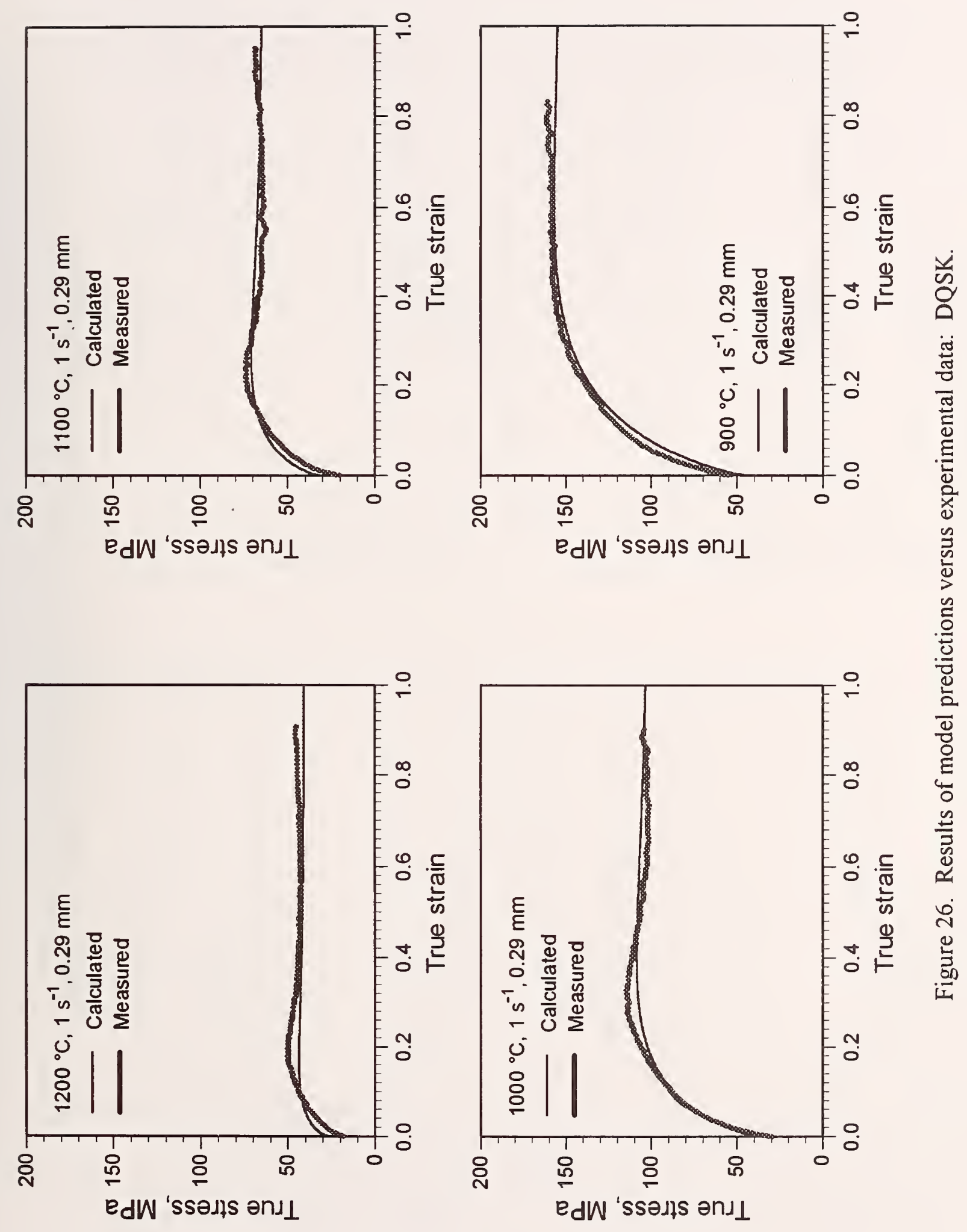

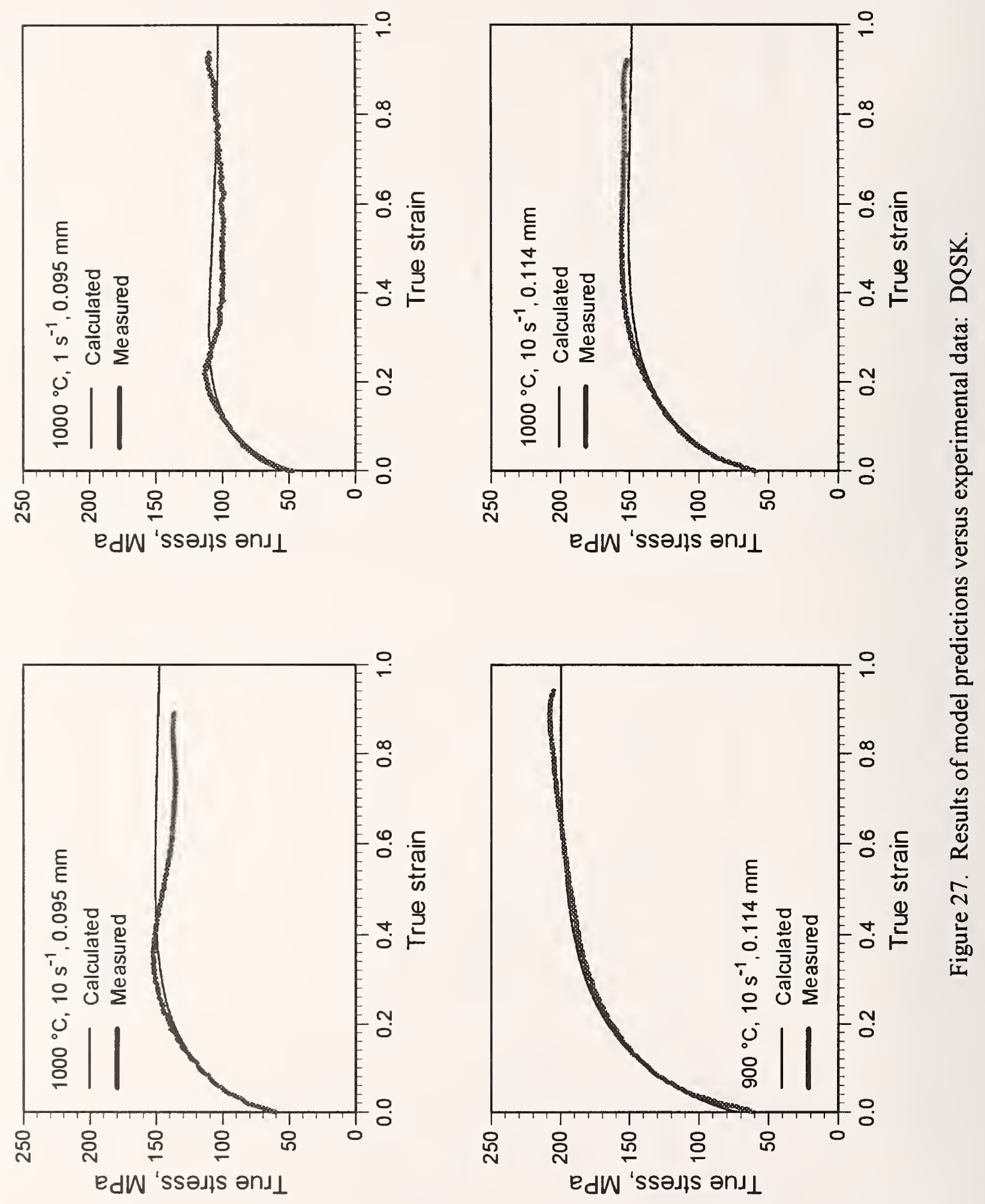

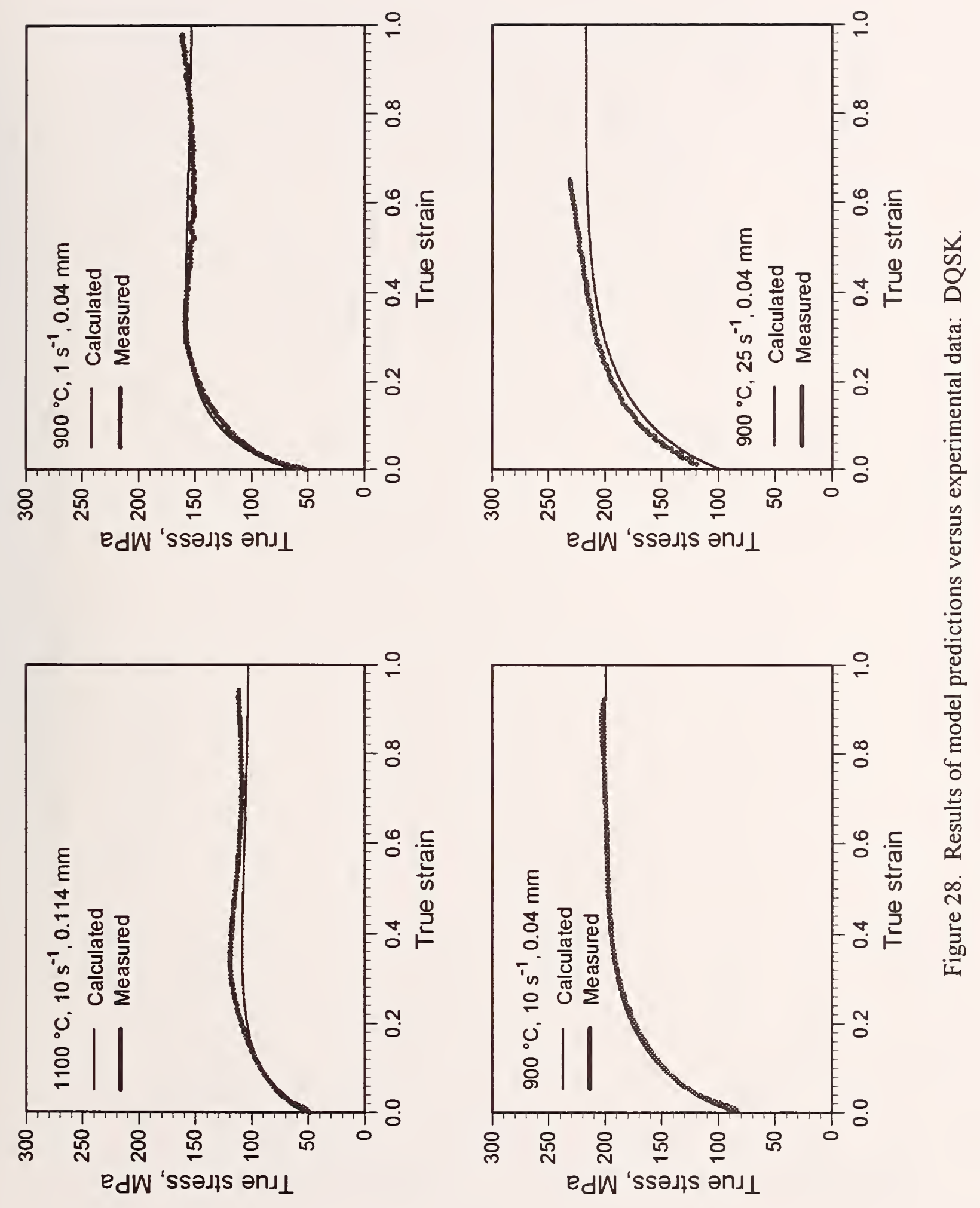

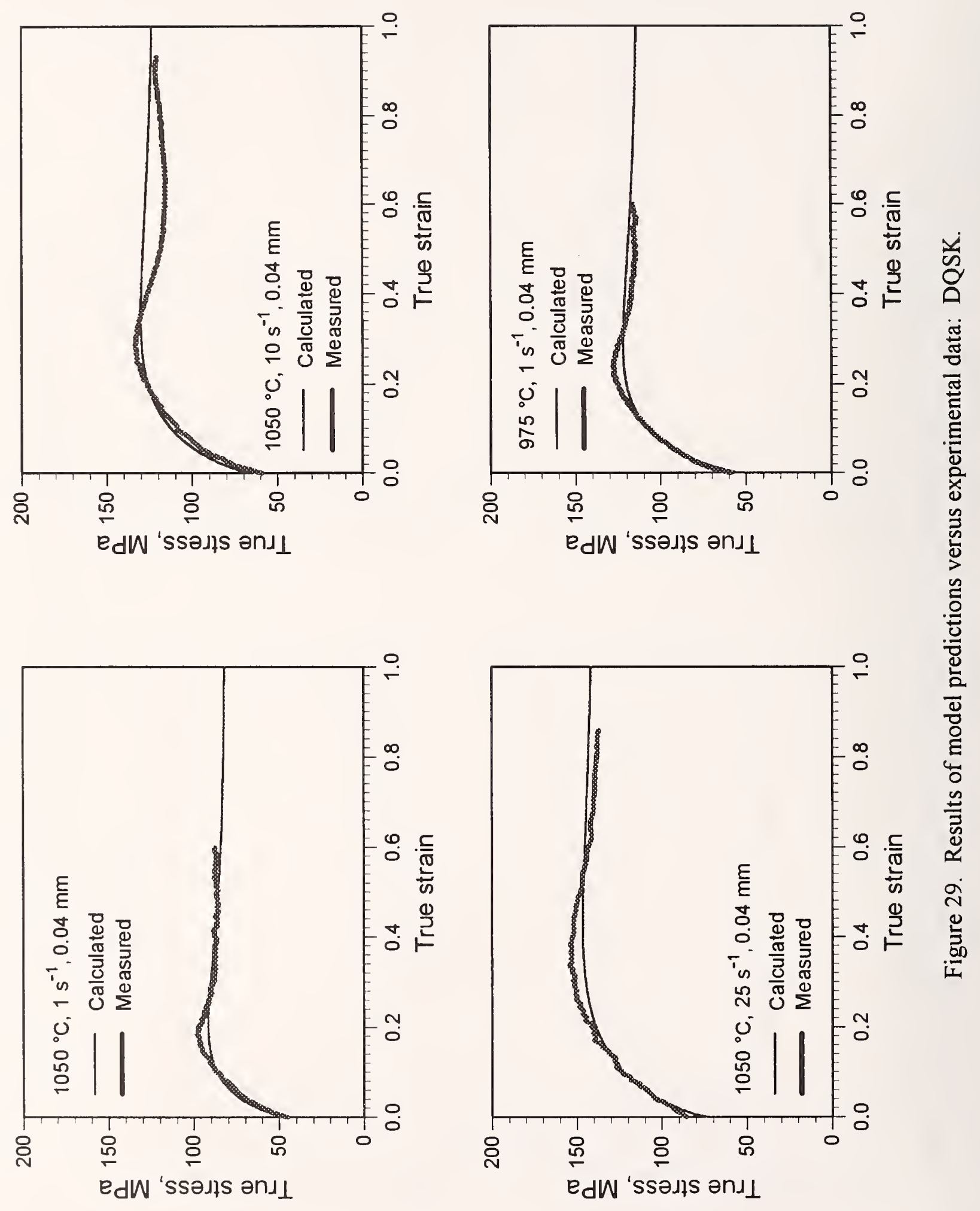

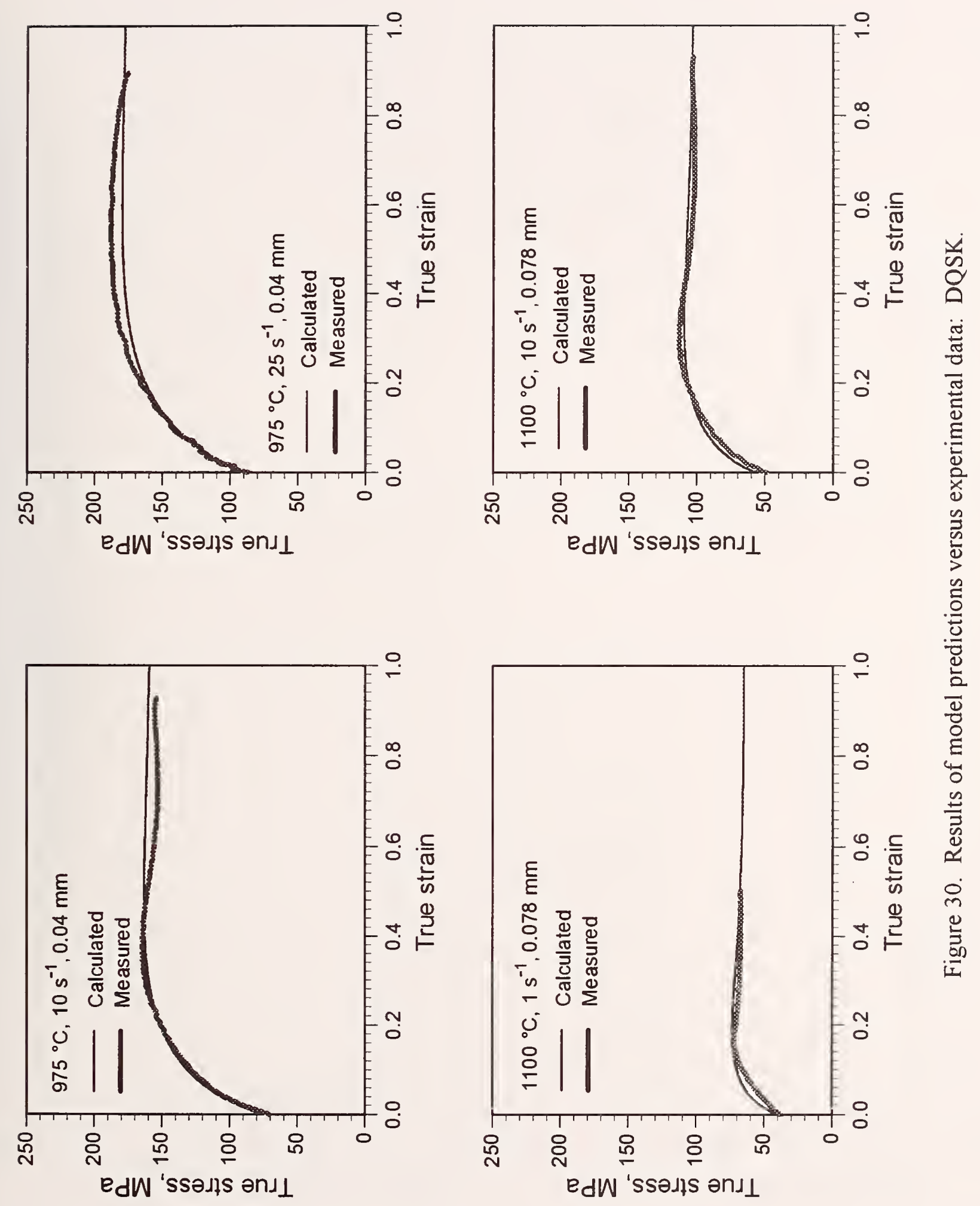

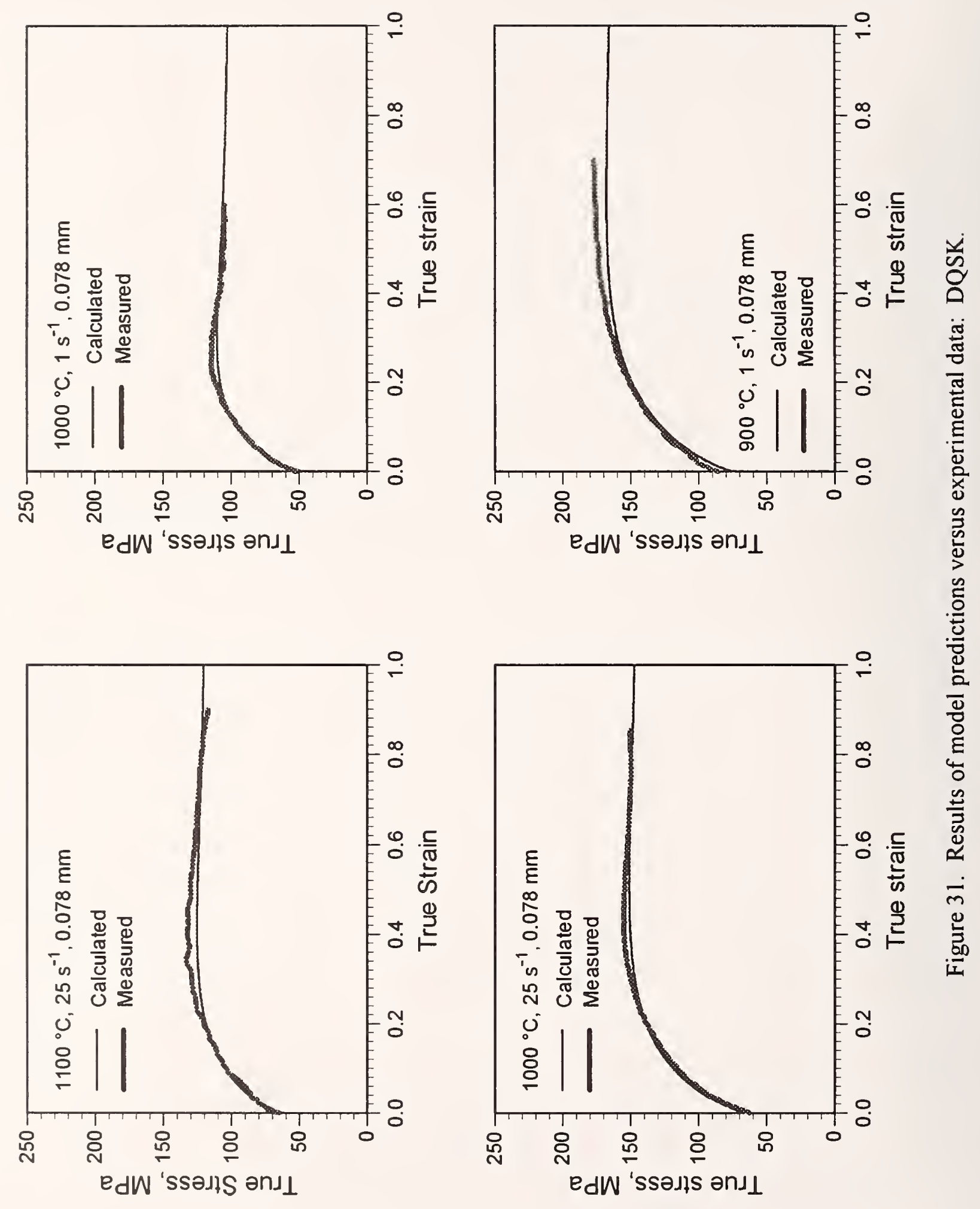

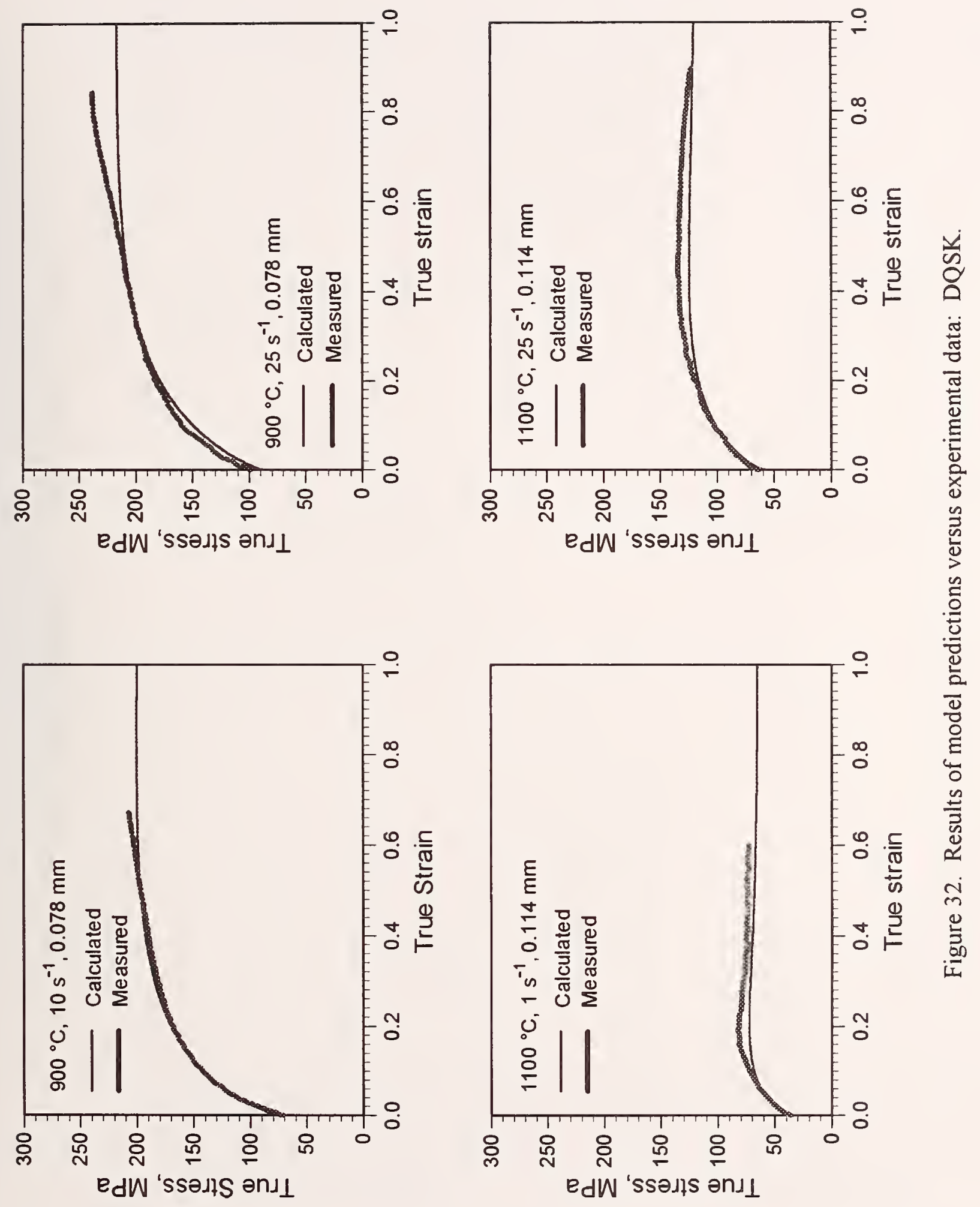

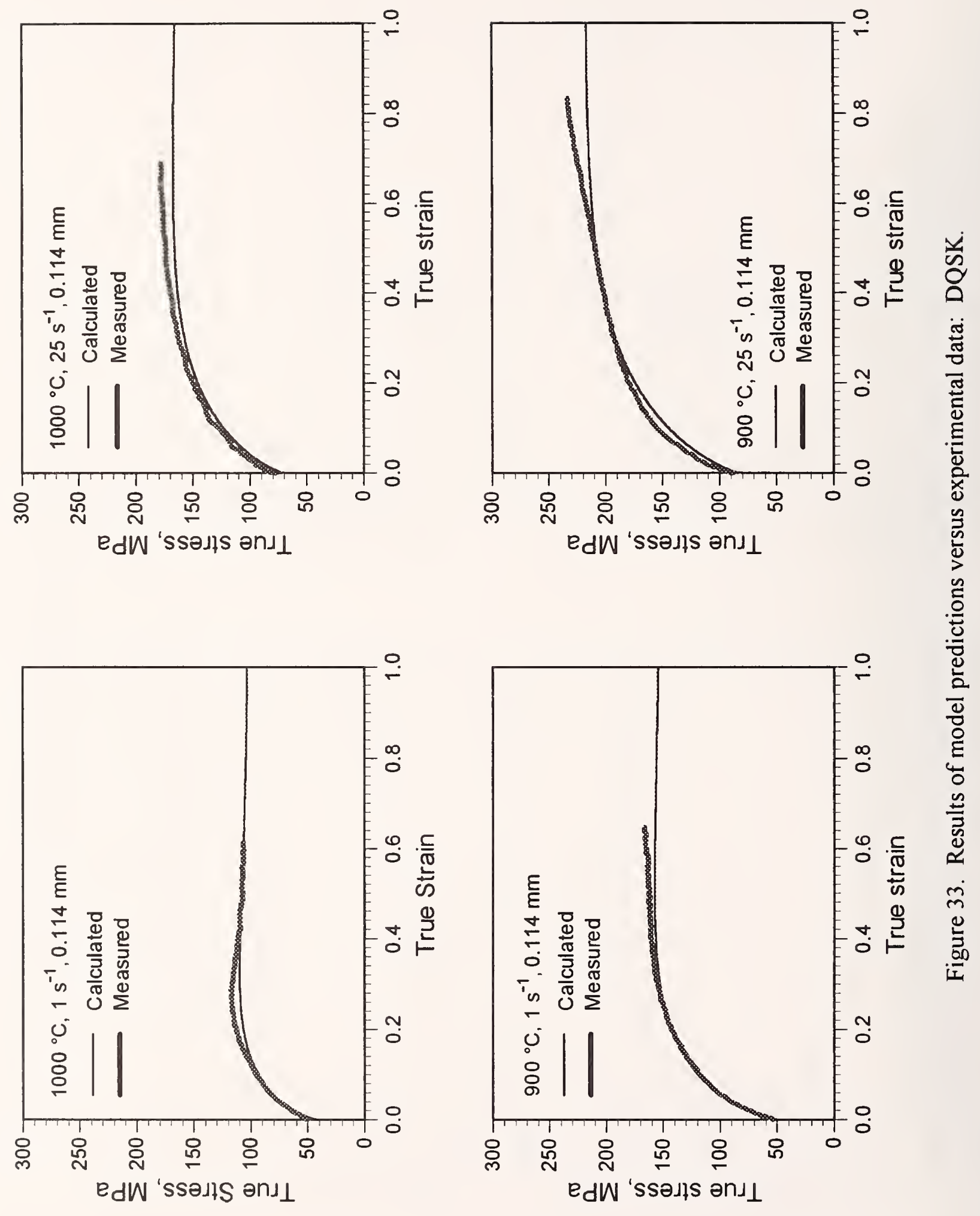

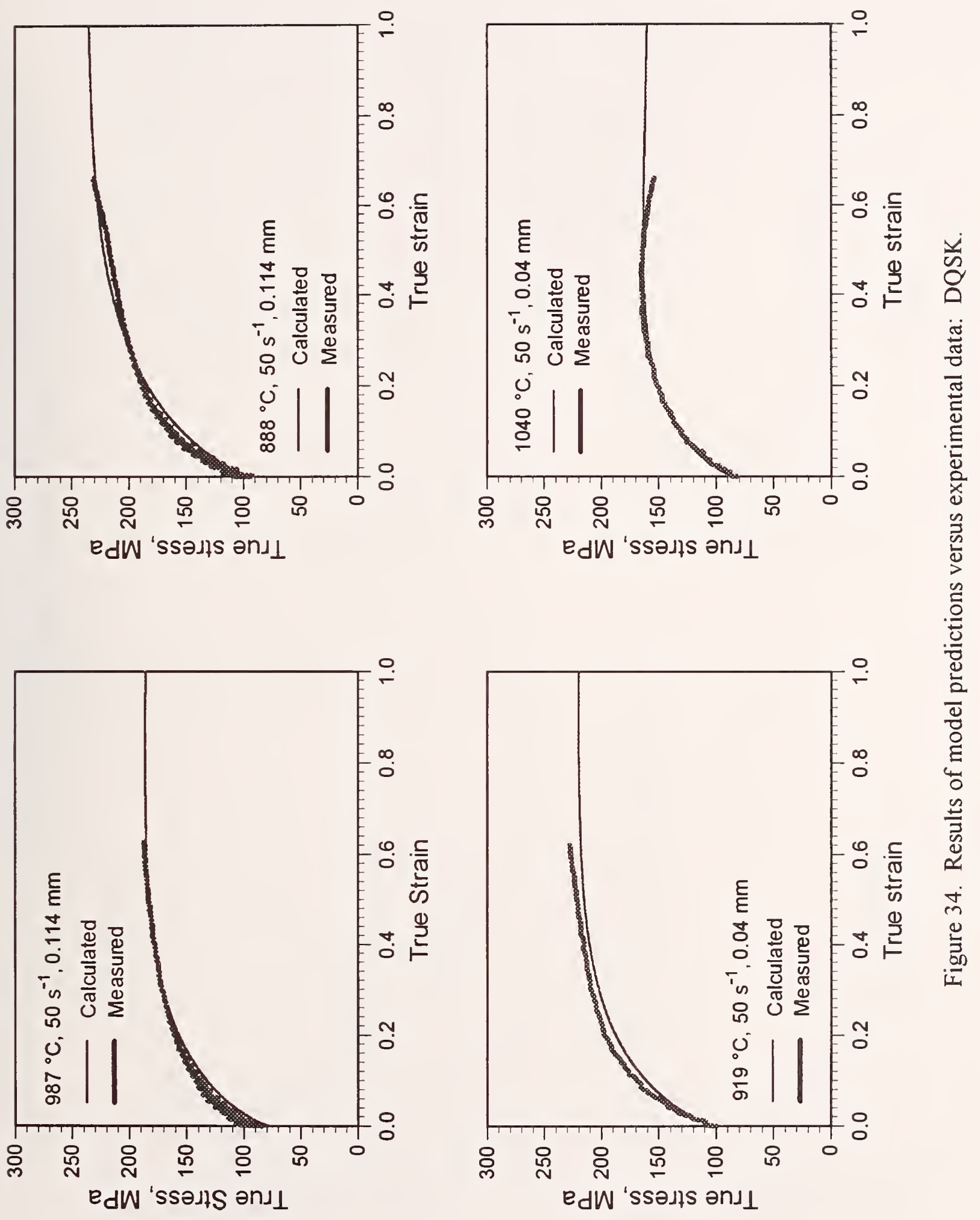

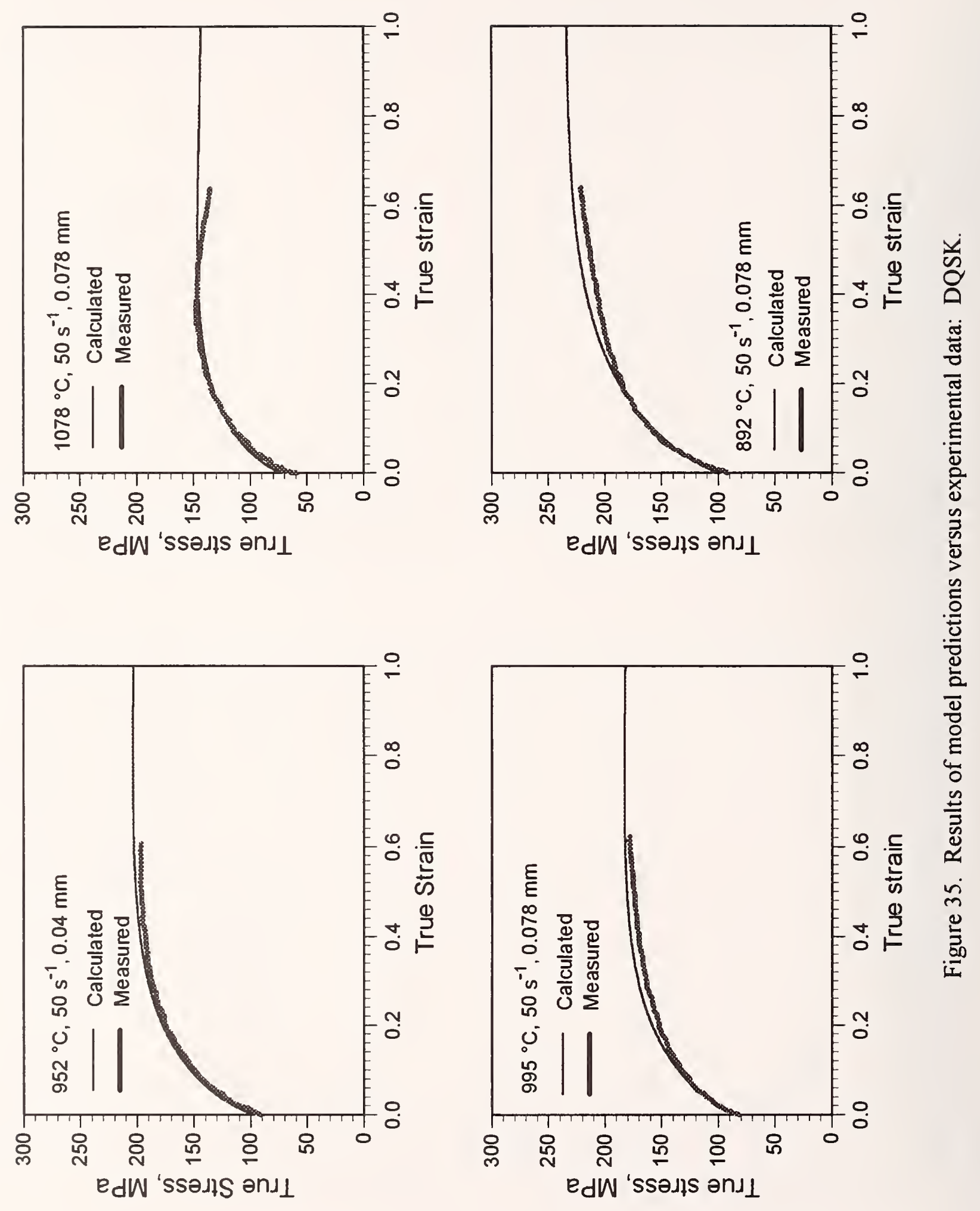


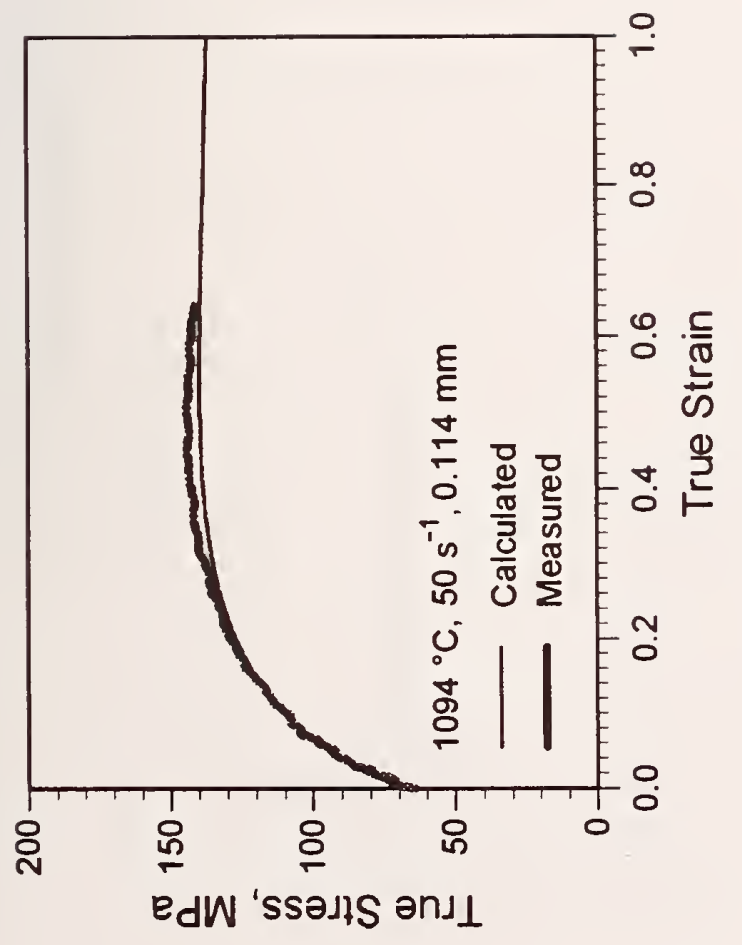

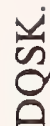

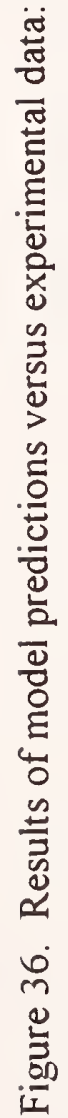



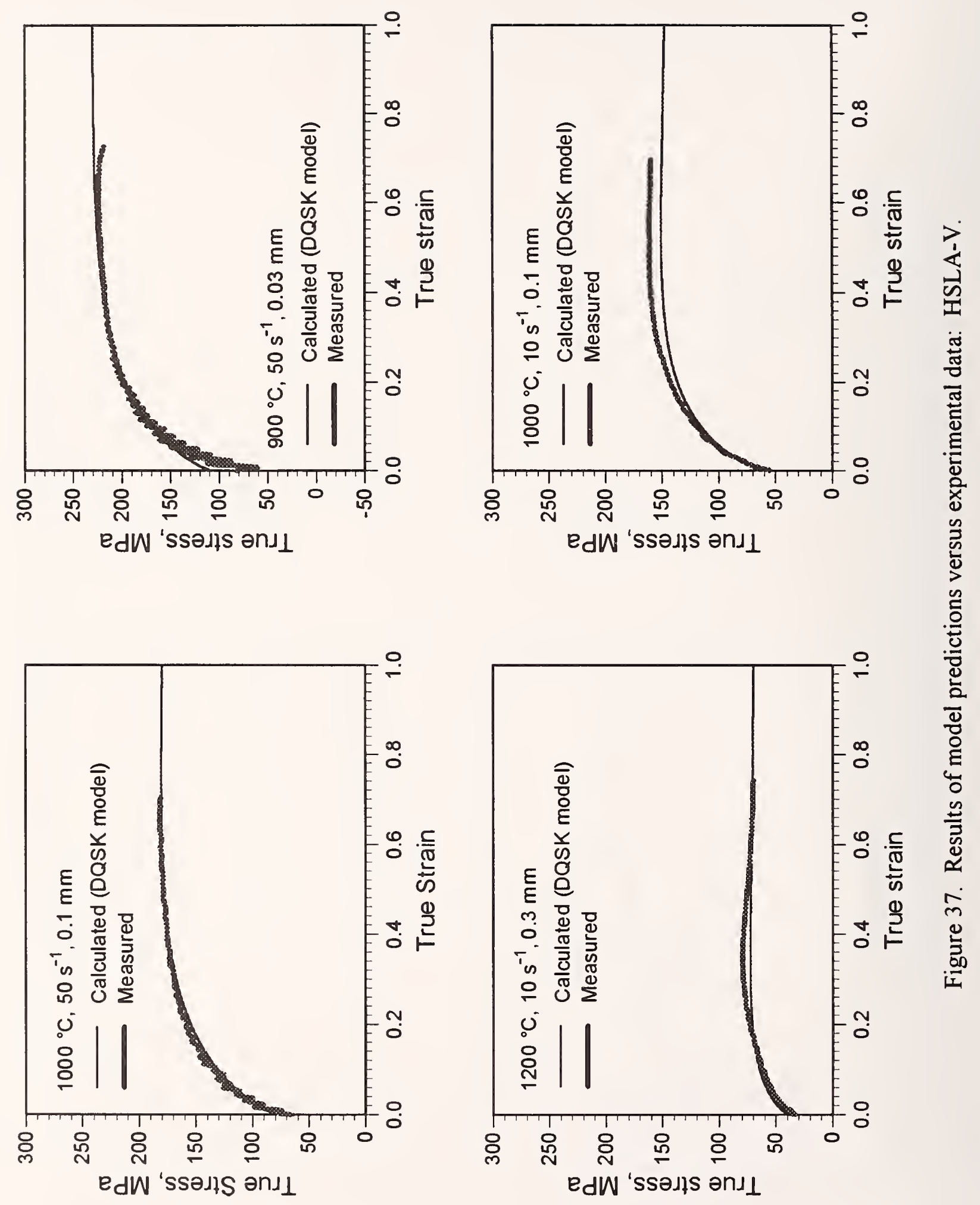

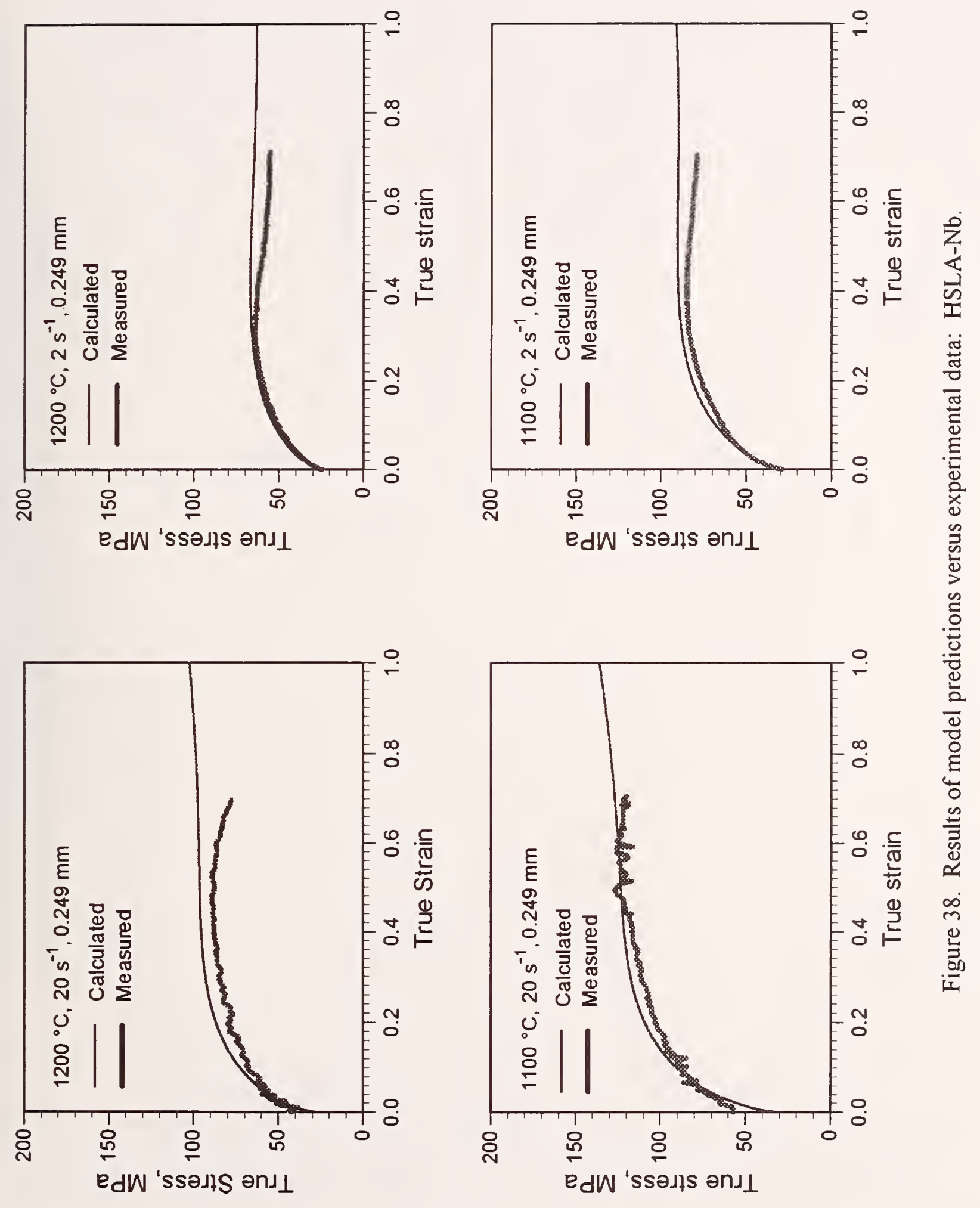

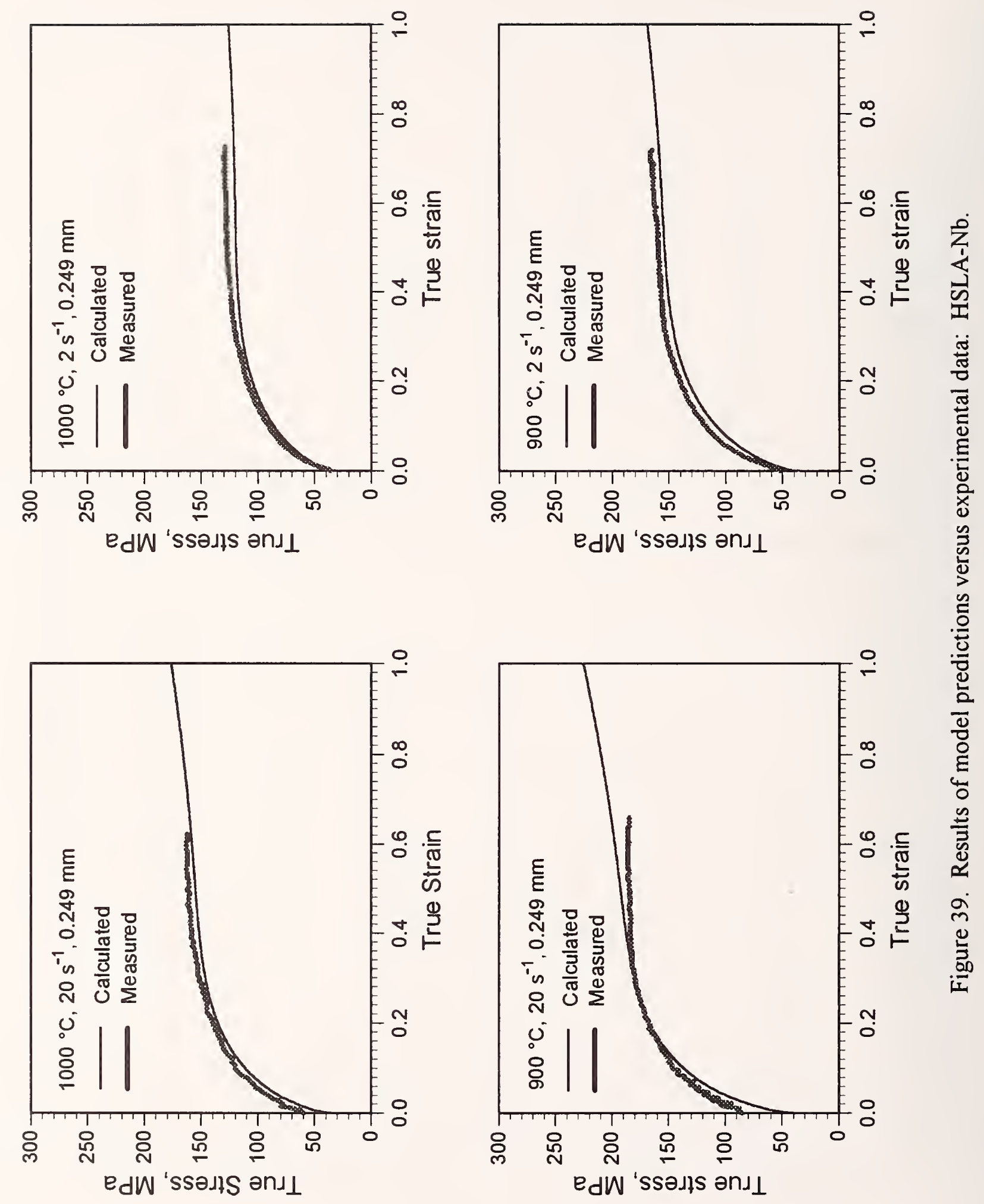

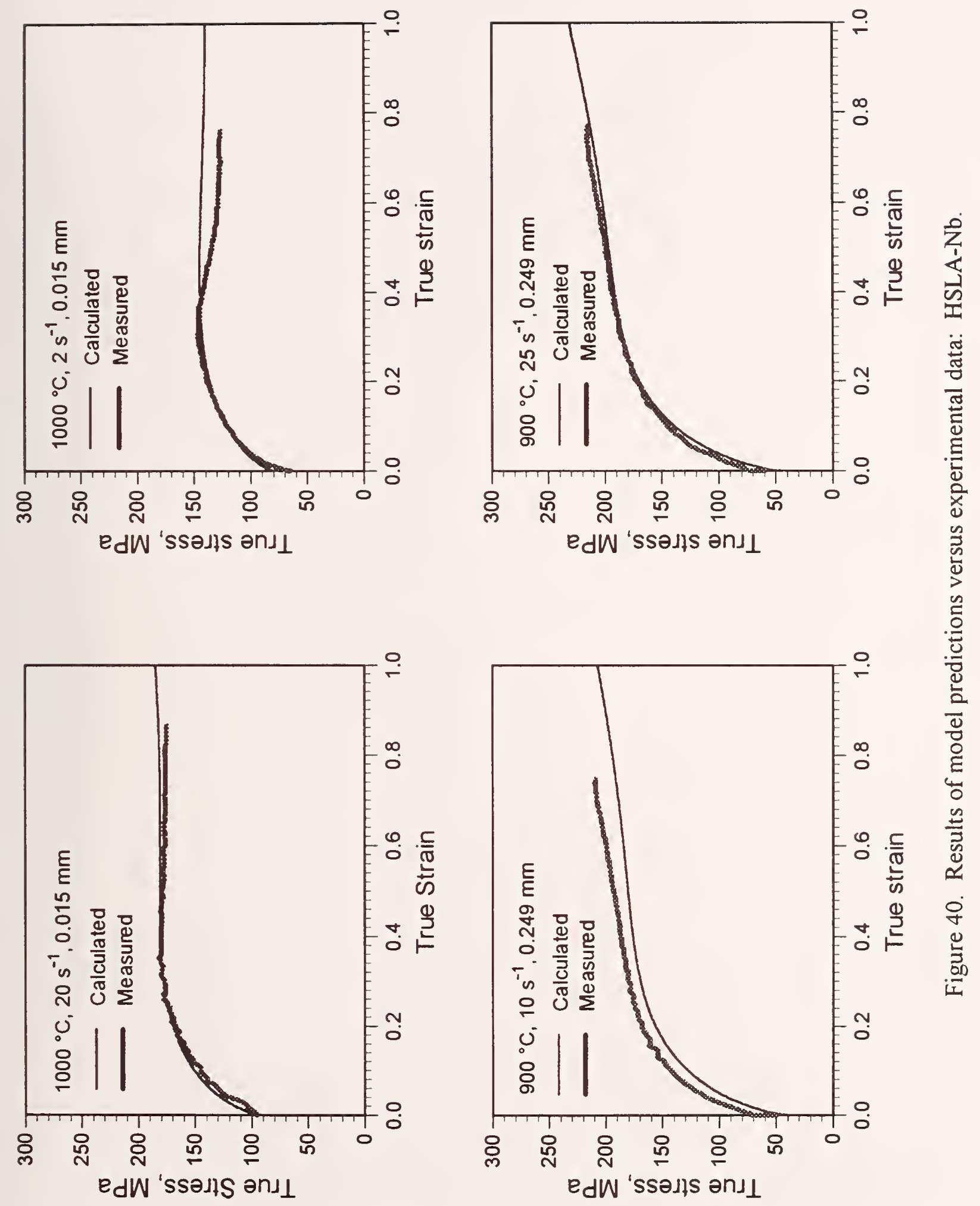

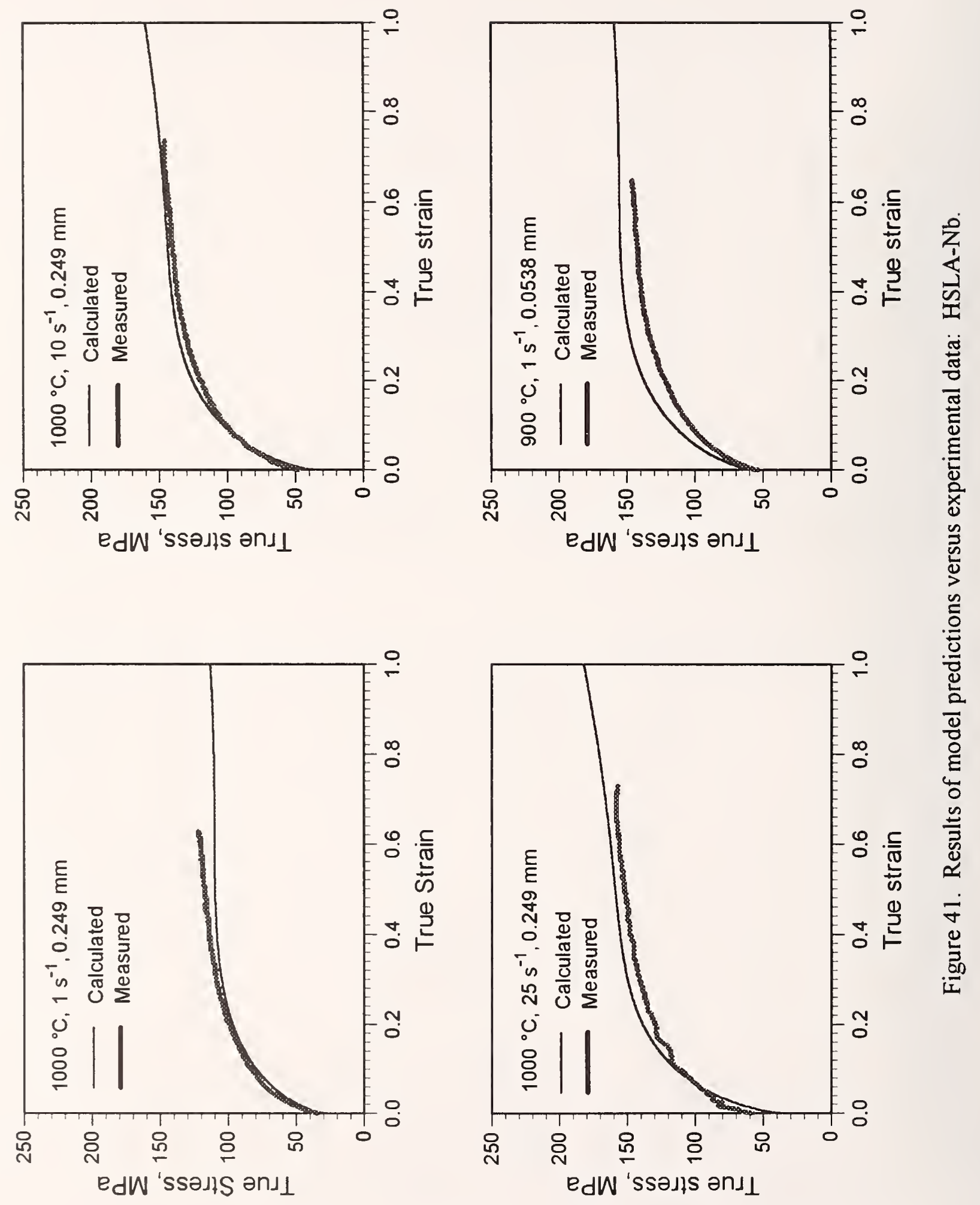

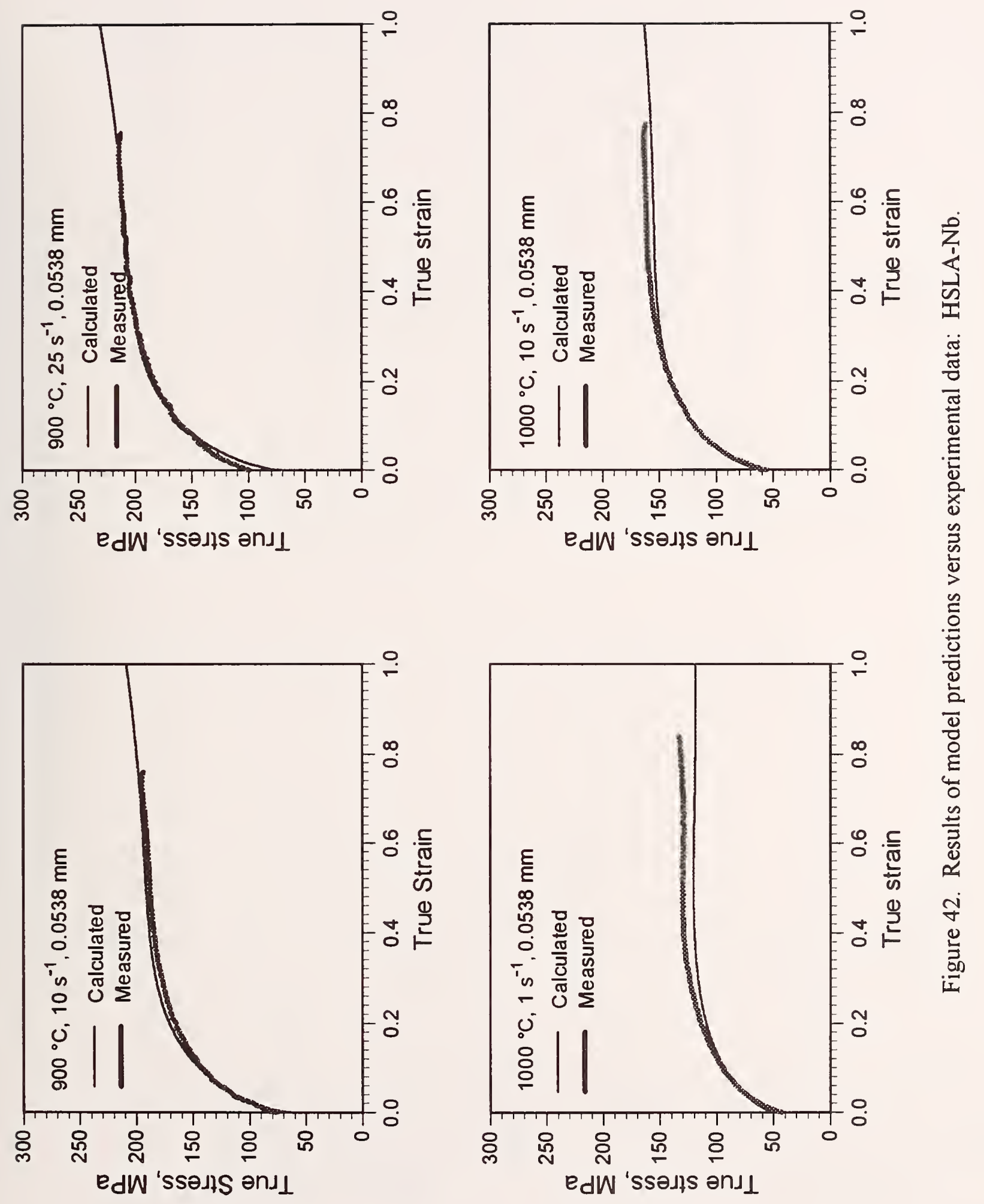

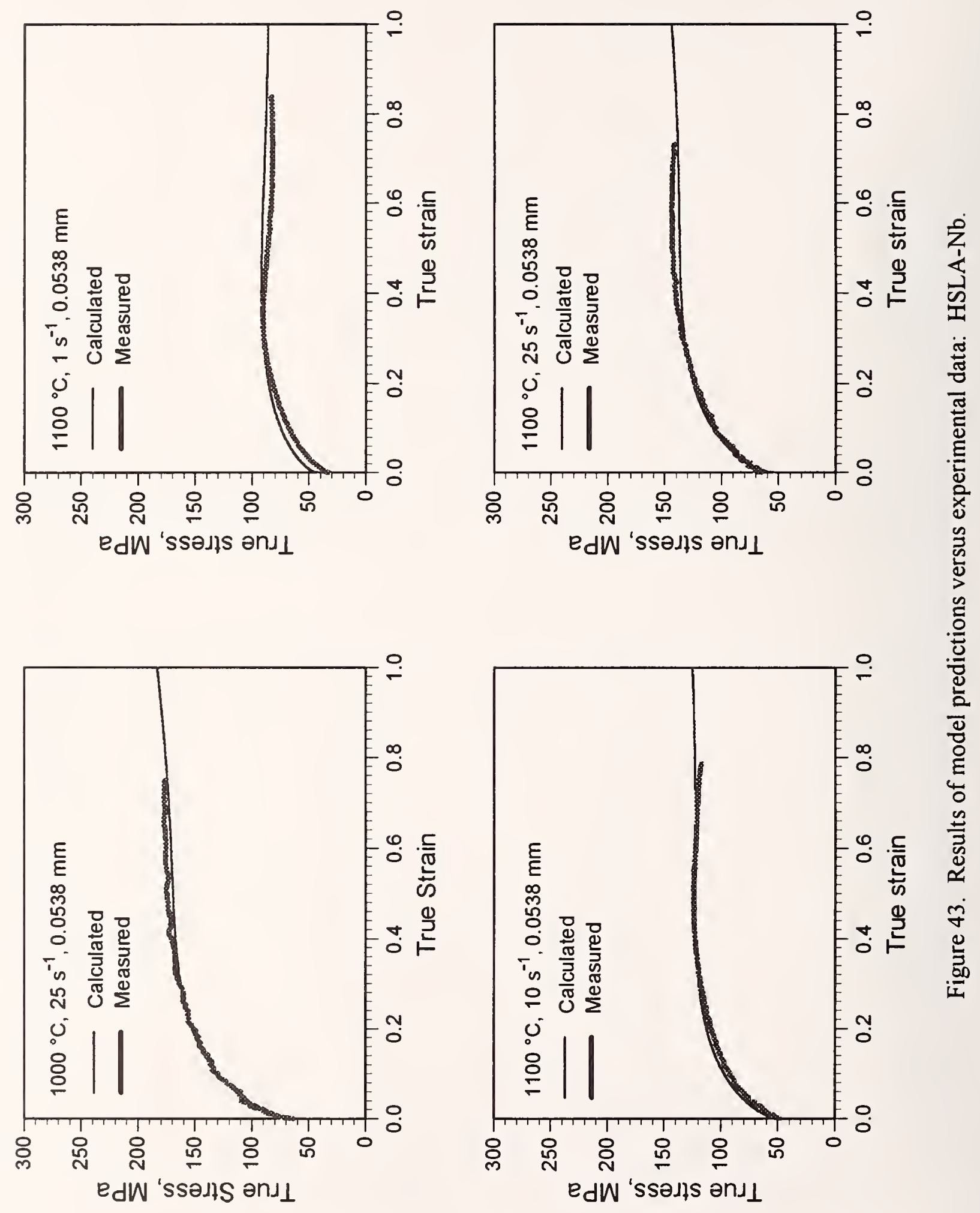

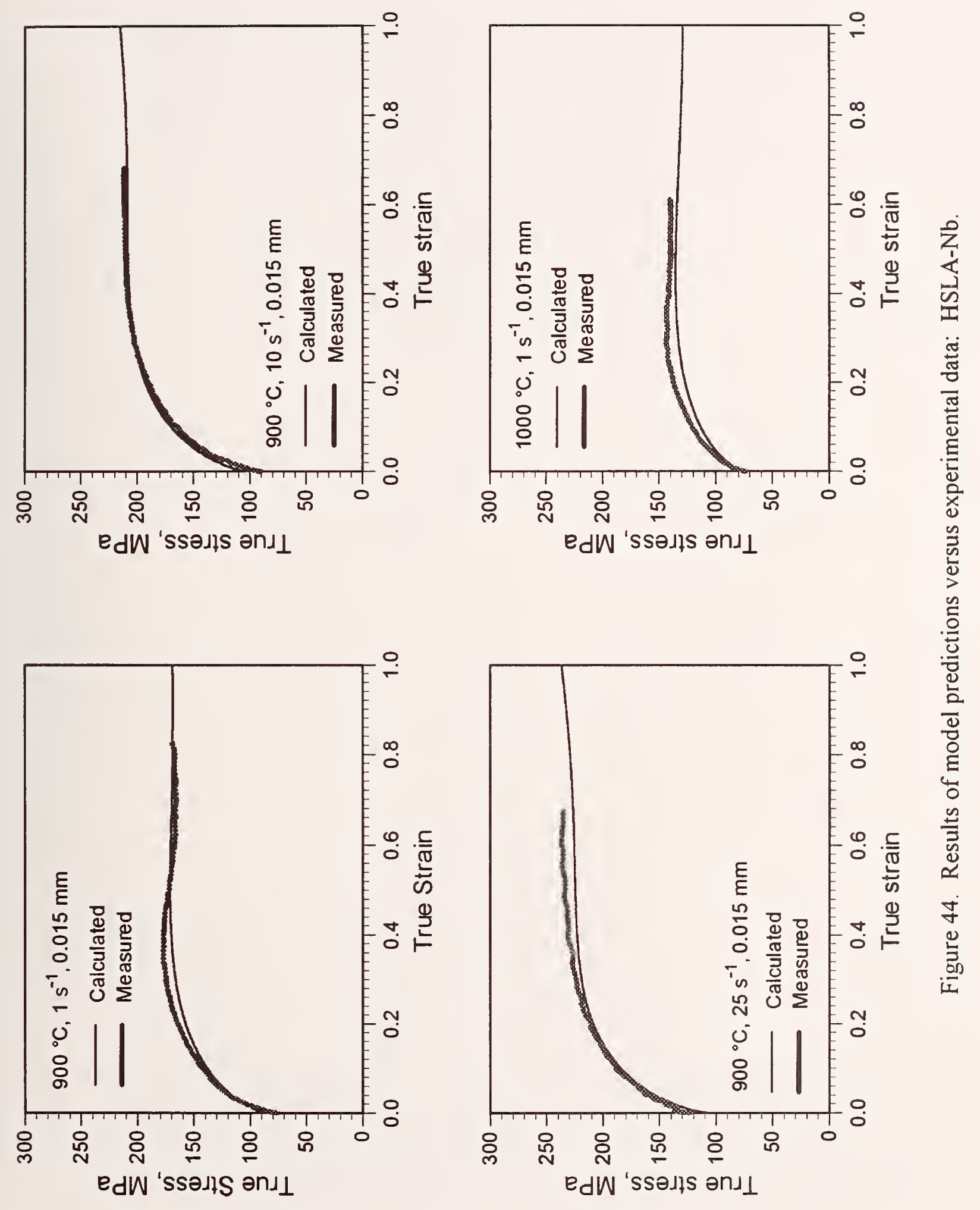

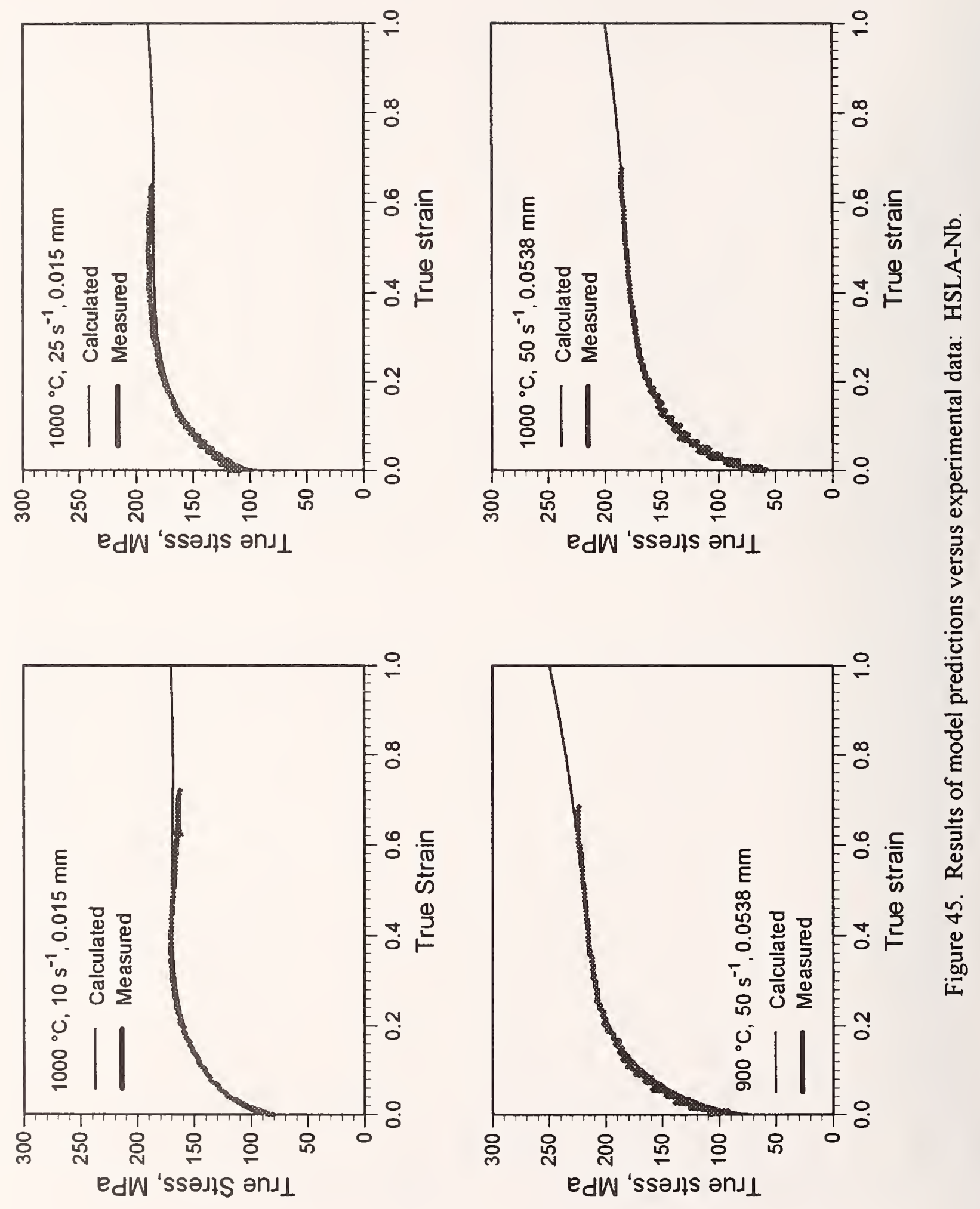


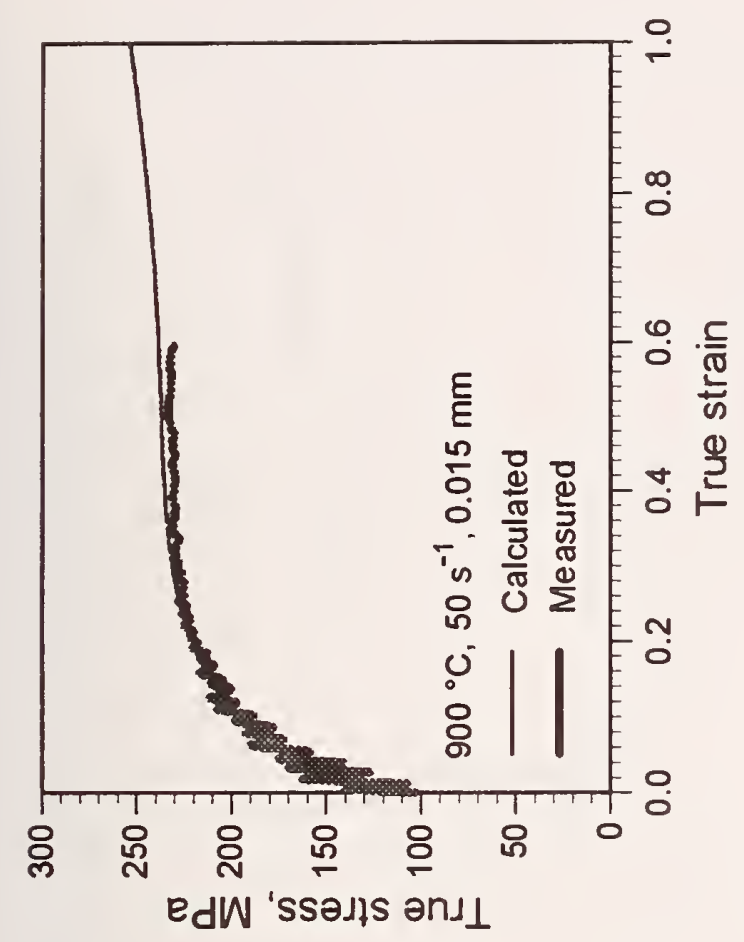

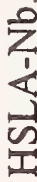
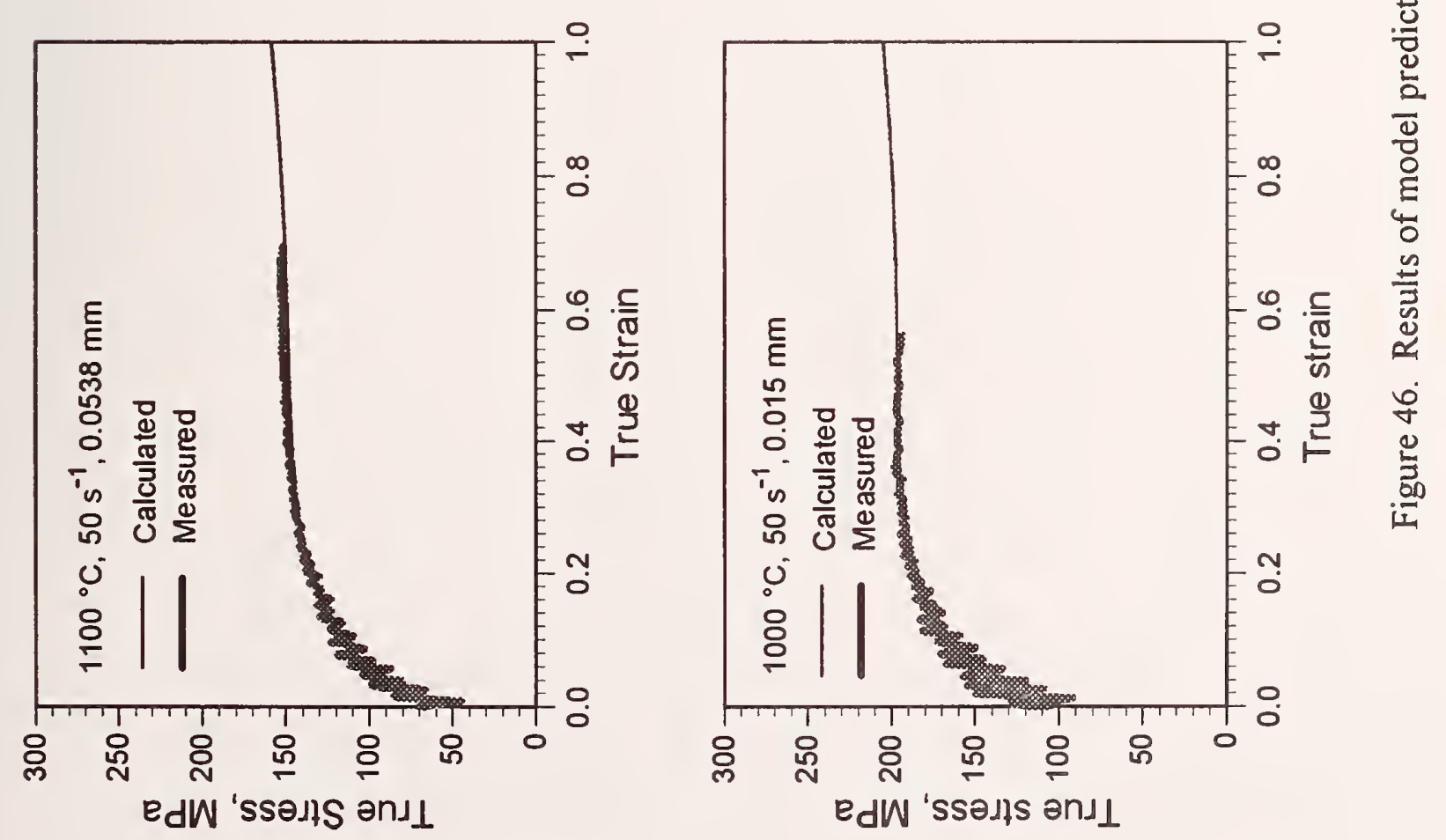

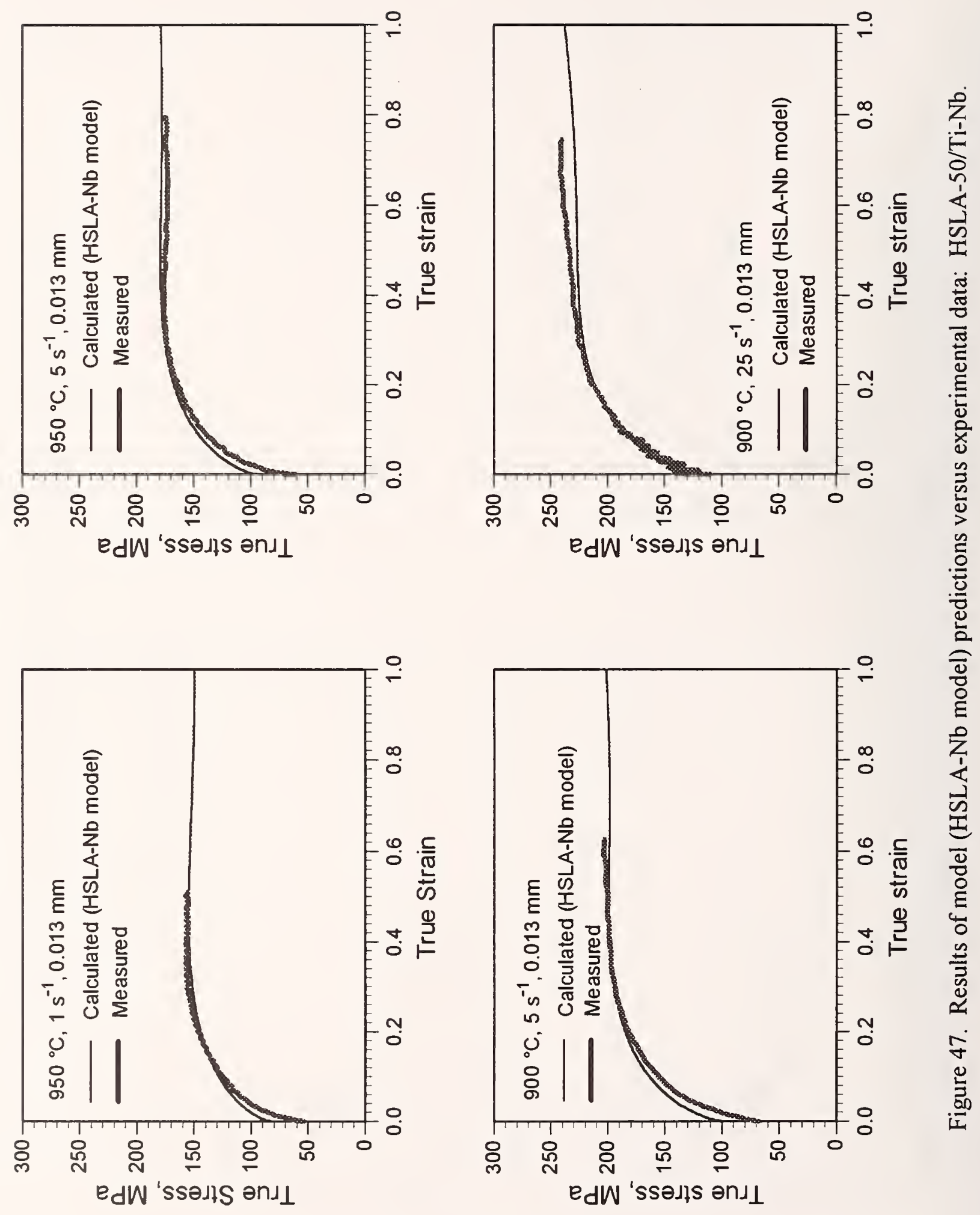

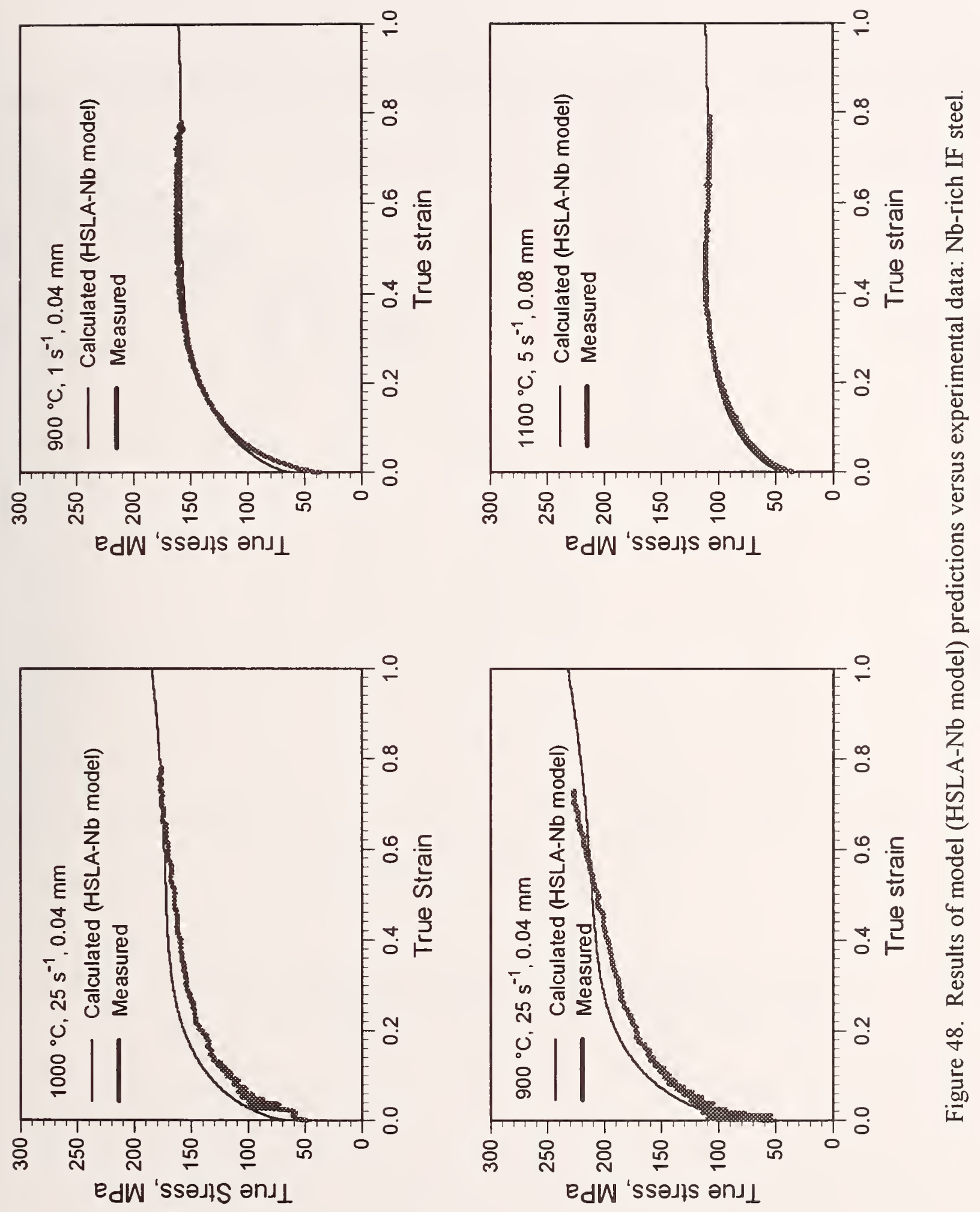
Soaking: $5^{\circ} \mathrm{C} / \mathrm{s}$ to $1200^{\circ} \mathrm{C}$ hold $15 \mathrm{~min}$; strain rate $=1 / \mathrm{s}$; strain $=q, 0.36,0.51,0.41,0.33,0.30,0.25,0.10$; interpass time $=10,8.0,4.8,3.2,2.3,1.7,1.3 \mathrm{~s}$; target temperature $=1100,1041,979,955,934,919,908,898^{\circ} \mathrm{C}$.

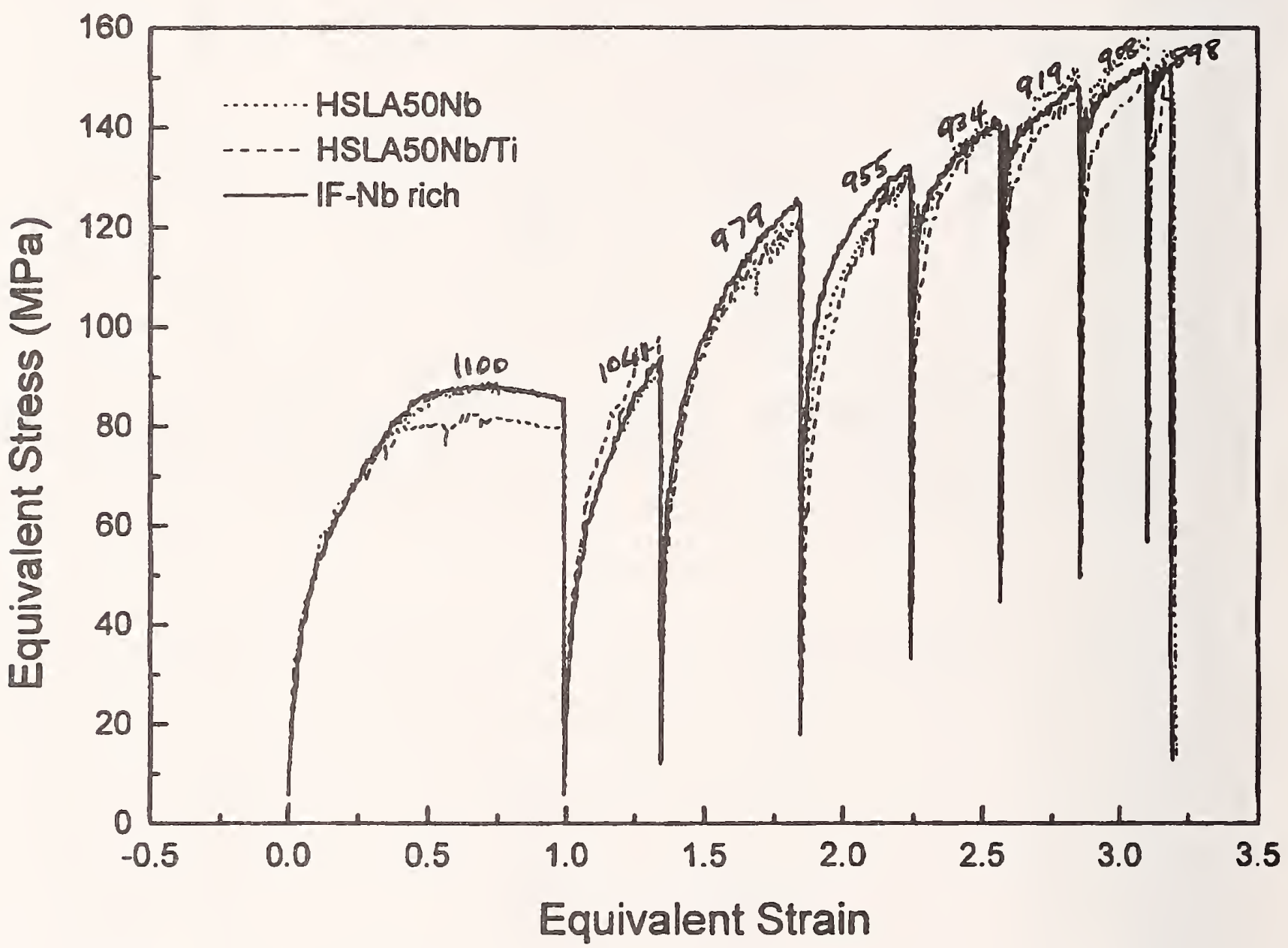

Figure 49. Torsion test results which show similar flow behavior between the $\mathrm{Nb}$-rich IF steel and the HSLA-Nb grades. 

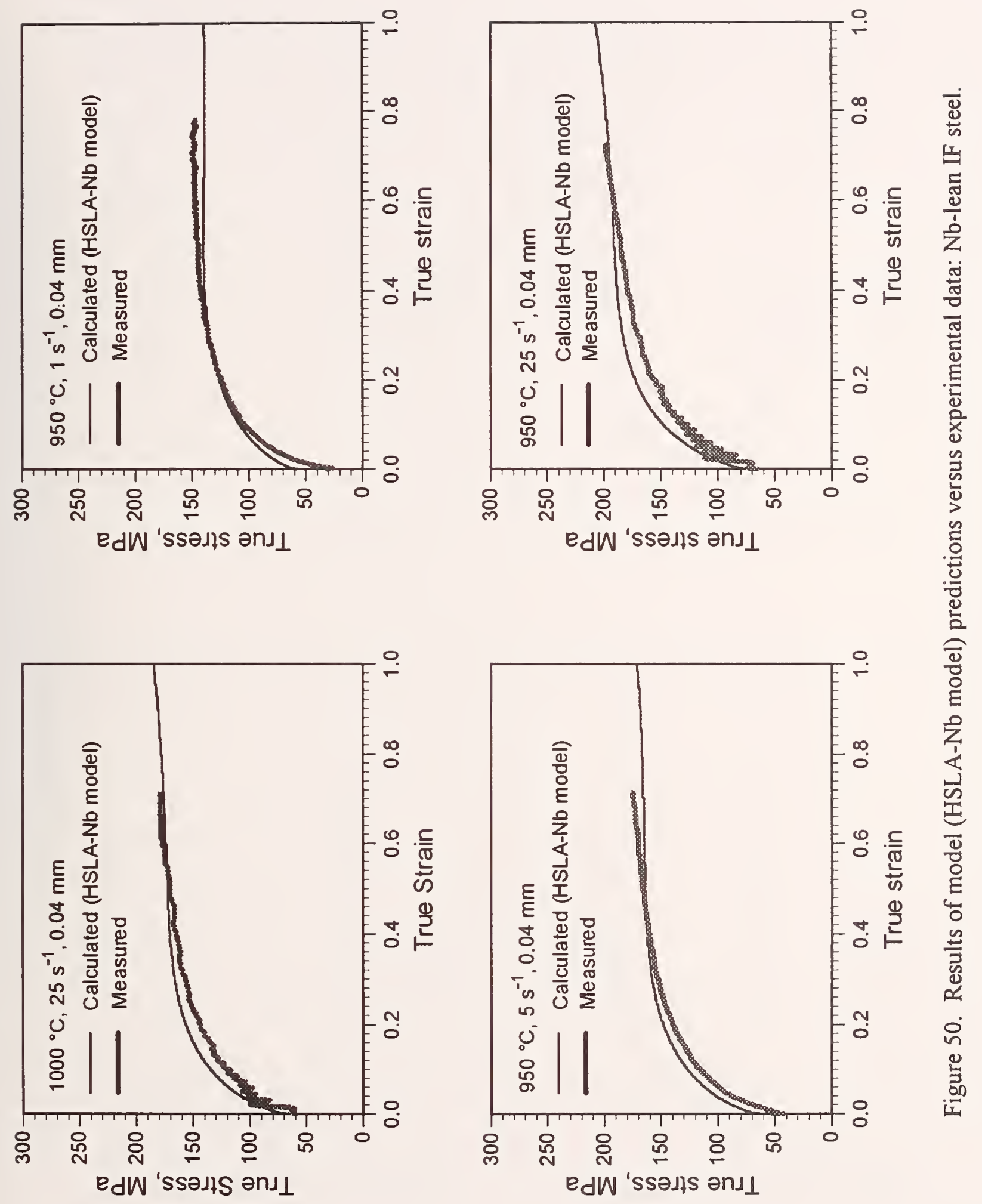

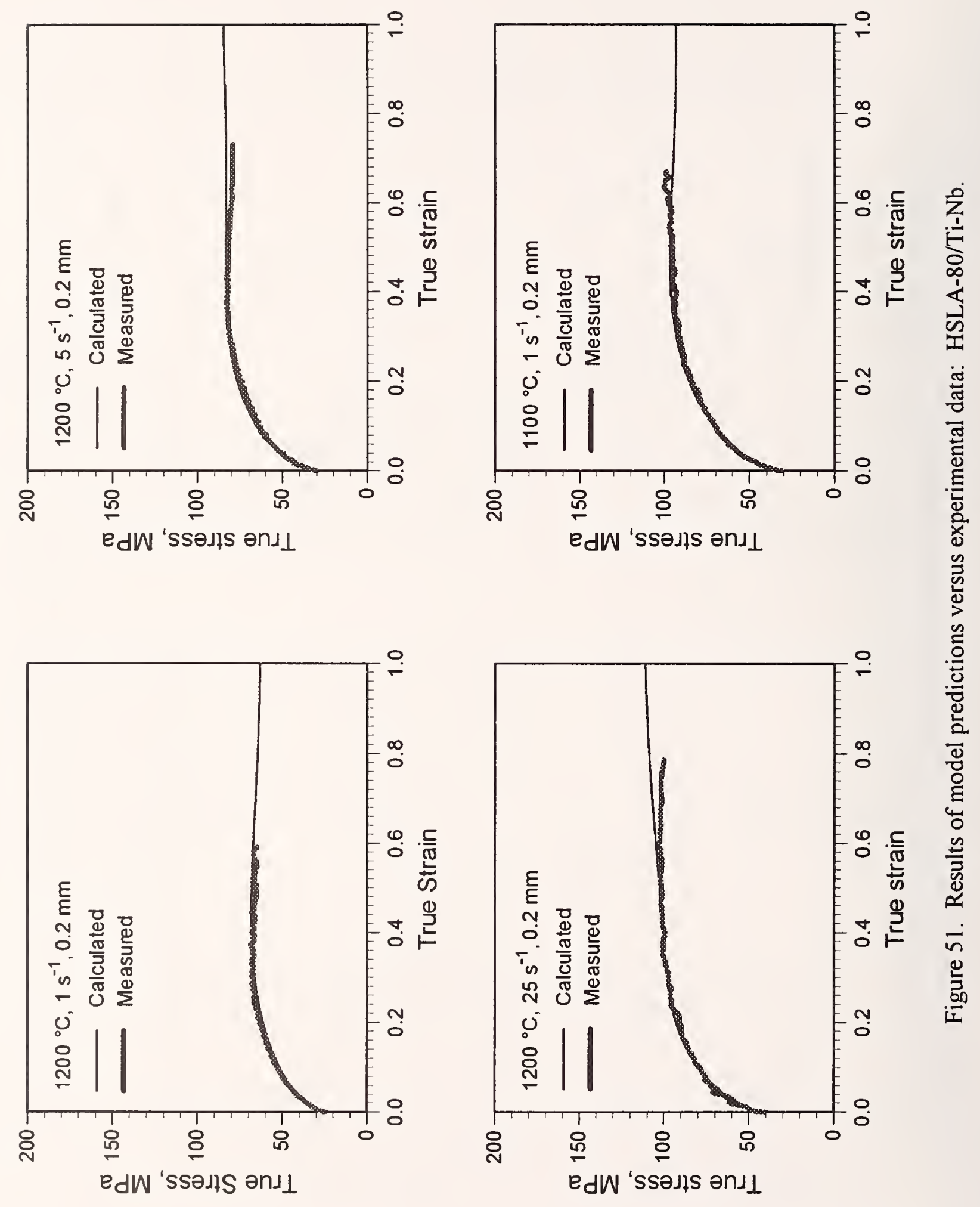

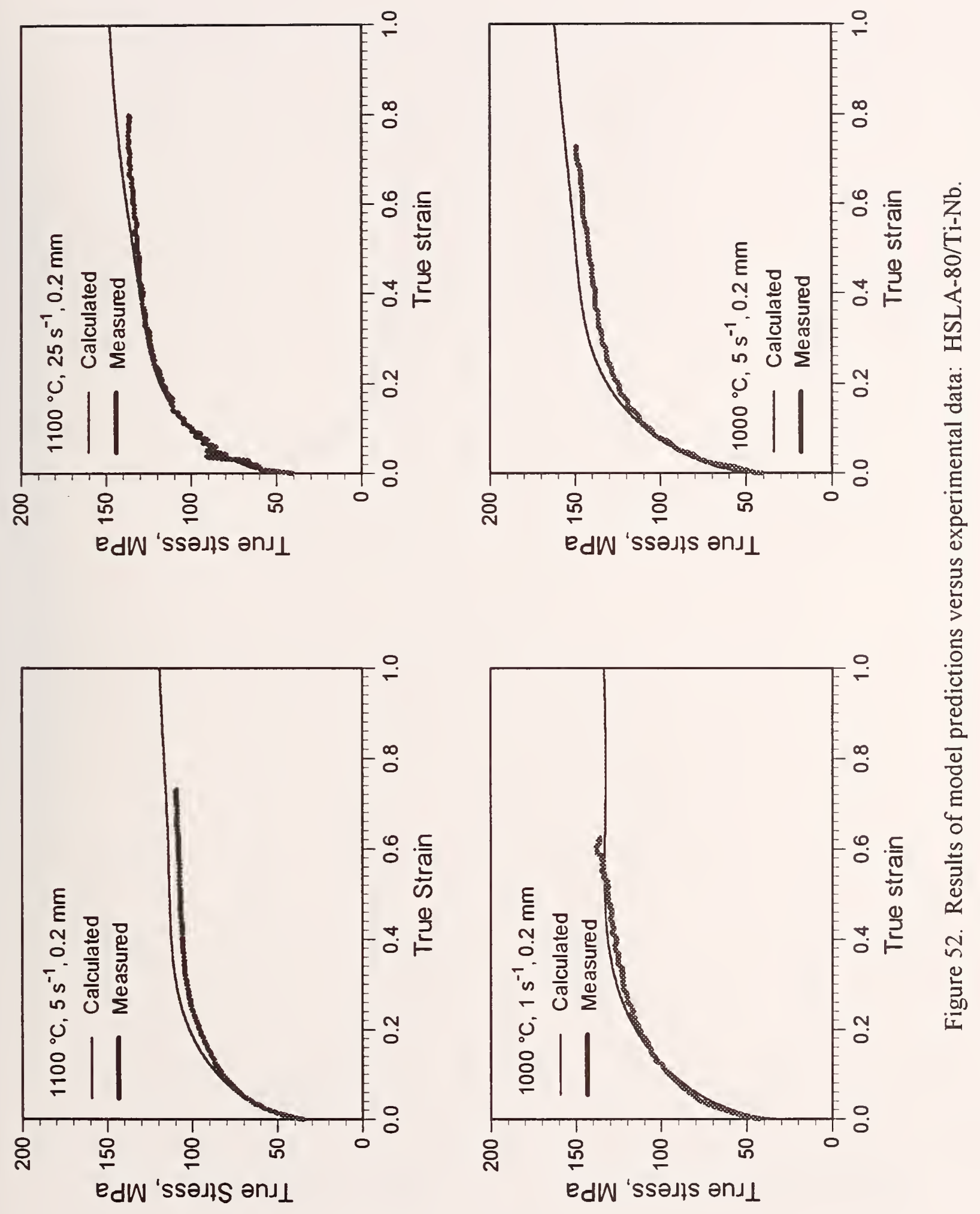

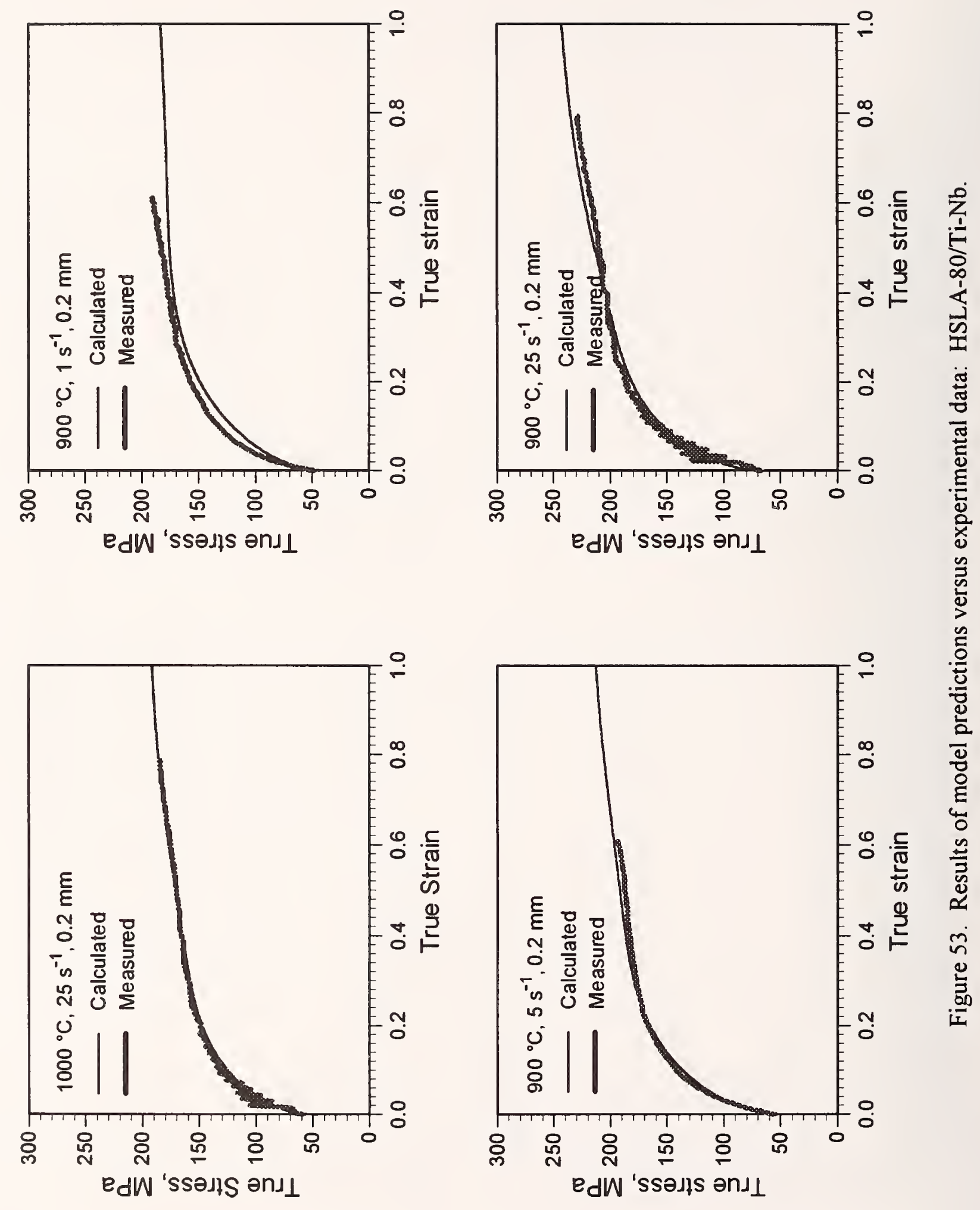

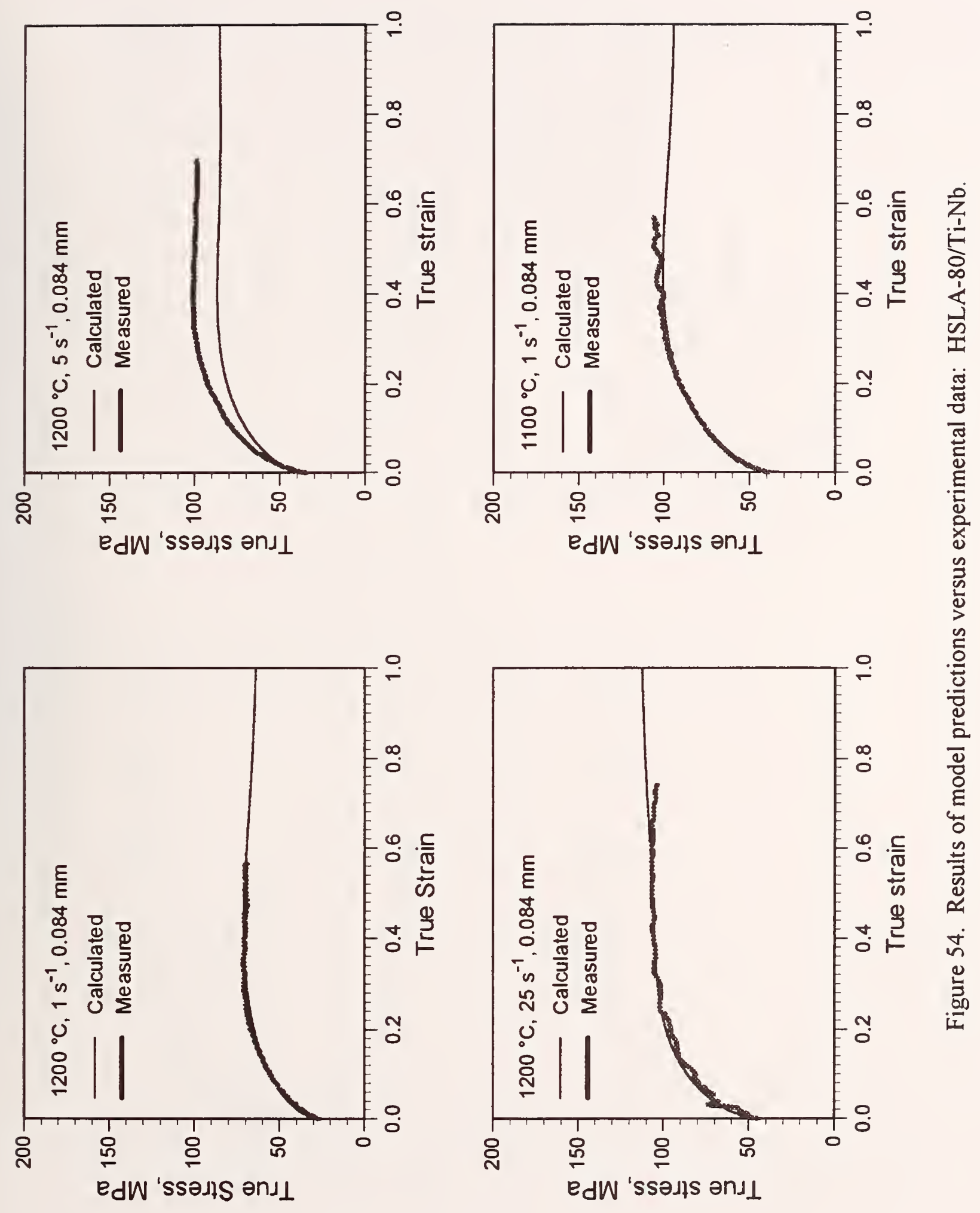

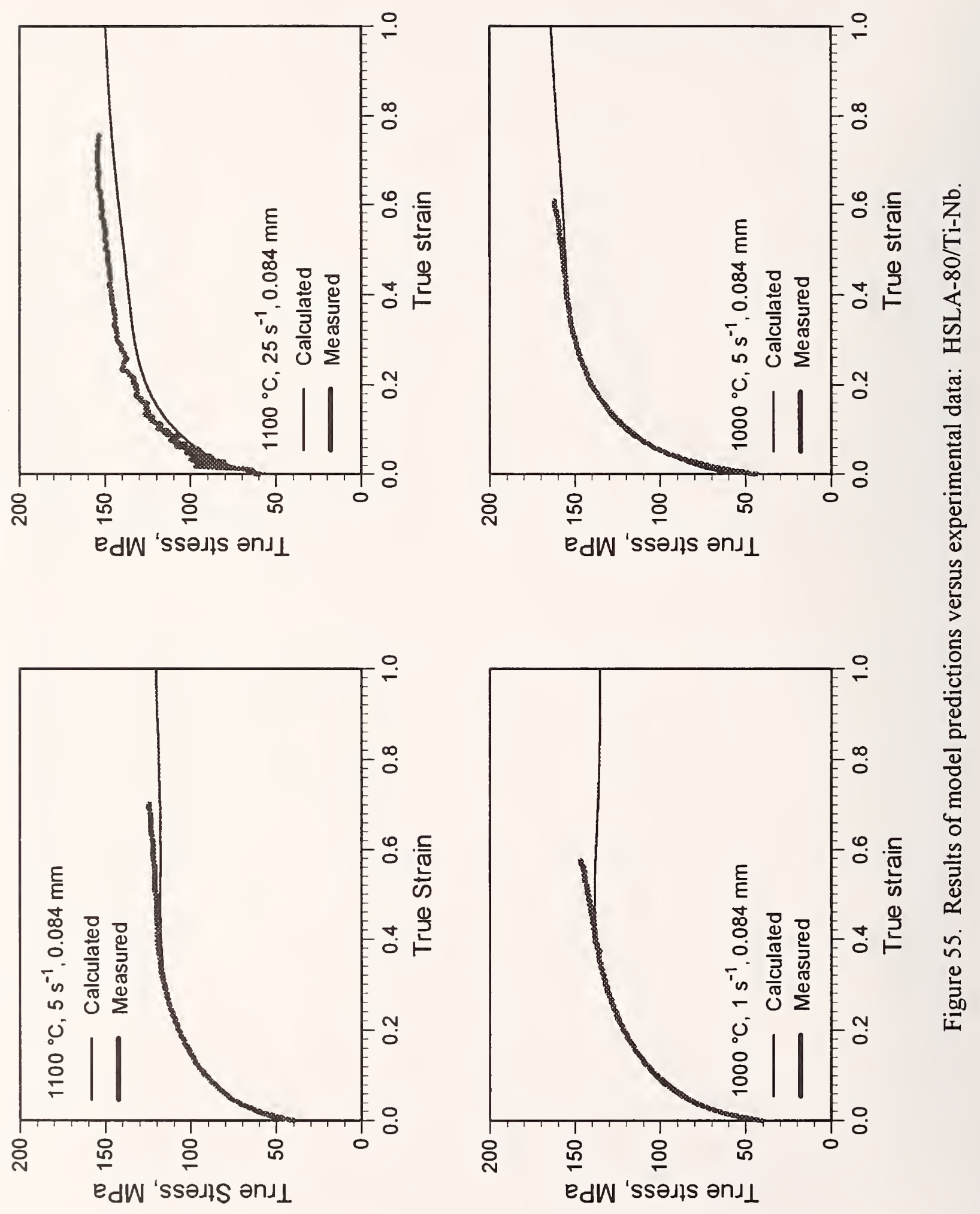

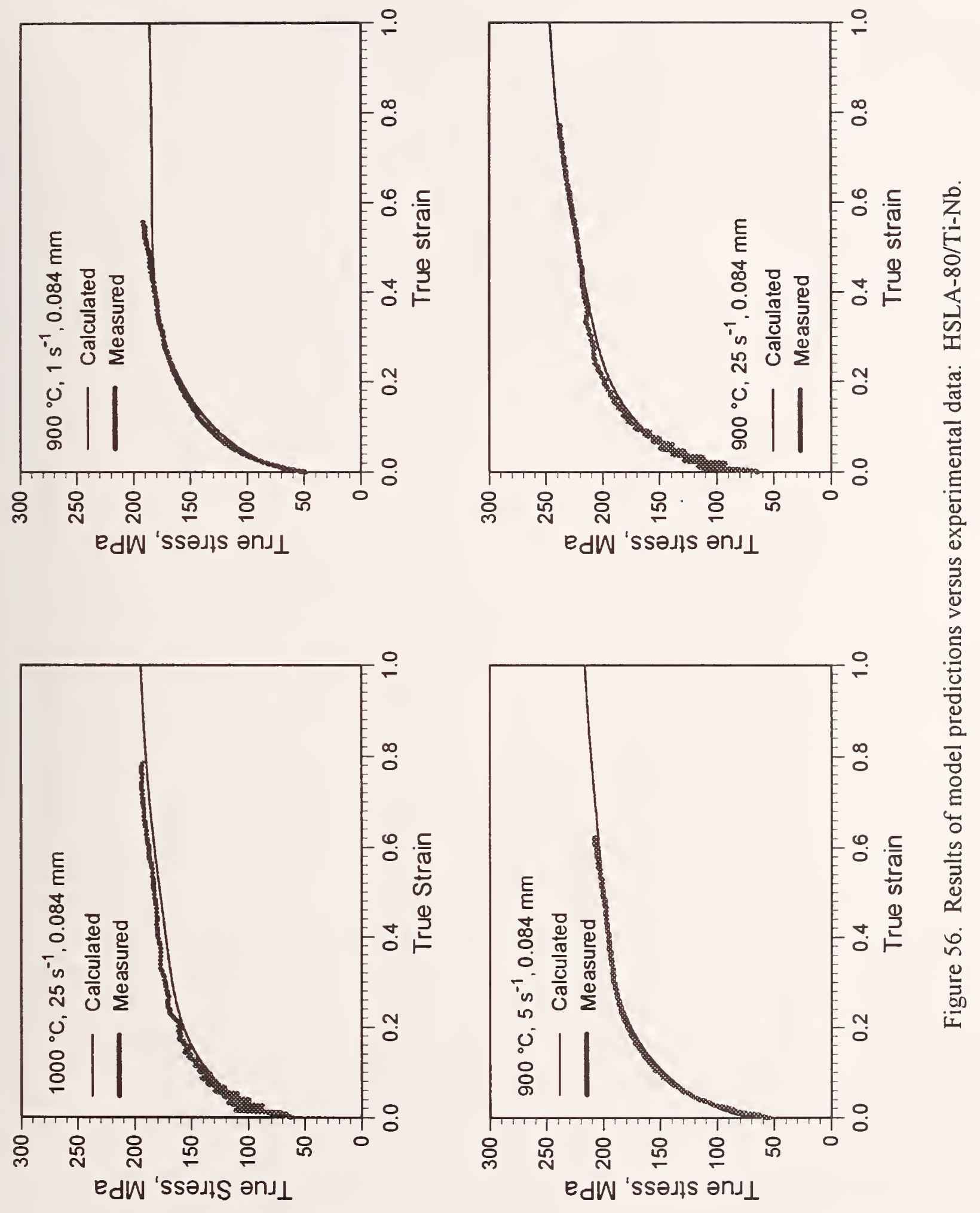

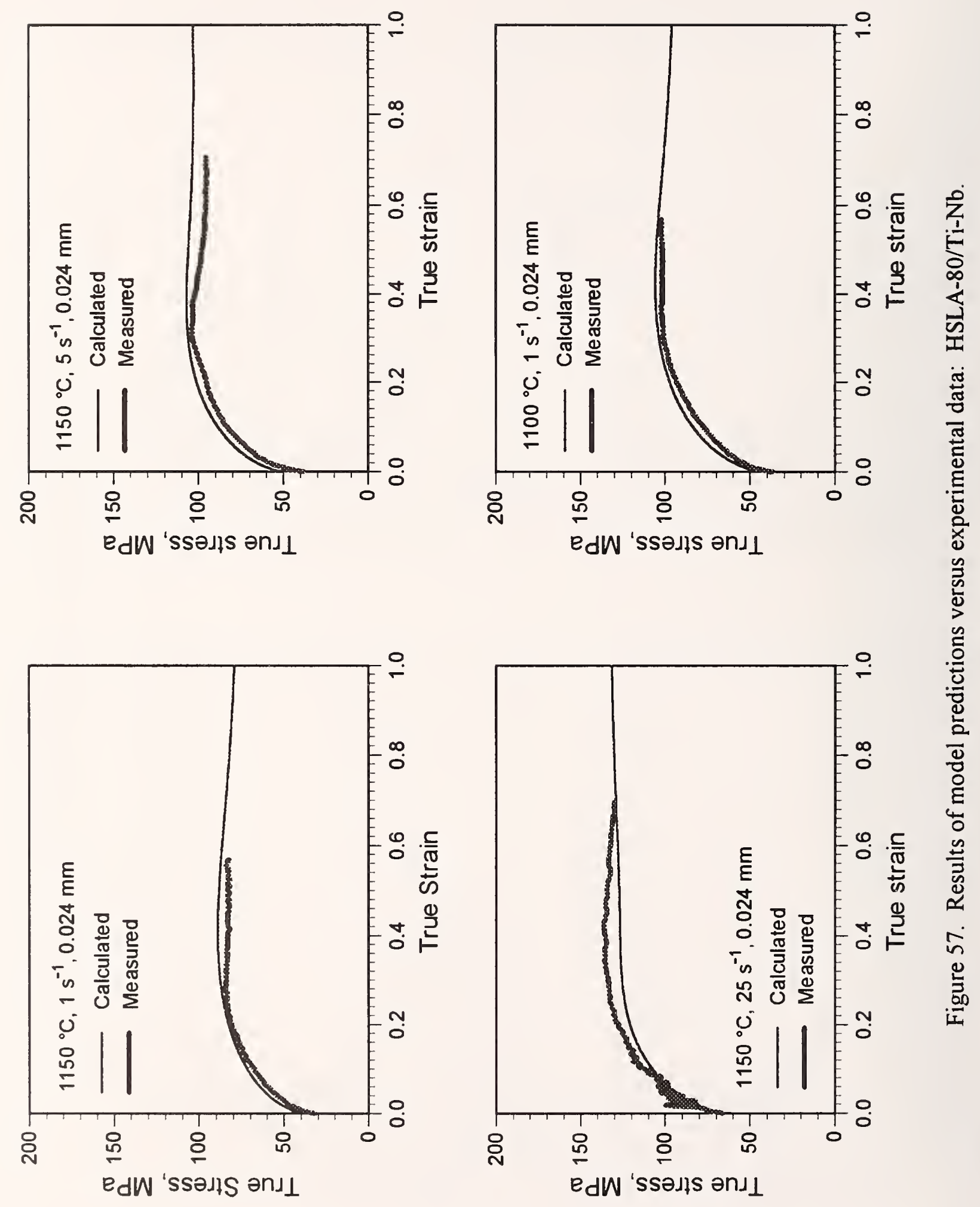

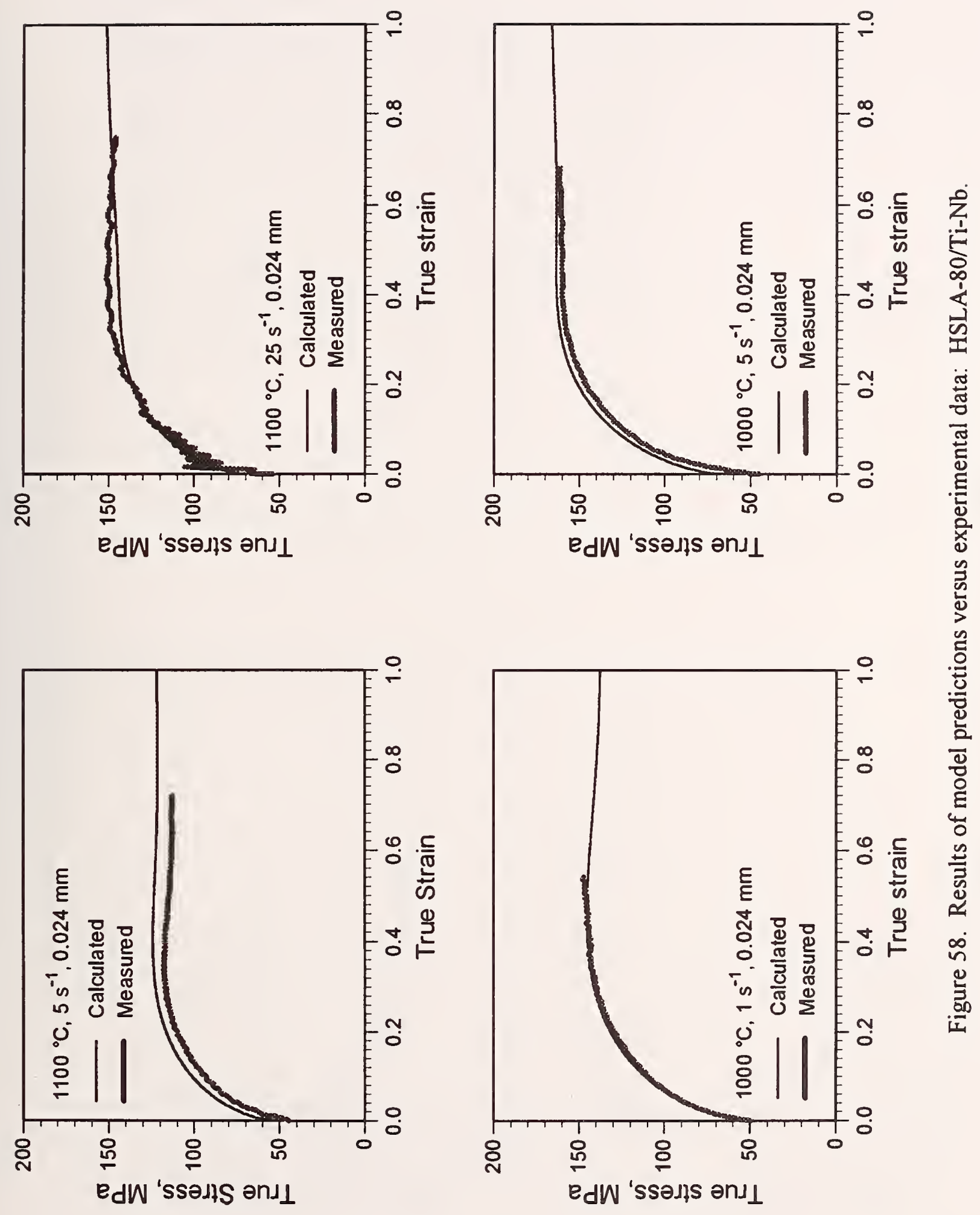

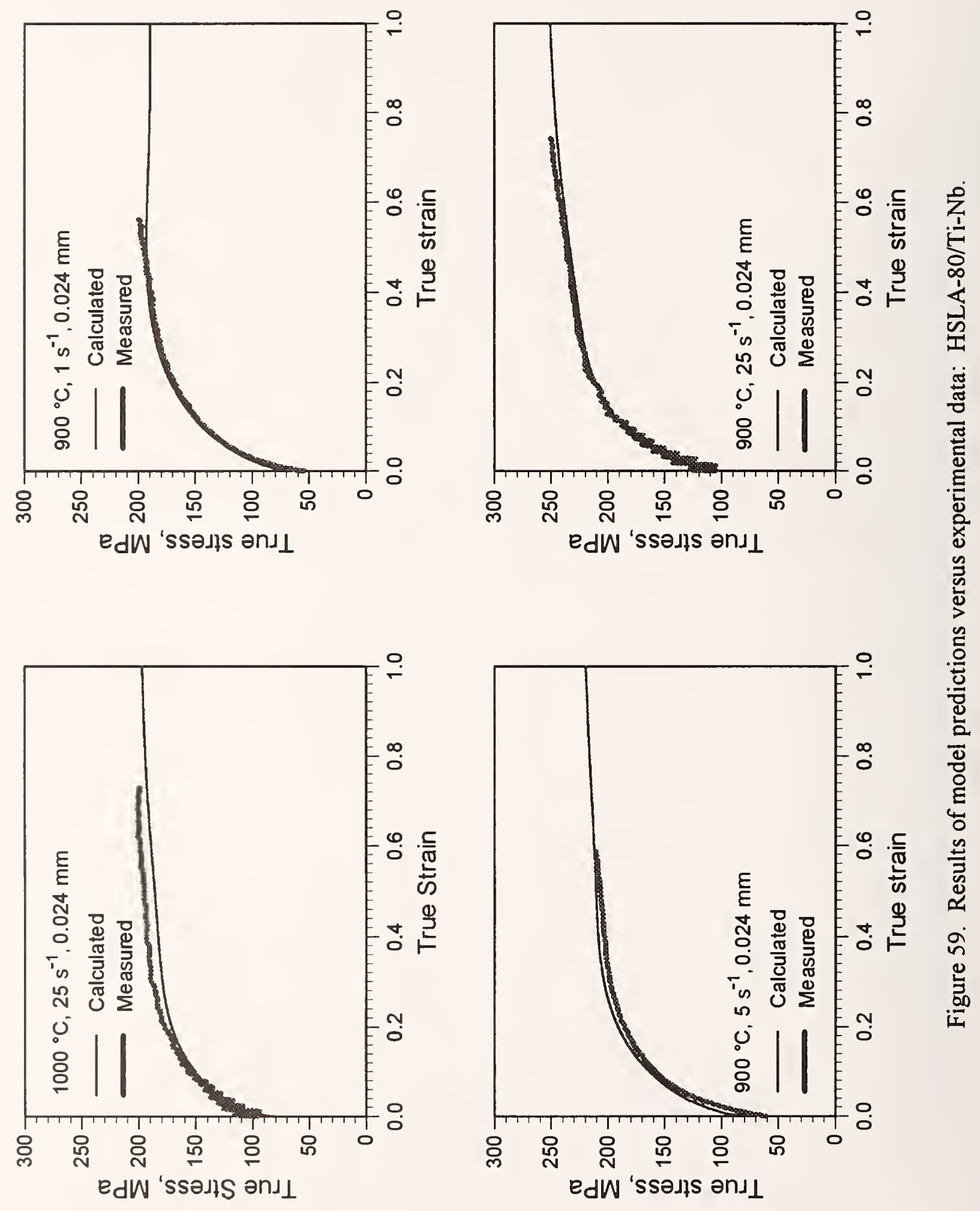

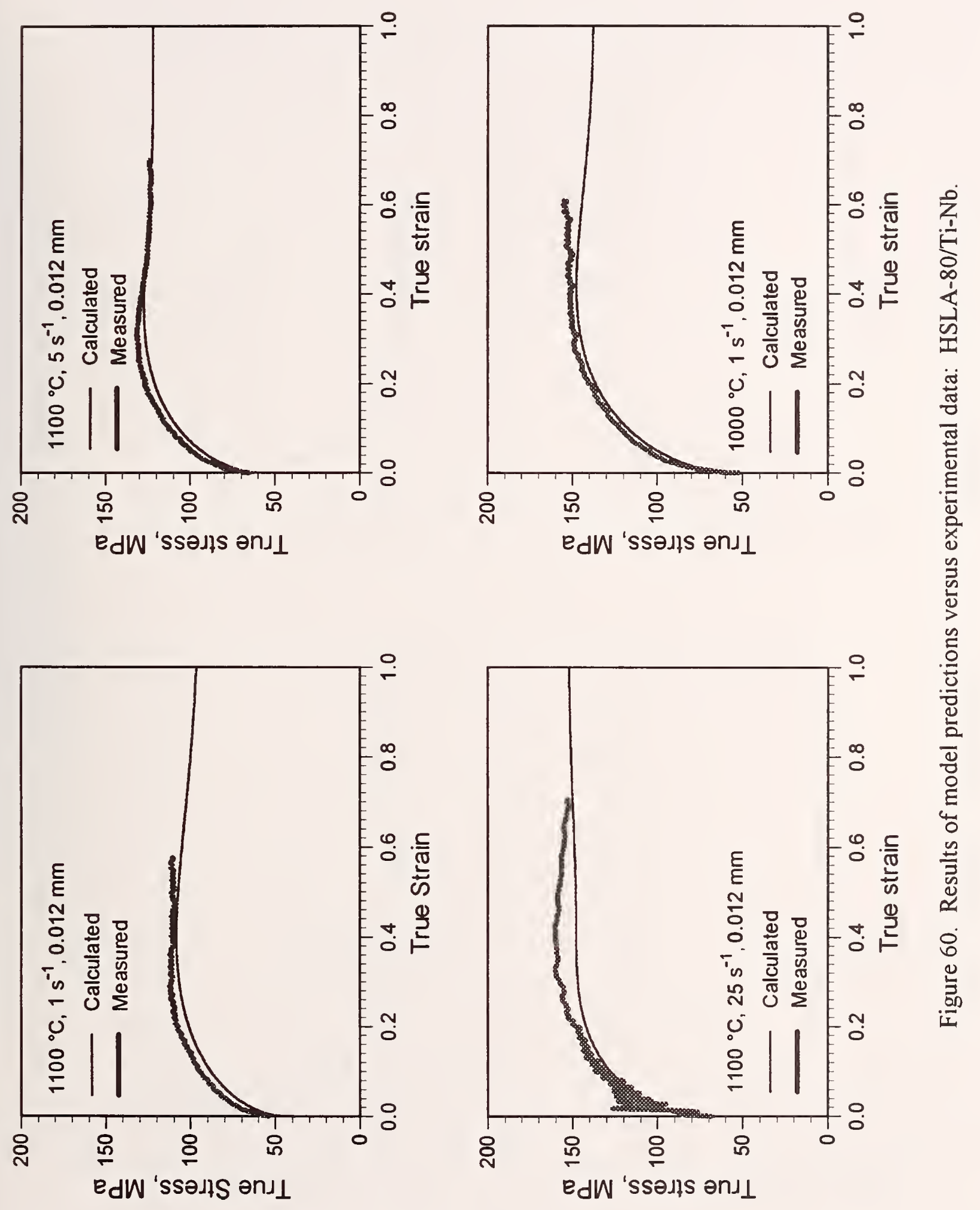

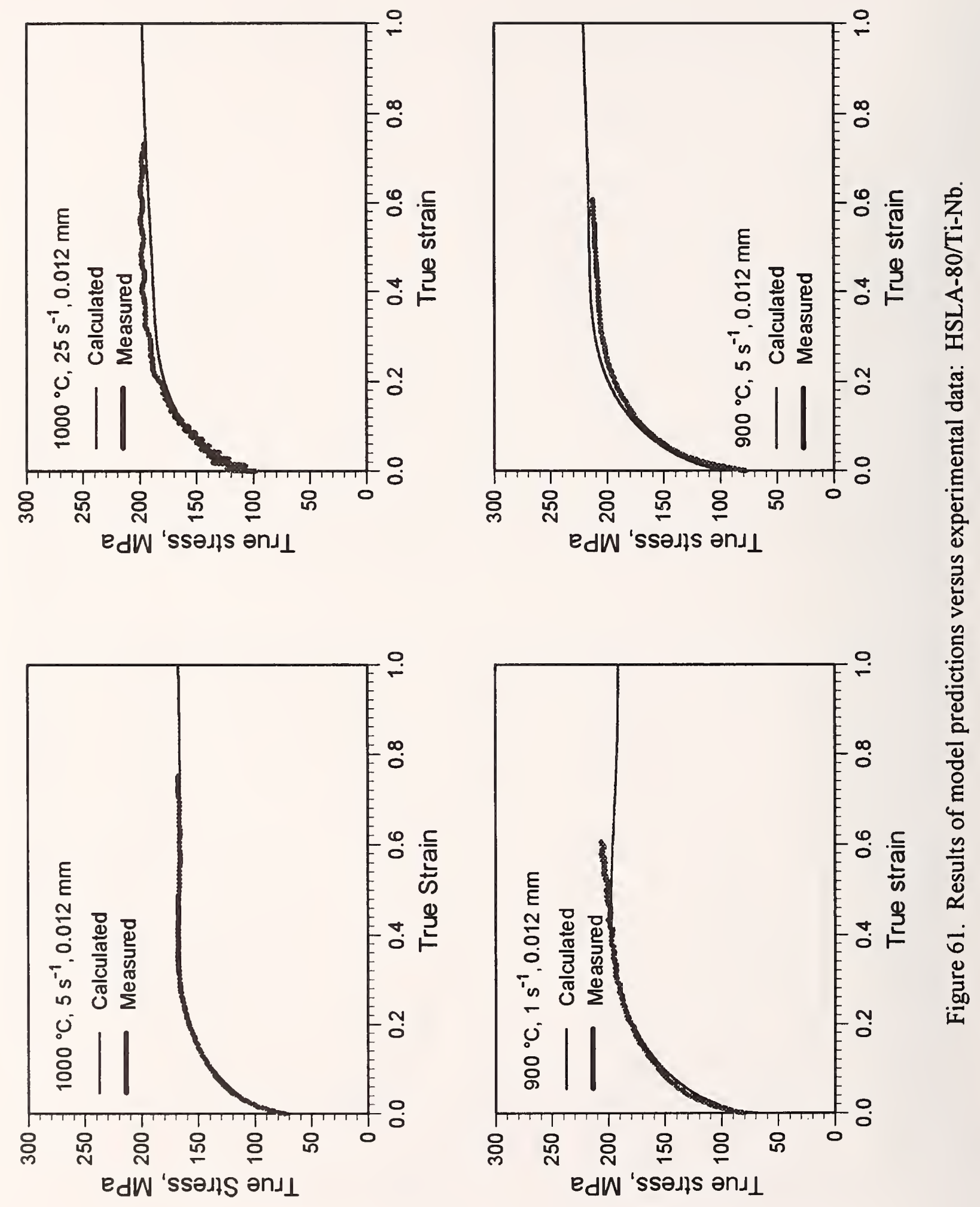


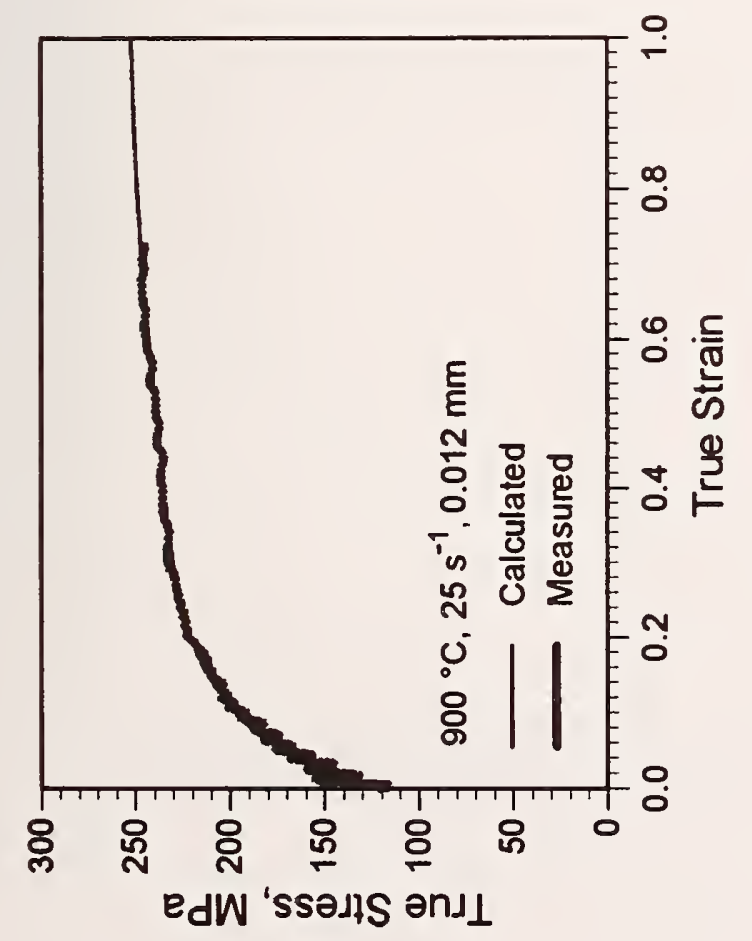

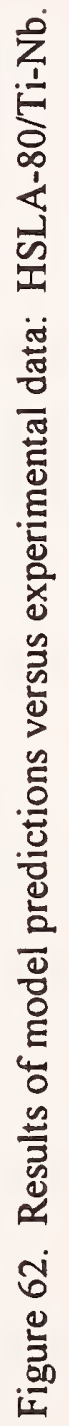



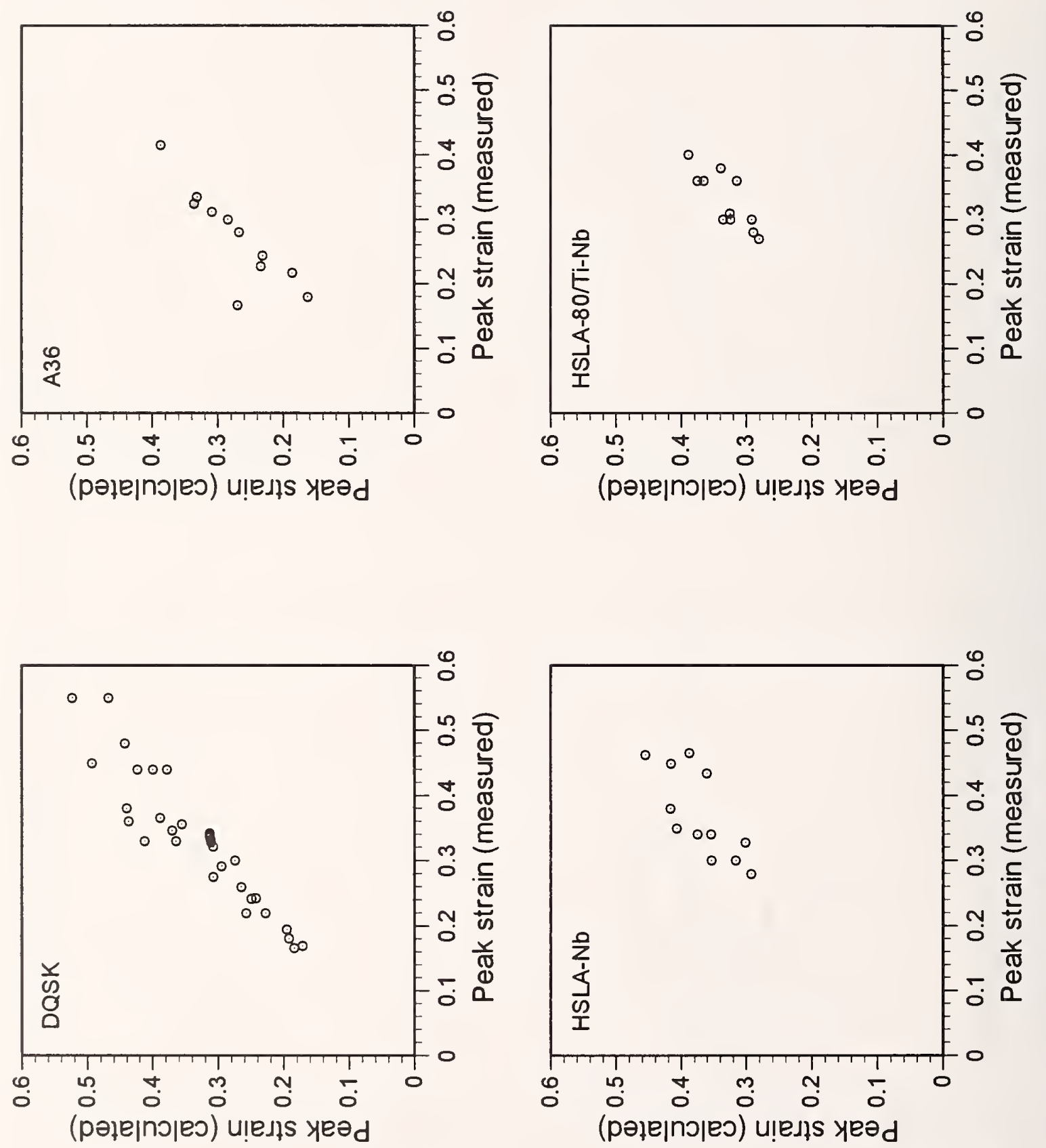

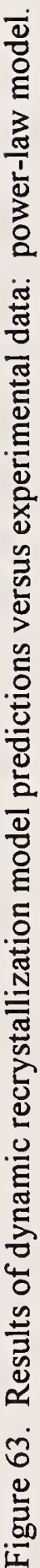



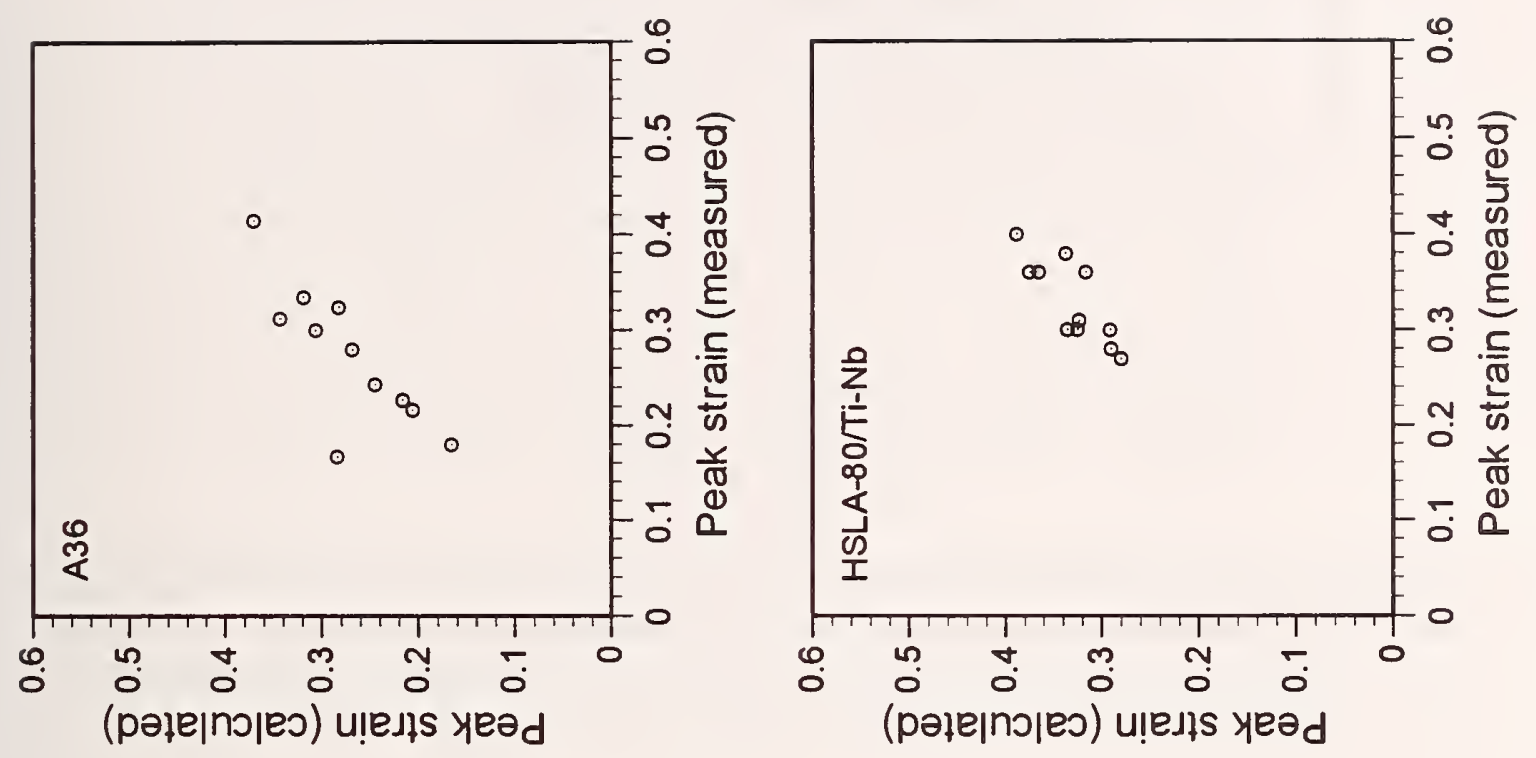

政

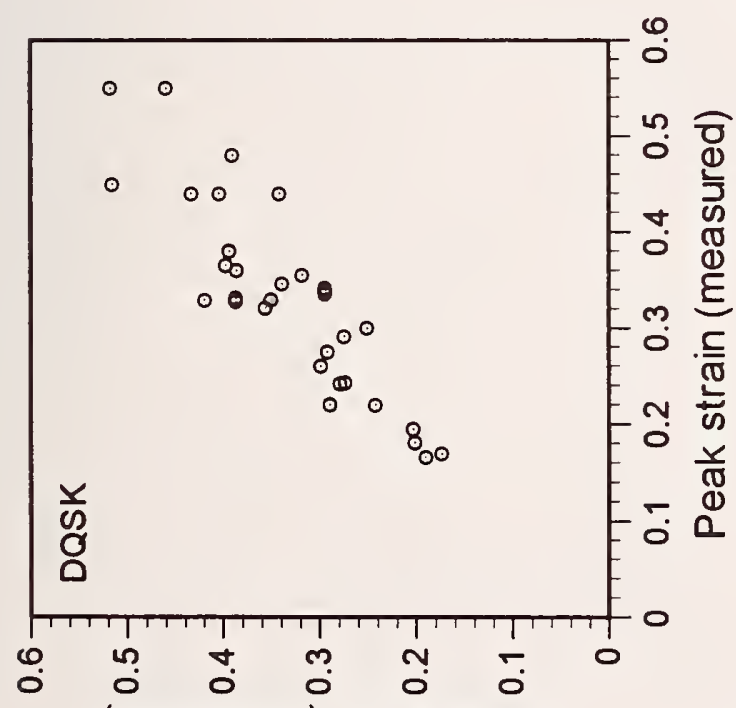

(pәןеןnગеэ) ulejs yeәd

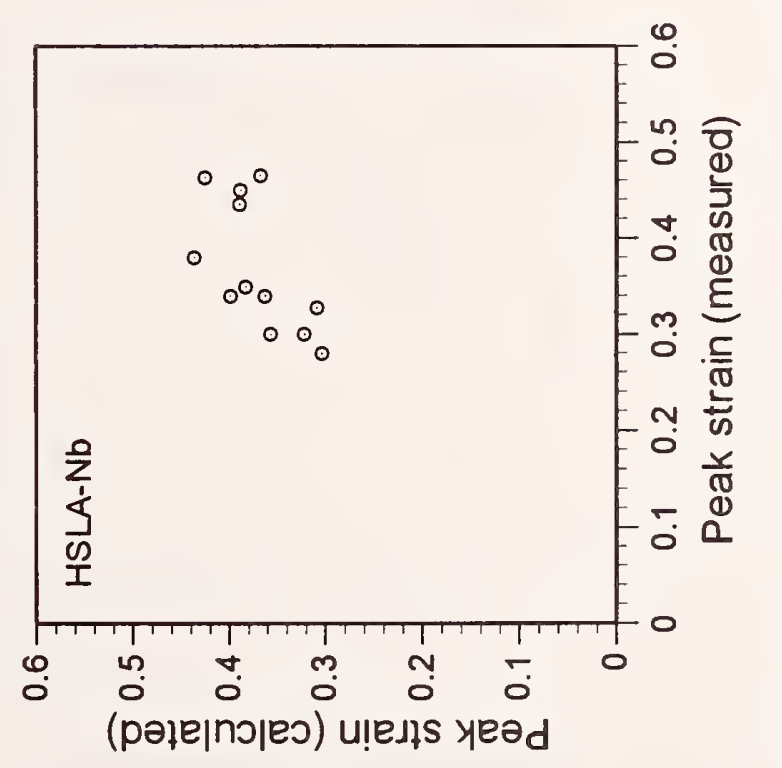

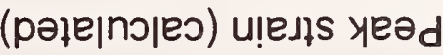




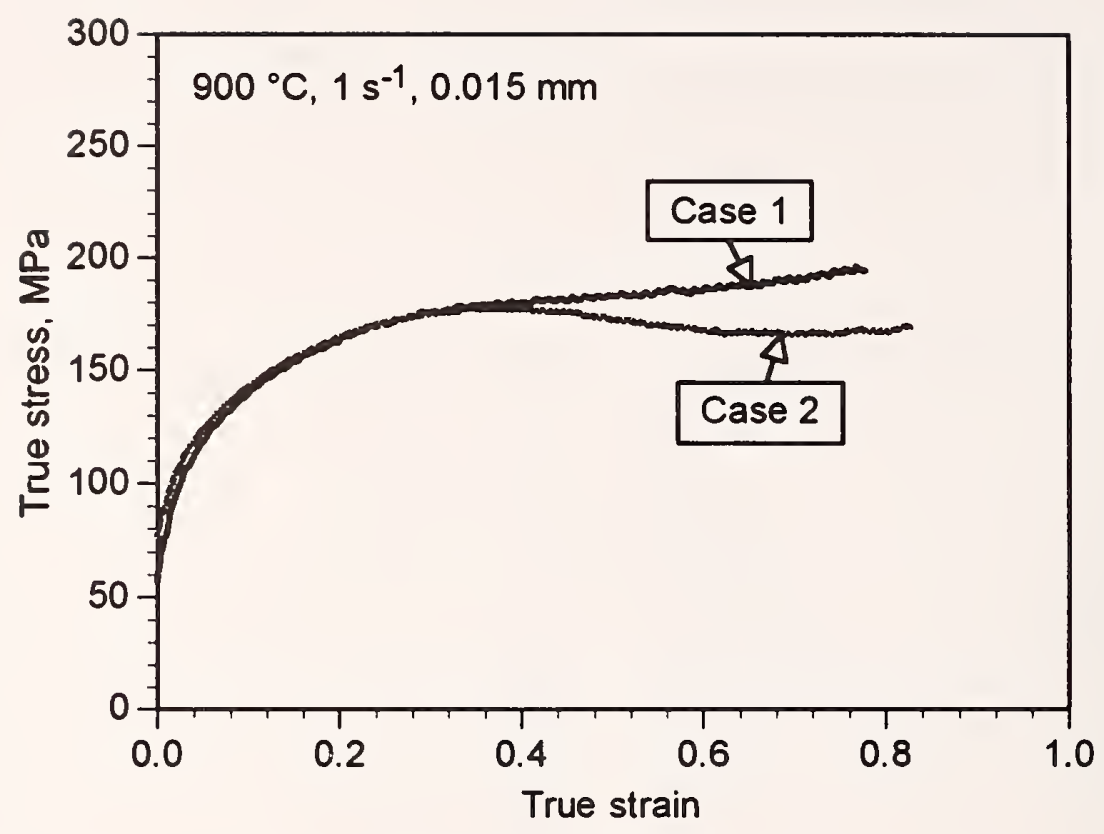

Figure 65. Effect of prior heat treatment on flow behavior: HSLA-Nb. There is no discernible differences in the flow behavior below strain of 0.4 between the two cases. Above 0.4, the behavior of Case 2 shows dynamic recrystallization while Case 1 shows continuous hardening. Case 1: with prior heat treatment; Case 2: without prior heat treatment.

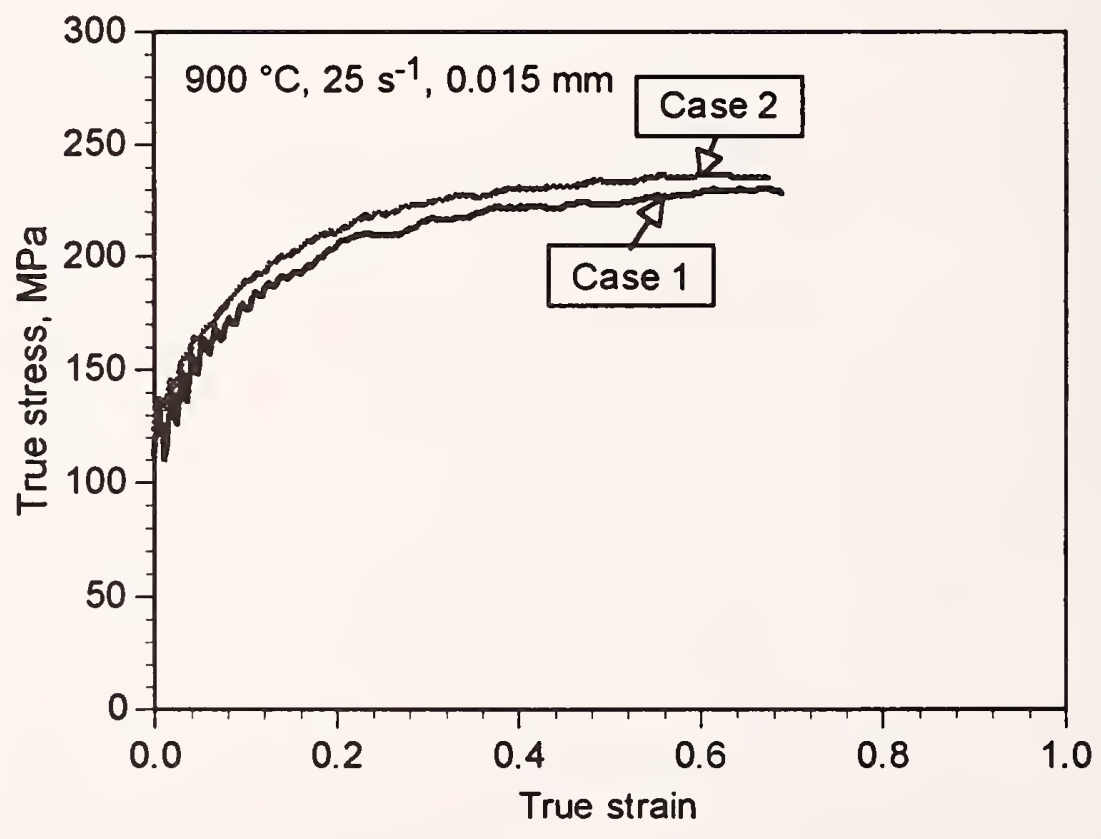

Figure 66. Effect of prior heat treatment on flow behavior: HSLA-Nb. The differences in the two cases are within the scattering band of experimental data. Case 1: with prior heat treatment; Case 2: without prior heat treatment. 


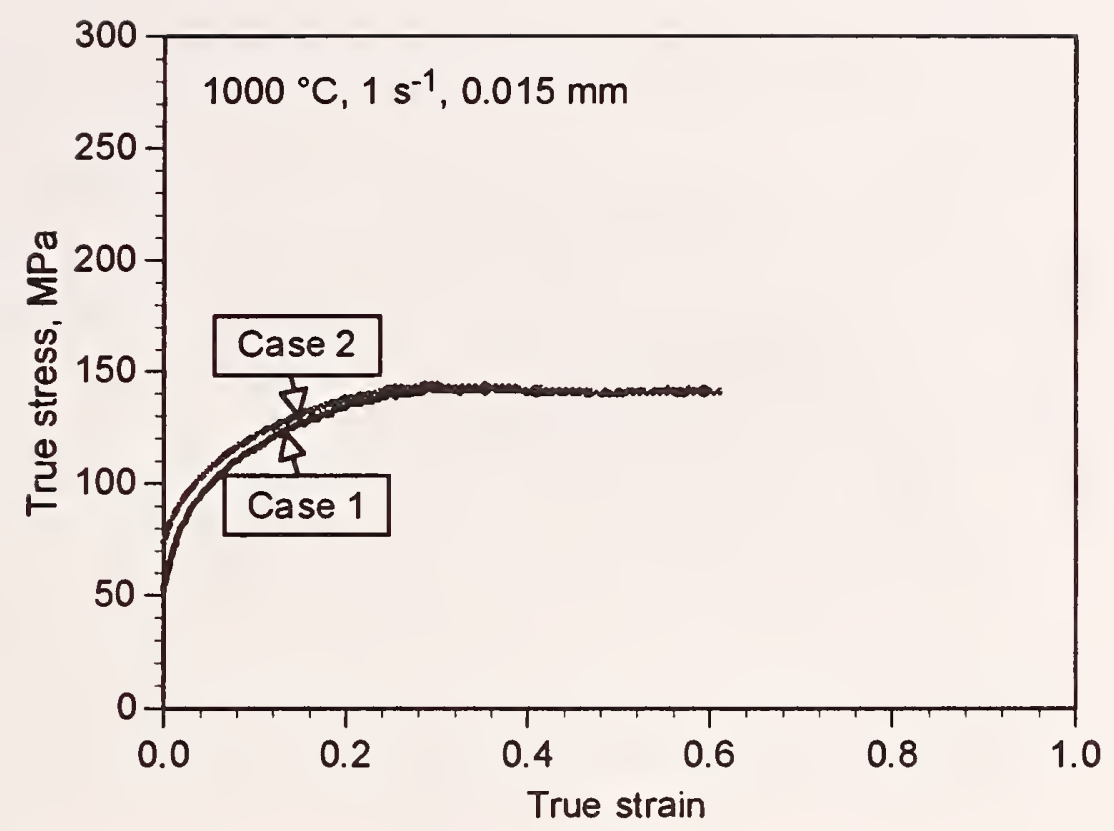

Figure 67. Effect of prior heat treatment on flow behavior: HSLA-Nb. The differences in the two cases are within the scattering band of experimental data. Case 1: with prior heat treatment; Case 2: without prior heat treatment.

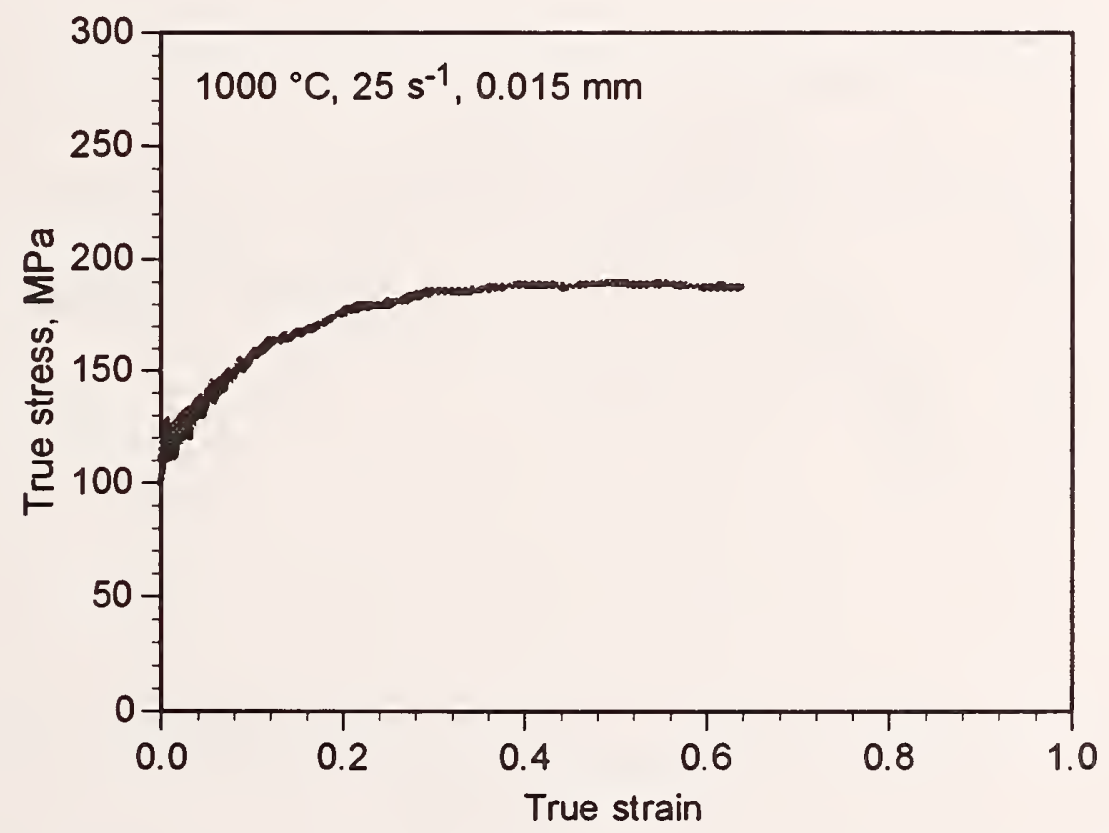

Figure 68. Effect of prior heat treatment on flow behavior: HSLA-Nb. There is no difference between the two cases. 


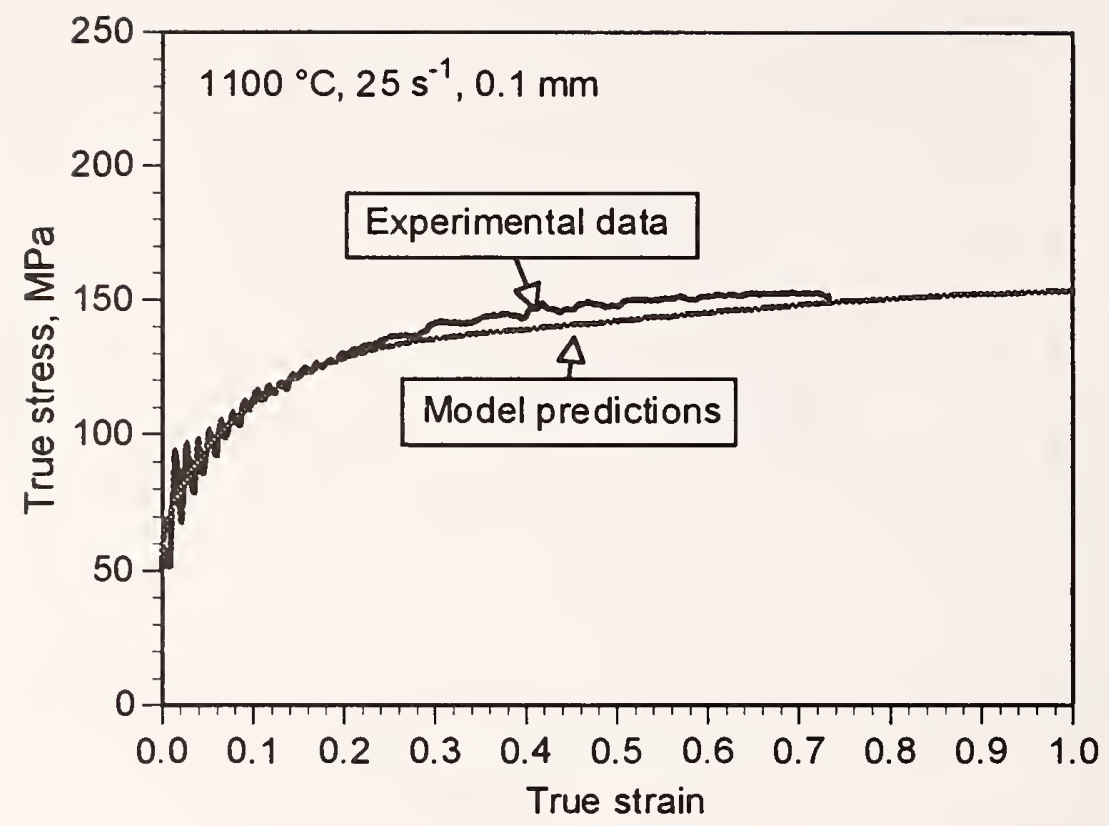

Figure 69. Effect of reheating temperature on flow behavior: HSLA-80. The differences between the experimental data and model predictions are insignificant.

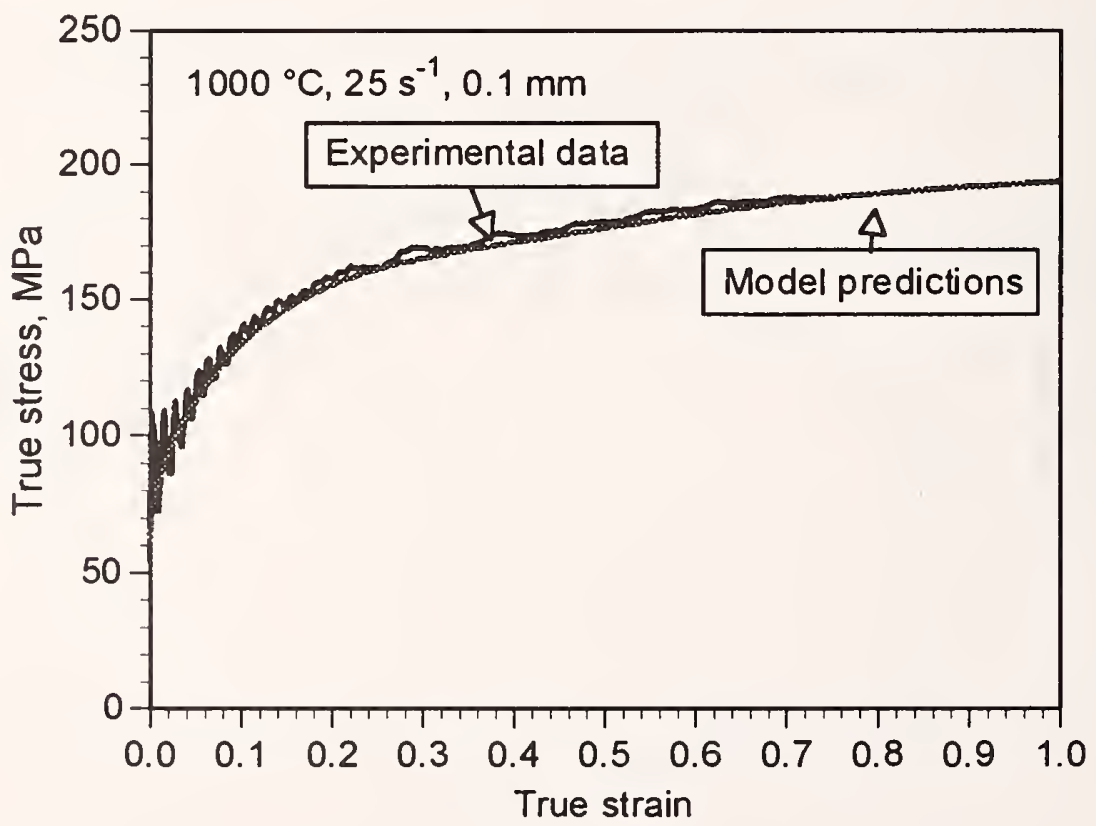

Figure 70. Effect of reheating temperature on flow behavior: HSLA-80. There is no significant difference between the experimental data and model predictions. 


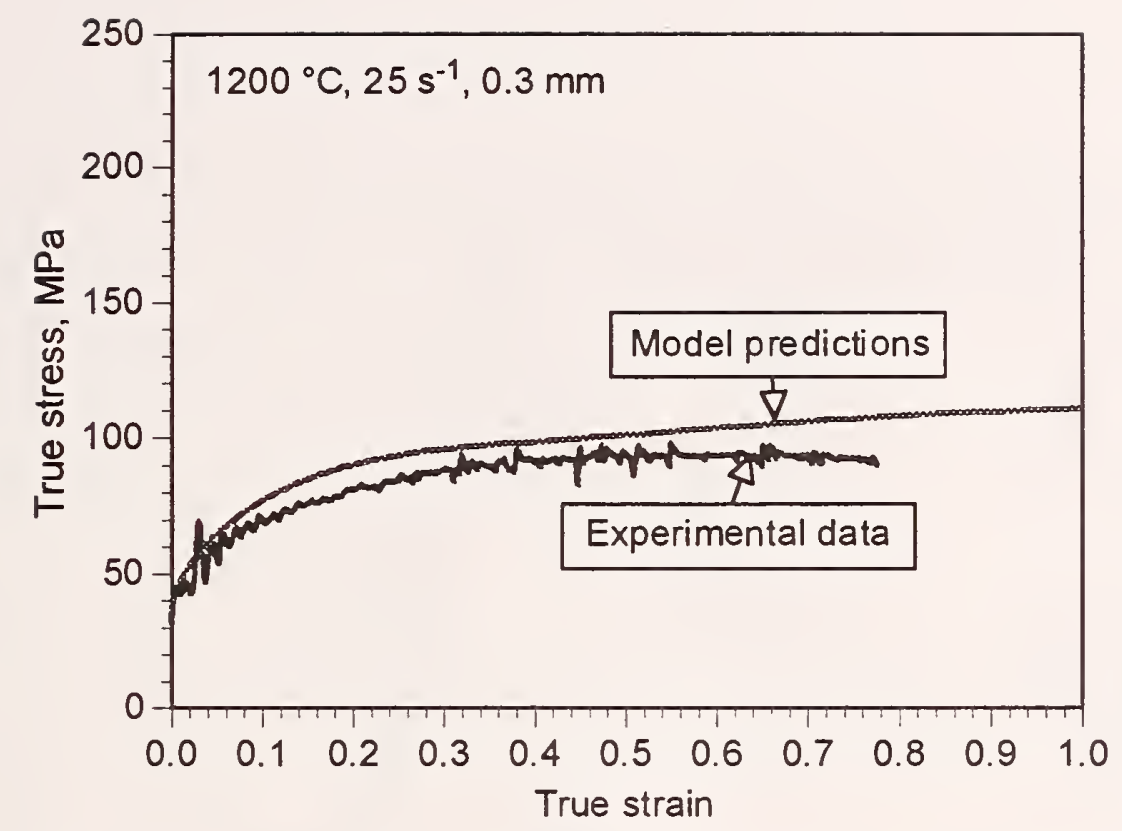

Figure 71. Effect of reheating temperature on flow behavior: HSLA-80. Experimental data are about $9 \%$ lower than the model predictions.

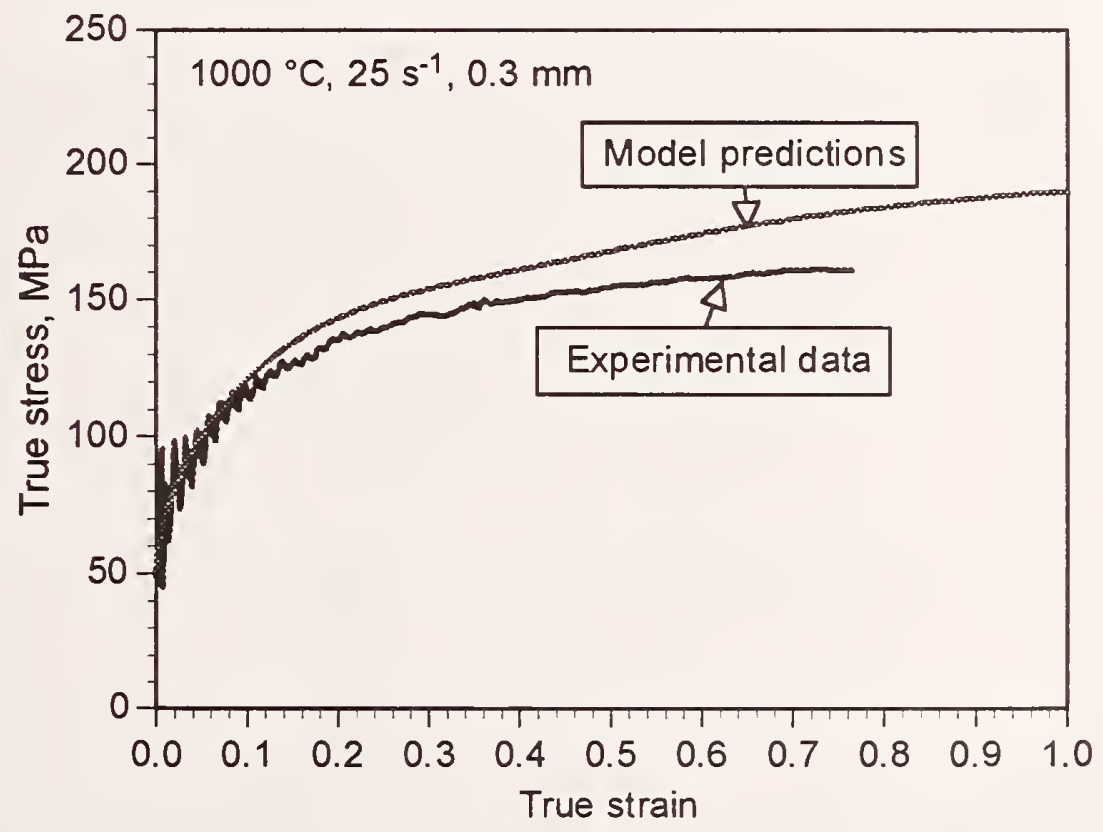

Figure 72. Effect of reheating temperature on flow behavior: HSLA-80. Experimental data are about $9 \%$ lower than the model predictions. 

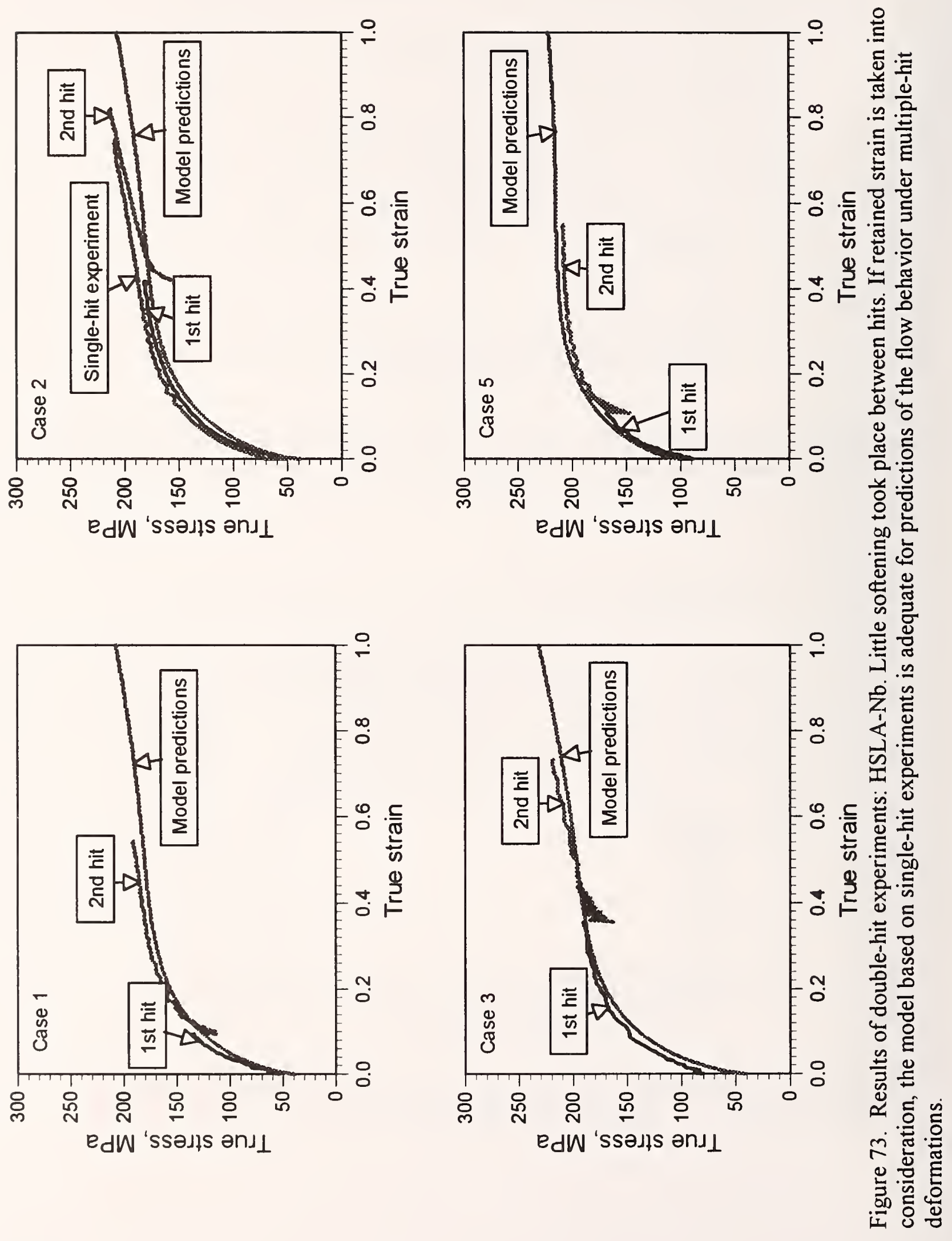


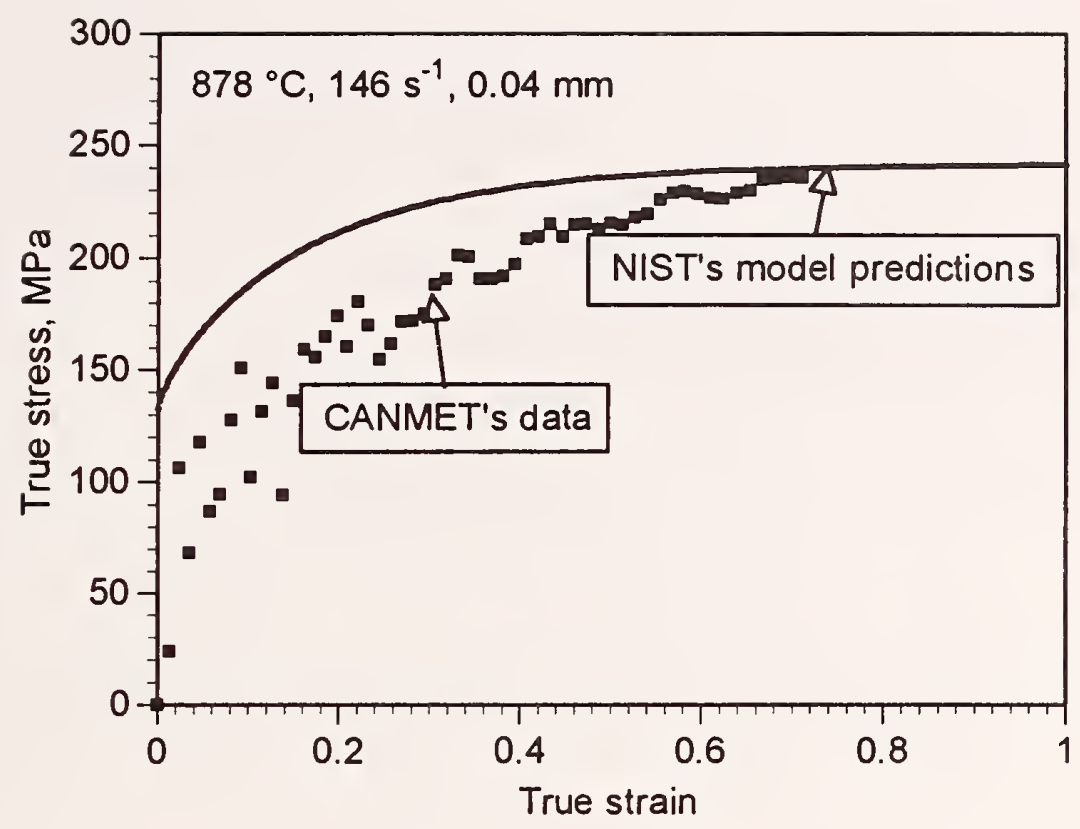

(a)

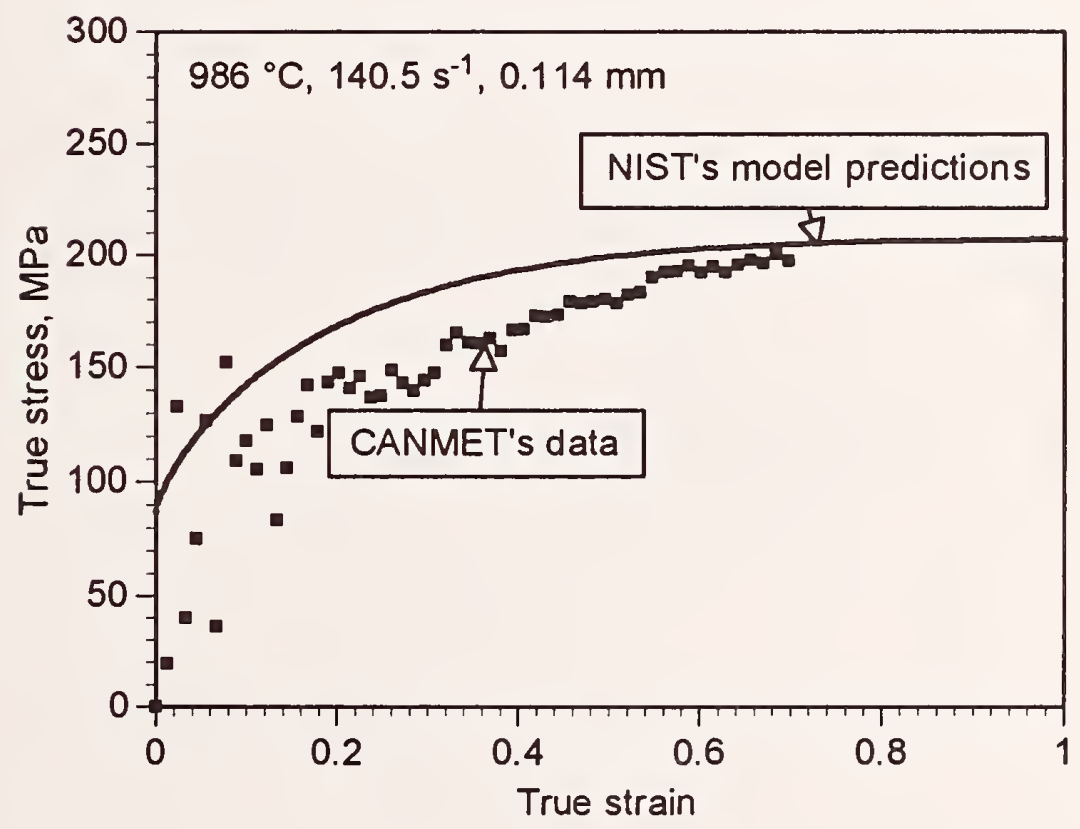

(b)

Figure 74. Examples of comparison between CANMET's high strain-rate results and NIST's model predictions: DQSK. 


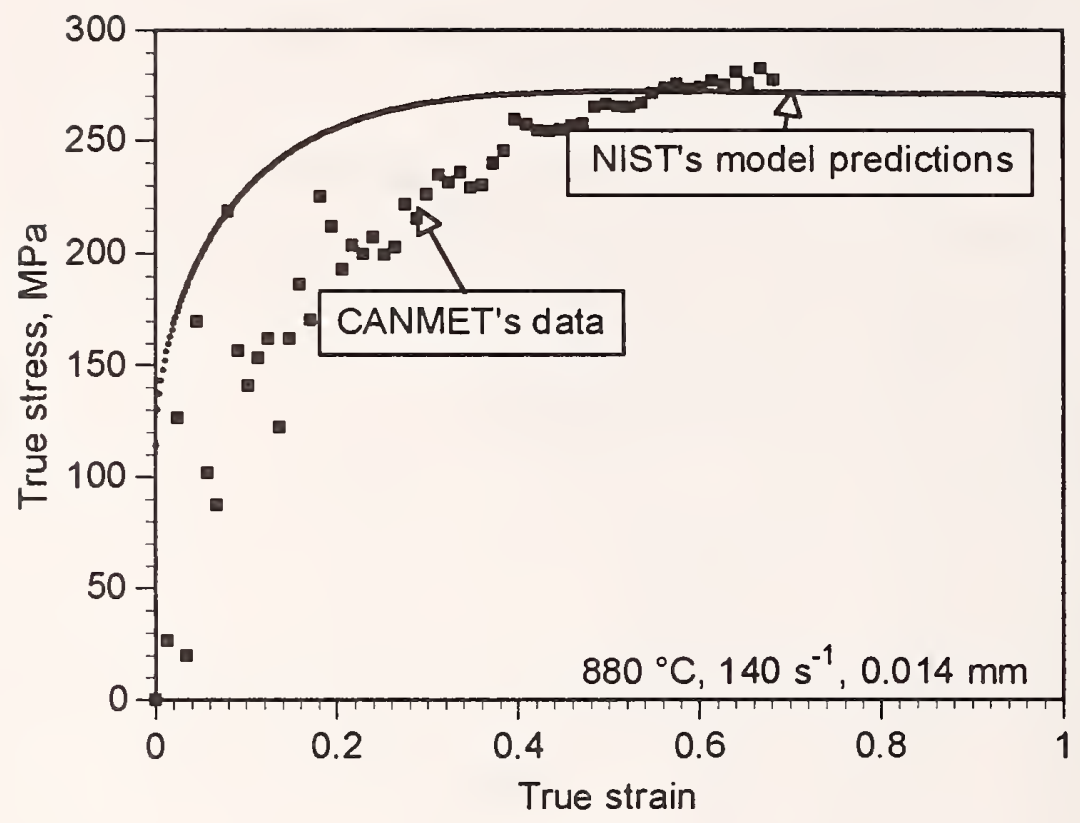

(a)

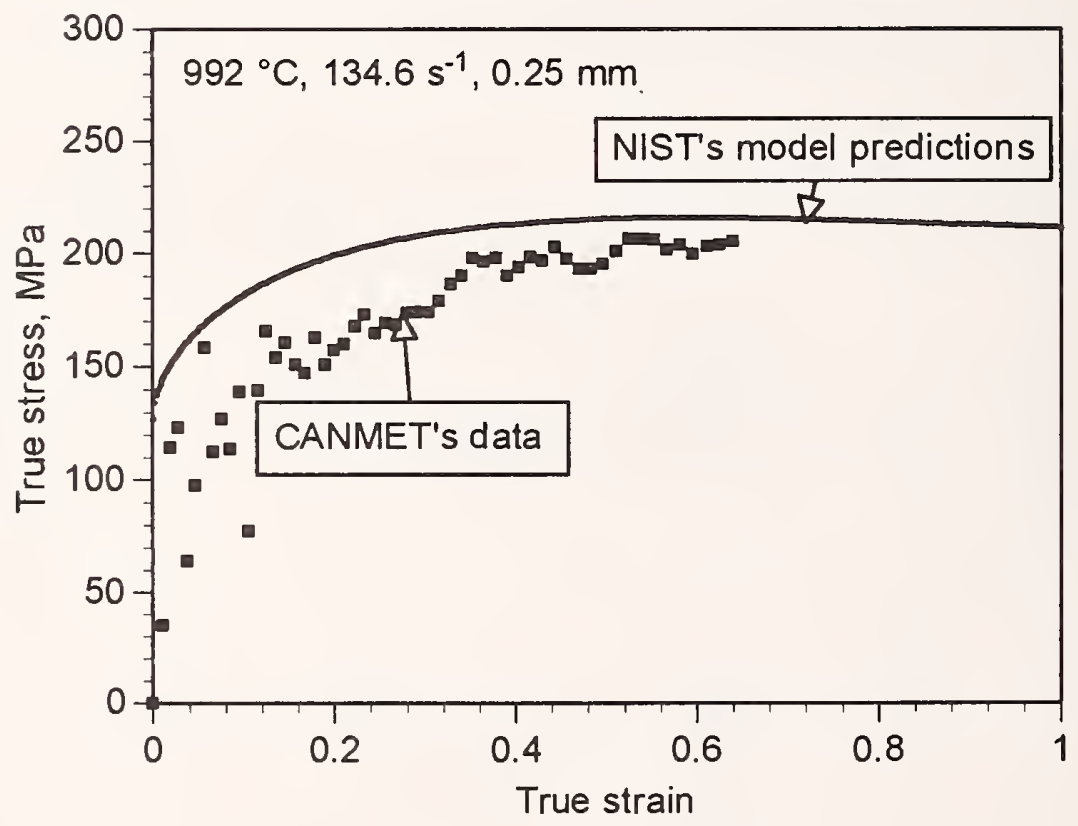

(b)

Figure 75. Examples of comparison between CANMET's high strain-rate results and NIST's model predictions: A36. 


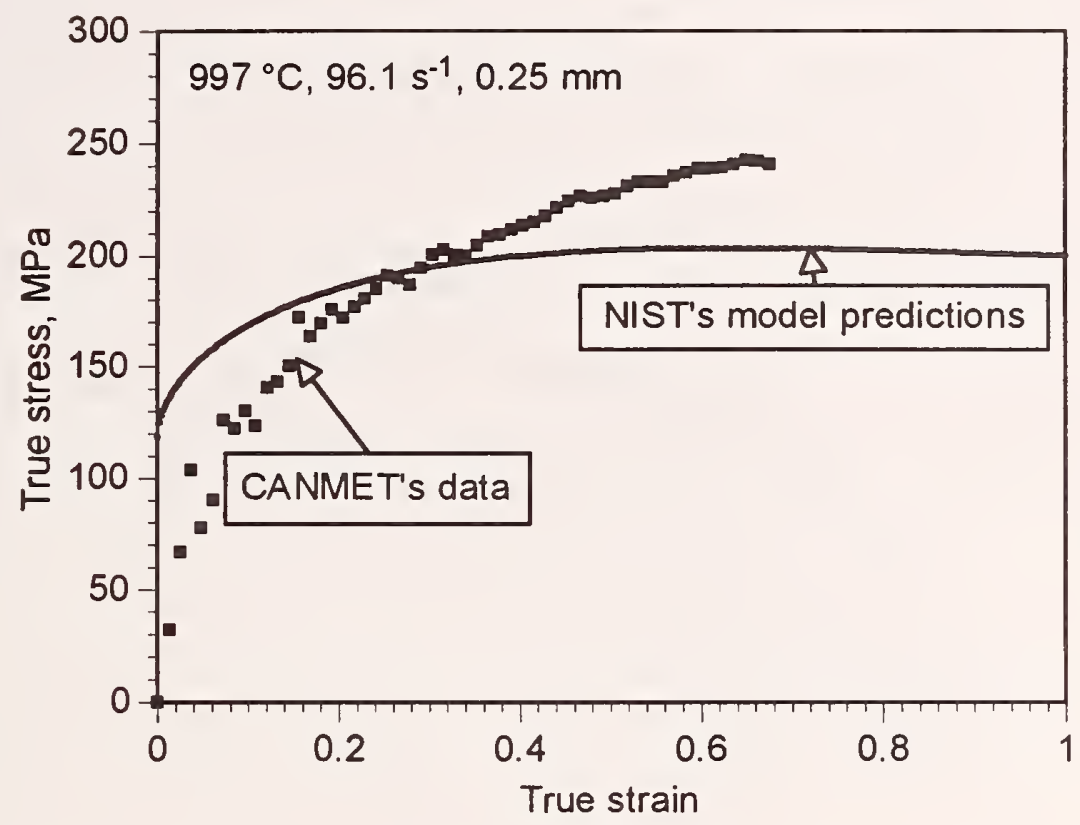

Figure 76. Example of comparison between CANMET's high strain-rate results and NIST's model predictions: A36. The agreement is poor.

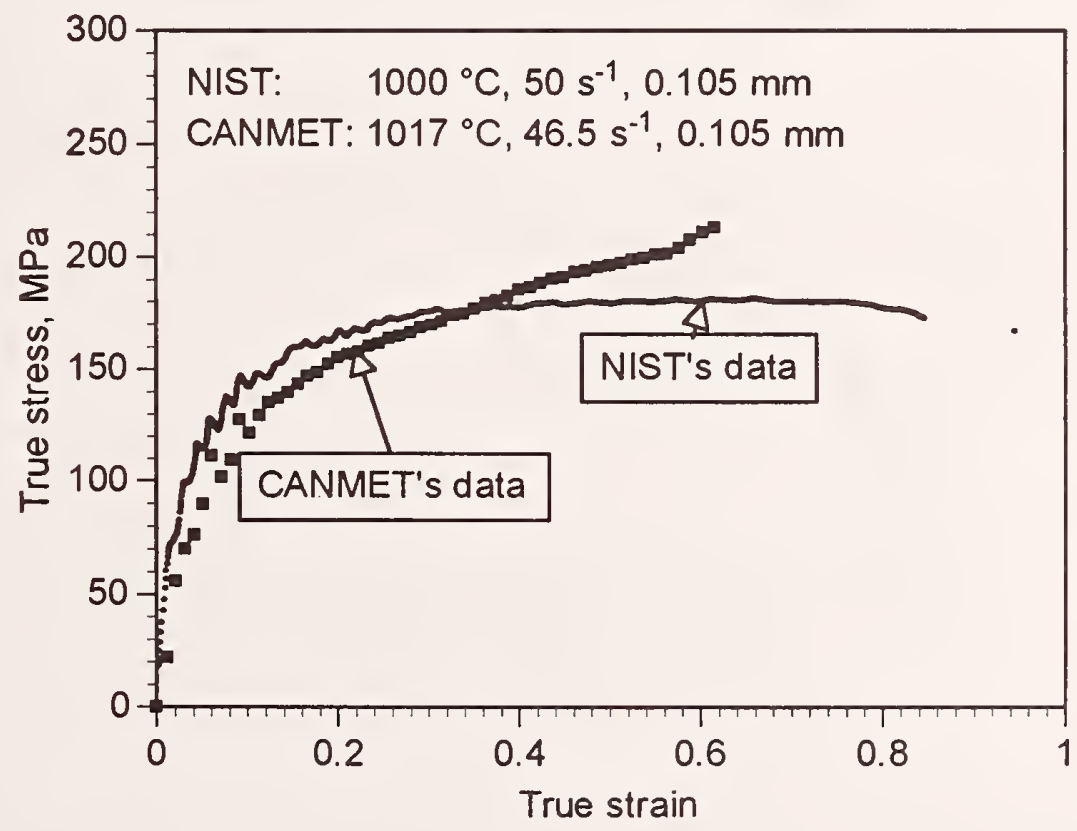

Figure 77. Example of comparison between CANMET's high strain-rate data and NIST's data: A36. Neither set of data corrected for machine compliance. The agreement is fair. 


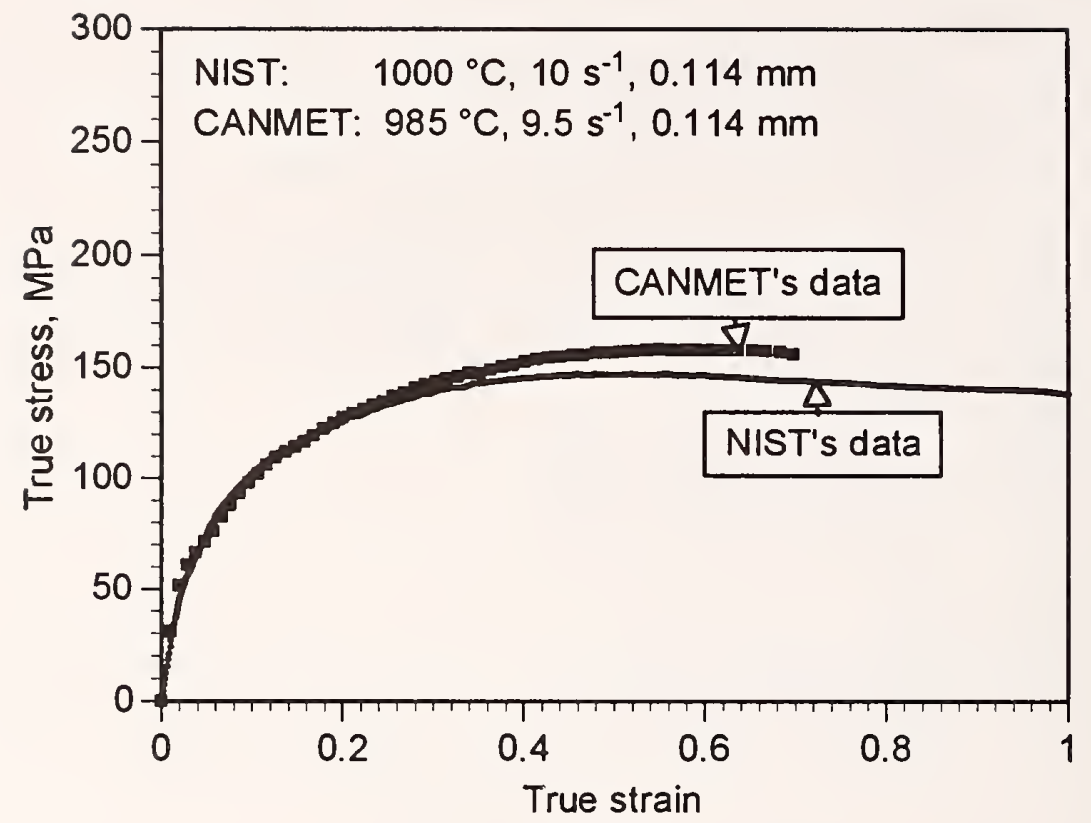

(a)

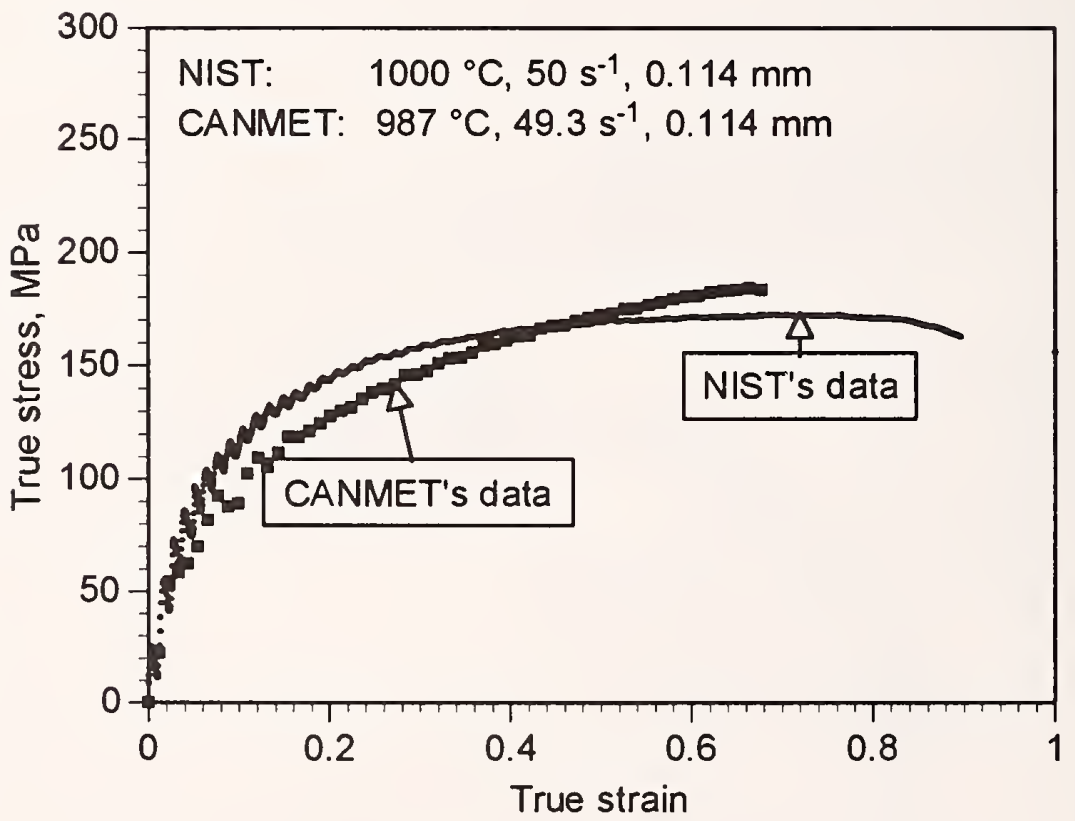

(b)

Figure 78. Examples of comparison between CANMET's high strain-rate data and NIST's data: DQSK. Neither set of data corrected for machine compliance. The agreement is fair. 


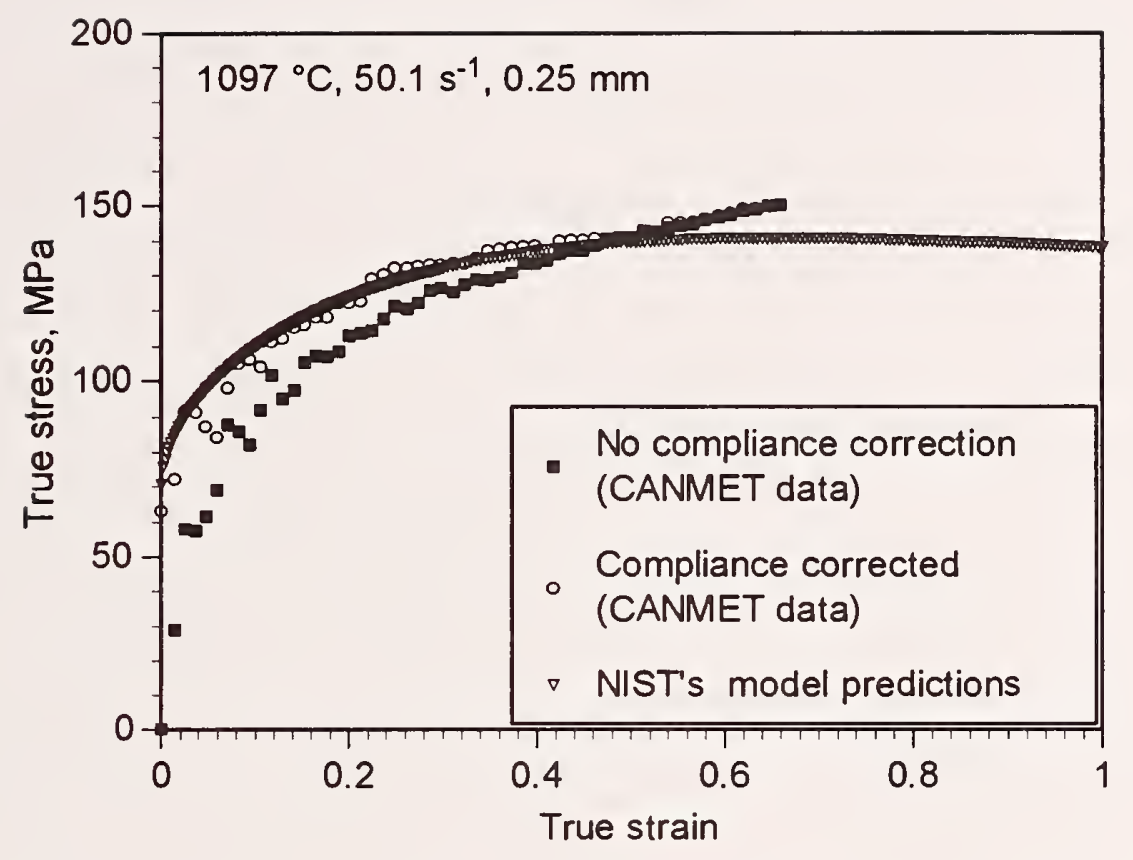

Figure 79. Comparison of CANMET's data (A36) with NIST's model prediction. Agreement is improved after correction for machine compliance.

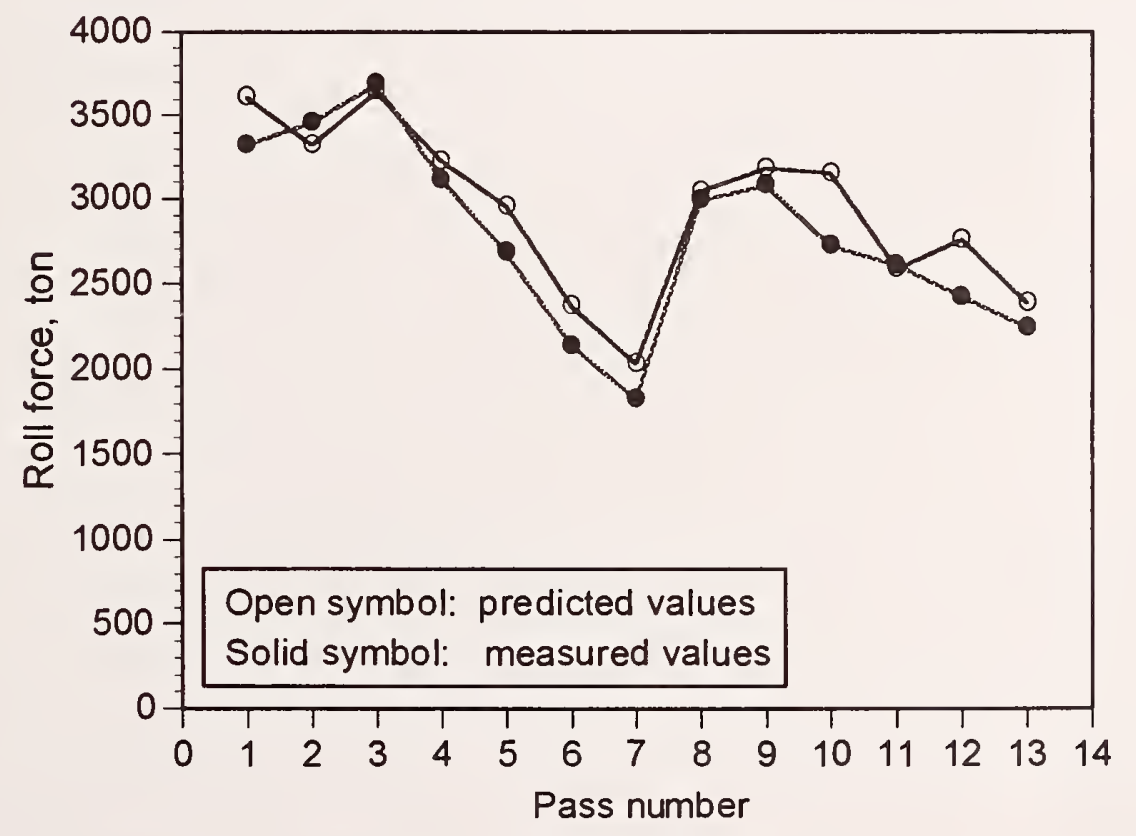

Figure 80. Results of roll-separating-force calculations. The agreement between the measurements and predictions is very good. 



\section{Periodical}

Journal of Research of the National Institute of Standards and Technology-Reports NIST research and development in those disciplines of the physical and engineering sciences in which the Institute is active. These include physics, chemistry, engineering, mathematics, and computer sciences. Papers cover a broad range of subjects, with major emphasis on measurement methodology and the basic technology underlying standardization. Also included from time to time are survey articles on topics closely related to the Institute's technical and scientific programs. Issued six times a year.

\section{Nonperiodicals}

Monographs-Major contributions to the technical literature on various subjects related to the Institute's scientific and technical activities.

Handbooks-Recommended codes of engineering and industrial practice (including safety codes) developed in cooperation with interested industries, professional organizations, and regulatory bodies.

Special Publications-Include proceedings of conferences sponsored by NIST, NIST annual reports, and other special publications appropriate to this grouping such as wall charts, pocket cards, and bibliographies.

Applied Mathematics Series-Mathematical tables, manuals, and studies of special interest to physicists, engineers, chemists, biologists, mathematicians, computer programmers, and others engaged in scientific and technical work.

National Standard Reference Data Series-Provides quantitative data on the physical and chemical properties of materials, compiled from the world's literature and critically evaluated. Developed under a worldwide program coordinated by NIST under the authority of the National Standard Data Act (Public Law 90-396). NOTE: The Journal of Physical and Chemical Reference Data (JPCRD) is published bimonthly for NIST by the American Chemical Society (ACS) and the American Institute of Physics (AIP). Subscriptions, reprints, and supplements are available from ACS, 1155 Sixteenth St., NW, Washington, DC 20056.

Building Science Series-Disseminates technical information developed at the Institute on building materials, components, systems, and whole structures. The series presents research results, test methods, and performance criteria related to the structural and environmental functions and the durability and safety characteristics of building elements and systems.

Technical Notes-Studies or reports which are complete in themselves but restrictive in their treatment of a subject. Analogous to monographs but not so comprehensive in scope or definitive in treatment of the subject area. Often serve as a vehicle for final reports of work performed at NIST under the sponsorship of other government agencies.

Voluntary Product Standards-Developed under procedures published by the Department of Commerce in Part 10, Title 15, of the Code of Federal Regulations. The standards establish nationally recognized requirements for products, and provide all concerned interests with a basis for common understanding of the characteristics of the products. NIST administers this program in support of the efforts of privatesector standardizing organizations.

Consumer Information Series-Practical information, based on NIST research and experience, covering areas of interest to the consumer. Easily understandable language and illustrations provide useful background knowledge for shopping in today's technological marketplace.

Order the above NIST publications from: Superintendent of Documents, Government Printing Office, Washington, DC 20402.

Order the following NIST publications-FIPS and NISTIRs-from the National Technical Information Service, Springfield, VA 22161.

Federal Information Processing Standards Publications (FIPS PUB)-Publications in this series collectively constitute the Federal Information Processing Standards Register. The Register serves as the official source of information in the Federal Government regarding standards issued by NIS' $\mathrm{T}$ pursuant to the Federal Property and Administrative Services Act of 1949 as amended, Public Law 89-306 (79 Stat. 1127), and as implemented by Executive Order 11717 (38 FR 12315, dated May 11, 1973) and Part 6 of Title 15 CFR (Code of Federal Regulations).

NIST Interagency Reports (NISTIR)-A special series of interim or final reports on work performed by NIST for outside sponsors (both government and non-government). In general, initial distribution is handled by the sponsor; public distribution is by the National Technical Information Service, Springfield, VA 22161 , in paper copy or microfiche form. 
U.S. Department of Commerce

National Institute of Standards and Technology 325 Broadway

Boulder, Colorado 80303-3337

\section{Official Business}

Penalty for Private Use, $\$ 300$ 